Portland State University

PDXScholar

1990

\title{
An exploratory study of female networking in a Mormon fundamentalist polygynous society
}

Janet Bennion Cannon

Portland State University

Follow this and additional works at: https://pdxscholar.library.pdx.edu/open_access_etds

Part of the Mormon Studies Commons, and the Social and Cultural Anthropology Commons Let us know how access to this document benefits you.

\section{Recommended Citation}

Cannon, Janet Bennion, "An exploratory study of female networking in a Mormon fundamentalist polygynous society" (1990). Dissertations and Theses. Paper 4025.

https://doi.org/10.15760/etd.5909

This Thesis is brought to you for free and open access. It has been accepted for inclusion in Dissertations and Theses by an authorized administrator of PDXScholar. Please contact us if we can make this document more accessible: pdxscholar@pdx.edu. 
AN ABSTRACT OF THE THESIS OF Janet Bennion Cannon for the Master of Arts in Anthropology presented June 4, 1990.

Title: An Exploratory Study of Female Networking in a Mormon Fundamentalist Polygynous Society

APPROVED BY THE MEMBERS OF THE THESIS COMMITTEE:

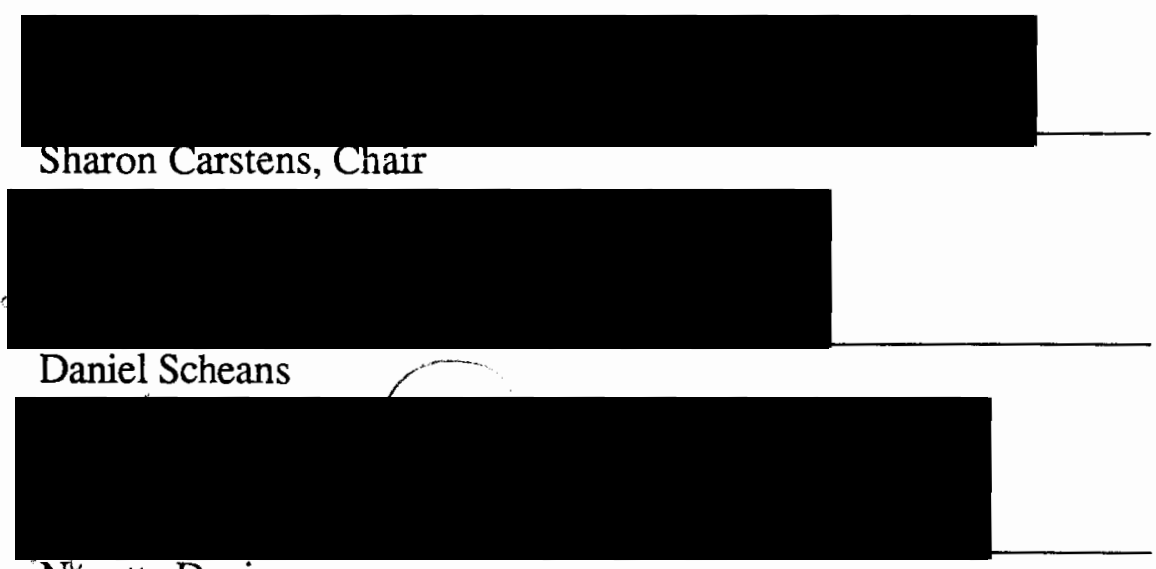

Nănette Davis

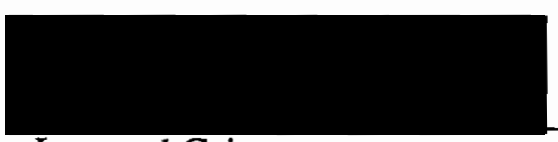

Leonard Cain

The present study is comprised of two parts: 1) an exploratory ethnography of a contemporary polygynous community governed by a strong patriarchal ideology in Pinesdale Montana with emphasis on social relationships, and 2) an analysis of the factors which have allowed women's groups to develop in Mormon fundamentalism. The ethnographic account of the community contextualizes the occurrence of female groups in Pinesdale. A model of the formation of female groups designed by Nancy Leis (1974) in 
her study of the West African Ijaw is used to provide a better understanding of how female groups are formed, and is applied to the Pinesdale community. This model suggests that the combination of features relevant to the occurrence of female groups are virilocality, patrilineality, polygyny, and economic independence. In spite of the kin-based nature of her African study, which limits its applicability to Western society, Leis suggests that her model "would predict the presence or absence of women's groups elsewhere," and encourages a cross-cultural study to prove her hypothesis. My thesis investigates the strengths and limitations of Leis' model within an ethnographic framework.

The data were obtained through four weeks of participant observation and informant interviews, and several months of library research conducted at Portland State University. The data are a reflection of the sociocultural patterns that shape the lives of Pinesdale women, and are compiled in the text to best illustrate how women group themselves with other women to support community structure and their own significance in a male-relegated system of power.

The results of this investigation indicate that both men and women have formed their own separate networks--one based on ideology, the other based on the reality of daily living. These two networks operate on the yin-yang dualistic philosophy which suggests that man and woman are complementary; the one cannot operate completely and wholly without the other, each operating within his/her own realm. The relations between men and women, rather than explained through biological propensities, are shaped by a culturally defined division of labor, a distinctive socialization, and a rigidly controlled ideology--all based on sex. The female network, the focus of this study, is by far the larger and more stable, and is founded on common belief and experience. Within the realm of this common experience, there are several vital factors which bond Pinesdale women together in groups: polygyny, ideology, economic interdependence, and the separation from the ecclesiastical and civil authority of men. Although common household residence and kinship are also 
factors in the formation of female groups in Pinesdale, I submit that these are minor factors and are not directly responsible for the grouping of females. ${ }^{1}$ Further analysis of female group formation in Pinesdale suggests that female networks are strongest in times of economic necessity, and during periods of religious and social change.

${ }^{1}$ Rather than one prototypic residence marker, such as matrilocality or patrilocality, there exists in Pinesdale a "matrifocal" residence, as defined by Smith (1956), which more directly affects the solidarity of women than either matrilocality or virilocality. The term, "matrifocality," is used to suggest that houses in Pinesdale are organized around women and that the children are raised mainly by their mothers. In other words, residence is "matrifocal" when household living conditions are under the sovereignty and primary care of the female. Kinship is a minor factor in group building because of the preadapted female relationship among co-wives. When sisters, cousins, and mothers and daughters, aunts and nieces, and affines marry the same man, they have already established a significant bonding prior to their entrance into polygyny. This strengthens further the solidarity of women as a whole, but is not a major factor in female group formation. Although Pinesdale residents are of bilateral descent, and do not subscribe to a unilineal pattern of kinship, there is still enough evidence that women in Pinesdale are able to successfully form groups in and among themselves. My analysis suggests that because Pinesdale residents adhere to a patrilineal ideology, that is, they align themselves in a patrilineal descent group after death, this strengthens the solidarity of the entire community. For females alone, however, this ideology has no significance in group building before death among other females. 


\section{AN EXPLORATORY STUDY OF FEMALE NETWORKING IN A MORMON FUNDAMENTALIST POLYGYNOUS SOCIETY}

by

JANET BENNION CANNON

A thesis submitted in partial fulfillment of the requirements for the degree of

MASTER OF ARTS

in

ANTHROPOLOGY

Portland State University

1990 


\section{TO THE OFFICE OF GRADUATE STUDIES:}

The members of the Committee approve the thesis of Janet Bennion Cannon presented June 4, 1990.

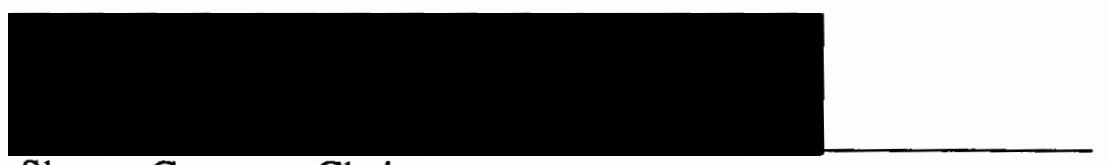

\section{Sharon Carstens, Chair}

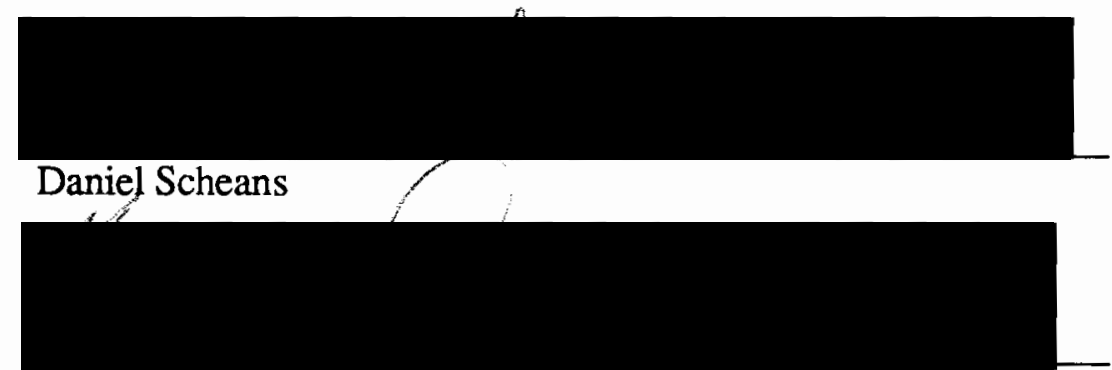

Nanette Davis

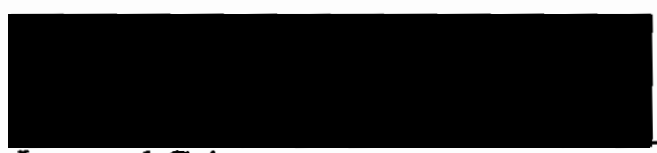

Leonard Cain

\section{APPROVED:}

Kenneth Ames, Acting Chair, Department of Anthropology

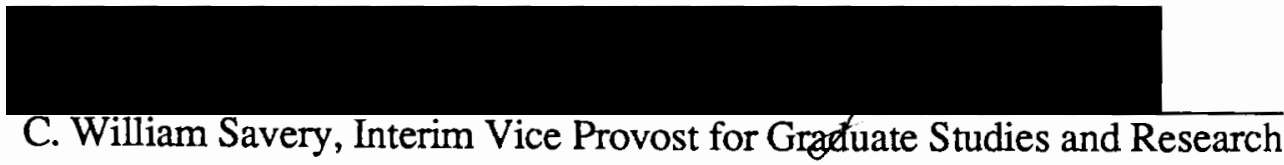


TABLE OF CONTENTS

PAGE

LIST OF FIGURES . . . . . . . . . . . . . . . . . . . . v v

PREFACE ...........................

CHAPTER

I THE HISTORY . ................ 1

The History of Mormonism . . . . . . . . . . . j

The Renunciation of Polygyny . . . . . . . . . 8

Pinesdale Fundamentalism . . . . . . . . . . 11

II WORLDVIEW: THE MALE IDEOLOGY . . . . . . . 16

Patriarchy: Kings and Kingdoms . . . . . . . . \$9

Celestial Marriage . . . . . . . . . . . . 26

The Order of Heaven . . . . . . . . . . . . . 30

The Female View of the Ideology . . . . . . . . 34

III THE PEOPLE . ..................... 42

The Socio-political Structure . . . . . . . . . 46

The Economic Order. . . . . . . . . . . . . 53

Community Life Patterns . . . . . . . . . . . 67

IV FAMILY STRUCTURE AND SOCIALIZATION . . . . . 86

The Family . . . . . . . . . . . . . . 86

Socialization . . . . . . . . . . . 97 
NETWORKING: THE FEMALE REALITY . . . . . . . . . . 127

Networking: How Does It Work? . . . . . . . . . . . 127

The Sisterhood . . . . . . . . . . . . 139

Summary of Female Networking . . . . . . . . 146

VI CONCLUSION: IN SEARCH OF FEMALE GROUPS . . . . . . 149

Factors Allowing For Female Groups . . . . . . . . . 150

Social, Economic, and Religious Change . . . . . . . . 161

Conclusion . . . . . . . . . . . . 167

REFERENCES . . . . . . . . . . . . . . . . . . . . 169 APPENDICES

A THE REVELATION OF PLURAL MARRIAGE AS

DICTATED TO JOSEPH SMITH, 1930-1934 . . . . . . . . . 176

B THE DOCUMENT OF THE UNITED ORDER OF PINESDALE

ESTABLISHED BY DR. RULON C. ALLRED, 1961 . . . . . . 182

C THE SERMON DELIVERED BY LEROY JOHNSON, JULY 10, 1977, SUNDAY, IN COLORADO CITY, ARIZONA . . 189

D THE RULES OF CONDUCT IN THE FAMILY ORDER BY

ORSON PRATT, 1853 . . . . . . . . . . . . . . 194 


\section{LIST OF FIGURES}

1. Map of the Bitterroot Valley, Montana . . . . . . . . . . . . . 43

2. A map of Pinesdale, Montana. . . . . . . . . . . . . 45

3. The Pinesdale Priesthood Hierarchical Structure . . . . . . . . . . . . 50

4. The Ten Most Common Male and Female Jobs . . . . . . . . . . . . 65

5. A Monthly Household Budget Sample for November 1989 . . . . . . . . 90

6. Sample Genealogy of Pinesdale Polygyny . . . . . . . . . . . . . . 94

7. Sample Chart of Co-wife Kinship Ties . . . . . . . . . . . . . 96 


\section{PREFACE}

Let us never cease from thinking--what is this 'civilization' in which we find ourselves? What are these ceremonies and why should we take part in them? What are these professions and why should we make money out of them? Where in the short is it leading $u s$, the procession of the sons of educated men?

\section{VIRGINIA WOOLF}

The third birth occurs when we have become comfortable within the other culture... and turn our gaze again toward our native land.

\section{VICTOR TURNER}

This thesis is the product of four weeks of anthropological field studies in the Mormon "fundamentalist" town of Pinesdale, Montana--a schismatic, polygynous colony on the Idaho/Montana border. In addition, I spent a total of three months of library research, text compilation, and thought in the production of this paper, which presents an ethnographic analysis of social relationships in contemporary polygyny with emphasis on the roles of men and women in society. This analysis contextualizes what interests me most about Mormon polygynous lifestyle--female support systems. By necessity, I will discuss sex roles and gender relations in the thesis. No ethnography of social relationships would be valid without such a discussion. My premise in regards to sex roles is that relations between men and women in Pinesdale are shaped by a culturally defined division of labor and religious duty based on sex. It appears in Pinesdale that both sexes tend to maximize the benefits of their roles in the ideological structure, distorting fundamentalism to provide each with his/her own specific needs and desires. They are both equal and opposite in this process, both complementary and contradictory. 
Because my special interest lies in the formation of female groups, I will be searching throughout the thesis for those factors within Pinesdale that contribute to female solidarity and convenience. The results of this search, given in the final chapter, will reveal that the vital factors contributing to female groups are: polygyny, ideology, economic interdependence, the separation from male authority, and co-wife kinship. My thesis question and methodology will be outlined in greater detail later in this preface.

This thesis represents a traditional ethnographic presentation, and raises questions about the type of 'civilization' found in a backwoods, polygynous community and the ceremonies, rituals and quotidian activities that provide women with "staying" power. Four weeks' time in the field can by no means provide a full ethnography. Rather, this text uses an ethnographic approach to answer certain questions about female groups--an exploration of a culture that has never before been studied by a social scientist. ${ }^{1}$ It is my hope that further anthropological research into the lifeways of Mormon fundamentalist women will be conducted as a direct result of this exploration.

I began studying polygynous cultures as a graduate student at Portland State University, reading about African, Middle Eastern, and South American women in anthropological texts. A friend asked me about my own polygynous heritage and wondered why I never considered studying the contemporary version of my own past-Mormon fundamentalism. I contacted several scholars of Mormon history at Brigham Young University, Utah State University, University of Utah, the Utah Historical Society, and various other academic institutions, asking their knowledge of any studies written on contemporary Mormon polygyny. I then searched the Human Area Resource Files, the Social Science Index, and spoke with several anthropologists who had studied sects that

1 Though there have been several excellent collections on the history of Mormon polygyny (Van Wagoner 1986, Embry 1987), and a few non-academic autobiographical accounts of life in contemporary Mormon fundamentalism (Solomon 1987, Merrill 1975), there has been no comprehensive, ethnographic study of contemporary Mormon polygyny. This thesis is intended as a body of reliable data for future use in anthropological research on the structure of polygynous cultures in North America. 
were somewhat similar to fundamentalist groups, such as Hans Baer's study of the Order of Aaron (1976) and Jon Wagner's study of the contemporary commune (1976). The result of this extensive literature search was the realization that there have been no basic ethnographies provided for these peoples. Baer recommended that I be the one to write these ethnographies. I thought I would begin by investigating the Apostolic United Brethren, a schismatic group which broke off from the orthodox Mormon Church in the early 1900 s, and later split from another fundamentalist group, now located in Colorado City, Arizona. After several months of correspondence with Owen Allred, the leader and prophet of the Apostolic United Brethren, headquartered in Salt Lake City, Utah, I received a letter of permission to live and study a branch of the AUB, in Pinesdale, Montana. Armed with a thesis proposal describing what I hoped to find about plural marriage among Pinesdale fundamentalists, I left Portland, Oregon, to conduct fieldwork studies on female networking in contemporary polygynous society. My 11-month old daughter, Liza, accompanied me. We arrived in Hamilton, a large town 10 miles southeast of Pinesdale, at approximately 3 a.m, December 1, 1989. When I entered the first hotel on the strip, I met Kay Barker, the second wife of an auto parts salesman who worked as a night hotel clerk. She wore her hair long, down to her waistline, with the hair in front pinned up away from her face. Her clothes were conservative but stylish--polyester pants and a long sleeved, high collared shirt. She smiled at Liza and told me she had an 11-month old boy. We became friends immediately.

She laughed when I told her I was going to study the "polygamists" and asked if she were going to have to lie down on the lens of a microscope. She gave me the phone number of one of the leaders of Pinesdale, Melvin Harris, whom I contacted for a luncheon date that afternoon. "Brother Melvin," as he is called, is a member of the General Council of the Priesthood, a group of ten "elders" who head the organization of the Apostolic United Brethren under the direction of their prophet, Owen Allred of Salt Lake City, Utah. 
Brother Melvin's special calling is to establish and sustain the practice of plural marriage among the Pinesdale community. Brother Melvin's father, J. L. Harris, had this same calling. At noon, I met Brother Melvin at the 4B's Restaurant across the street for some tomato soup. I tried to restate--in a noisy, crowded restaurant--my intentions of studying the interrelationship of plural wives for personal reasons and to express my desire to learn more about plural marriage within Pinesdale culture.

Brother Melvin seemed hesitant and somewhat cynical. Liza, seated in a high chair between us, softened the coldness of our meeting with her baby jabber and soup splashing, but there was still a heavy layer of tension. Brother Melvin decided to test my sincerity by taking me to the one he called his "leader," his wife, Shelly, who after 13 kids was in the hospital having surgery. She was bright and confident, in spite of the after-effects of anaesthesia, and seemed to be one of those people capable of determining a person's total character within minutes. Shelly explained that there had been an "awful" girl from the University of Montana, who had promised not to disclose personal details of their lives. This girl persuaded Shelly to expose intimate details of her lifestyle and afterward betrayed that trust by publishing with Associated Press, worldwide. In light of this, Shelly was quite hesitant to allow me into Pinesdale. I attempted to reassure both her and Brother Melvin that I had no intention of sensationalizing their lives, nor of publishing in the popular press. I explained that I had already corresponded with and had the approval of the prophet of the sect, Owen Allred, of Salt Lake City--who, by now, surely, had contacted them. I also spoke of my deep interest in their community, which stemmed from curiosity about my own past. I assured them that I would make no move without consulting either Brother Melvin, or another member of the community, and that I would not betray them.

I left the hospital feeling that I would not be able to stay in Pinesdale. How could I write an ethnographic account of a polygynous lifestyle when I couldn't even get into the 
community? Once I did get in, what could I say that would not hurt these people who have suffered at every hint of exposure? I felt a great burden of responsibility.

The next morning I called my husband and told him to expect me back earlier than planned. I then called Brother Melvin's workplace, a garage door installation company, and was told that he and his family were watching a junior high basketball game in Corvallis, 12 miles east of Pinesdale. Determined to confront Melvin and explain once more my desire to visit his community, I drove over to the game and met him and about seven of his kids outside his truck in the parking lot. They stared at me in confusion and looked back at Brother Melvin. To my surprise, he kindly said, "Follow us, we'll take you into Pinesdale. You'll be staying at Hannah's place. She's my third wife; I am sure you'd like to know that little fact." He and the sect's prophet, Owen Allred, who had arrived the night before, had been talking about what to do with me. They had decided to give me a chance.

Strangers aren't welcome in Pinesdale. There is no hotel, no restaurant, only one small store, and, a gas station. Residents eye visitors warily, especially if you ask a lot of questions. Even in asking simple directions, people stared at me suspiciously, and sometimes, didn't even answer. While walking down the road or on the sidewalk, others would move to the other side to avoid a confrontation. Word got around that I was there to study them. I understood their desire to avoid me. Yet, after one week of promoting my study of their culture, visiting with the women, attending church, and helping with daily chores, I became a temporary member of the community, and felt welcomed. After this first week of testing, I felt more comfortable with the wives I lived with. Without thinking so much of the ethics and rigidity of observer-observed mores, I told them about myself as much as they told me about their lives and families. During these visits with the Pinesdale women, an important exchange occurred between what I was and stood for and what they represented. I learned that no matter how elevated in the academic cycle of achievement 
one gets (or one thinks one gets), when with an informant, one must give as much of ones self as one receives. This is how I was able to collect so much data and, achieve so much understanding in so little time--I shared myself with them.

I lived with the Pinesdale "saints" for one month, staying with three different families, during which time I learned a great deal from both men and women about sharing-sharing one's time, sharing one's space, sharing one's material goods, and sharing one's husband. I also learned that the Pinesdale polygynists marry more for religious reasons than for material or sexual ones. Their purpose in coming to Pinesdale in the first place is not to find a more comfortable living style--most live at or below poverty level in the community--but to find a united pursuit of the kingdom of heaven. Most importantly, I came in contact with some fascinating women who taught me the art of service, and how to love through giving and selflessness. Anthropologically, these women taught me how women in a male-dominated society can play an equal part in the total structure and maintenance of the community. I observed that the Pinesdale women, though officially subservient to males, unofficially complemented the male's authority role with a support system--a system that has worked effectively to perpetuate religious conviction and maintain economic stability for nearly 30 years (Pinesdale was established in 1961).

As mentioned, part of my interest in contemporary Mormon polygyny arose from a desire to learn more about my past. I am a descendent of polygyny through four sets of great-grandparents. ${ }^{2}$ As a member of the mainstream Mormon Church, which discontinued sanction of plural marriage in 1905 (Quinn 1985), I have been taught to view polygyny as sinful. I have been confused about my relationship to those who continue to practice plural marriage and live the way my own ancestors lived less than two generations

${ }^{2}$ A peripheral concern of this study is to dissolve a few misconceptions about Mormon polygyny, and shed light on the ways in which women form bonds. Richard Van Wagoner, a Mormon historian, states that many mainstream Mormons are descendants of polygynists, yet most Church members today are no better informed on their past than non-Mormons (1986). 
ago. I hoped that a study of modern plural marriage would promote my understanding of this prohibited lifestyle and what motivates women to enter into polygyny today.

More and more anthropologists have been turning to their own pasts and their native cultures for answers about Western culture in general. Barbara Myerhoff in her study of Jewish old people in an urban California ghetto (1978), Colin Turnbull in his book The Human Cycle (1983), and Zora Neal Hurston in her work with Black women of the South (1937) are among those scholars who have sought to understand more about themselves and American culture, through experiments in "reflexivism," a way of mirroring one's native culture back to oneself and to others in that same culture. In so doing, they have provided a mirror in the form of a cultural critique to be seen by others in and outside the culture in question. This thesis is one such "reflection."

Because of the reflective nature of this study, at times the boundaries between the native view of life in Pinesdale and the references I draw upon in my own culture may seem confused. This is because I am, in effect, a "native anthropologist" in the Pinesdale setting, and must rely on my own knowledge of the sect as well as direct observations of behavior. In clarifying these boundaries, Chapter I, "The History," and Chapter II, "The Worldview," rely on both informant interviews and personal experience and knowledge of Mormon culture. In Chapters III and IV, I rely on eye-witness accounts and informant interviews, with very little interjection of my own culture. Chapter $\mathrm{V}$ depends almost exclusively on informant interviews, and Chapter VI, the summary, is a combination of anthropological interpretation and personal observation, relying on informant interview; eye-witness account, and personal experience. 


\section{THESIS AND METHODOLOGY}

The primary aims of this study are to provide:

1) an exploratory ethnography of the community of Pinesdale with focus on social relationships, and

2) an analysis of factors relevant to the formation of women's groups, comparing Pinesdale female networking with the incidence of female groups elsewhere, particularly with Nancy Leis' study of West African women. ${ }^{2}$

I use Leis' model against which to test Pinesdale women for grouping ability because her study of the West African Ijaw women (1974), as well as Murphy et al.'s study of the Mundurucu women of Brazil (1974), as these studies are well publicized and similar to Pinesdale in terms of its male-dominated structure, polygyny, and the economic and social interdependence of females.

I collected the data during December of 1989 . While living with three different families, I simulated membership by working with the women of each household in cleaning, food preparation, honey straining, childcare, teaching, and supplying goods to that family. I also worked with the men by feeding the cattle, and visiting work sites in construction, cabinet making, and wood gathering. I attended all meetings: Sunday school, the meeting of the Sacrament, Relief Society, Young Women, and morning community prayer. I did not attend Priesthood Meeting, which is for men only. I experienced first hand the female health network when a flu epidemic hit the neighborhood and Liza caught it

2 Nancy Leis conducted a study of the West African Ijaw women in 1974 to analyze significant factors in the formation of female groups. She developed a model suggesting that the combination of features relevant to the occurrence of female groups to be virilocality, patrilineality, polygyny, and economic independence. In spite of the kin-based nature of her African study, limiting its applicability to Westem society, Leis suggests that her model "would predict the presence or absence of women's groups elsewhere," and encourages a cross-cultural study to test her hypothesis (Leis 1974: 232). 
from the other children. Additionally, the midwife gave me counsel on some ailments of my own, and I received herbal treatments and a list of more than one hundred home remedies for future reference. I also gathered several genealogies of families in the town and a map of the area--including all houses and buildings. A complete budgeting chart for one wife's monthly income will serve to illustrate how female networking can stretch a small income.

An essential part of the methodology took place every night from 10 p.m. to midnight, when I would enter the notes taken of all the activities and behaviors I observed that particular day. I used no tape recorder, as this would have made respondents nervous. They were extremely wary of any types of note taking, as well, except during a formal interview. This led me to make use of a helpful field technique shown me by Dr. Sharon Carstens, my anthropological advisor at Portland State University, which incorporates good memory, quick note and symbol taking, and long, journal-form entries at night. These entries at night were extremely valuable in compiling the final thesis, as they were written with certain codes on a portable computer which could be manipulated later at the university.

For the qualitative sorting of my data, I used the sort mechanism of Mircrosoft Word's outline mode. My 75 pages of fieldnotes were systematically subcoded in both male and female networking terms. For males, the subcodes were "priesthood," "council," etc. For women, the subcodes were "sisterwife," "Relief Society," etc. The fieldnotes already had code words signifying female or male affinity to a certain ritual or activity, such as $\mathrm{M}$ for male and $\mathrm{F}$ for female. In this way, it was a simple task to list in outline form all activities that contributed to the grouping of females. I have incorporated the results of the sorting of female group attributes in my general ethnography, citing studies of the Mundurucu (Murphy et al. 1974), the Duley and Edwards comparative guide of women (1986), an HRAF survey of female autonomy and male dominance (Schlegel 1972), and 
female studies by Rogers (1975) and Nelson (1979), as cross-cultural references. These studies have not only enabled me to better test the model presented by Leis (1974), but have allowed for additional insight into the traits of female groups. In preparing my text, I used Zablocki's ethnography of the Bruderhofs (1971), Clignet's study of West African polygyny (1970), Spiro's study of the Israeli kibbutzim (1970), and Wagner's study of Midwestern male supremacy (1982), as guides. In order to give continuity to the definition of polygyny, since there are numerous ways in which the term may be defined (plural marriage, celestial marriage, "the Principle," polygamy), I will use the more specific term, "polygyny," to refer to the marriage of one man to two or more wives.

All names used to identify members of the Pinesdale community are fictional to protect certain individuals' rights of privacy, with the exception of historical characters and the leader of the community, Owen Allred, who is a public figure. With the permission of the community, however, all references to the town of Pinesdale, its geographic location, and details of its cultural patterns are real and as exact as possible. Considering the illegal nature of polygyny in the United States, special precautions against personal identification and possible consequent incarceration have been taken, through scrambling names and places within the community. There is virtually no way that certain persons, other than the prophet, can be identified from this text alone. There is also no fear of any criminal action taken against me, as the author of this text. There has not been a single polygynous arrest since 1961. In a documentary written and directed by Utah's KUED television channel, entitled, "A Matter of Principle," a statement was given by the head of the police department of Salt Lake City regarding the cessation of arrest of polygynous felonies (Verdoya 1990). There have also been a large number of books and articles published recently having reference to fundamentalist activity, with no criminal action taken against the authors of these works (Van Wagoner 1986, Embry 1987, Bradley 1990, Verdoya 1990). There should be no doubt in the minds of the reader that the following study is 
written with the complete cooperation of polygynous informants and the federal and state governments.

The paper begins with an account of the historical background of the Pinesdale community, including a summary of the origin of Mormonism, Mormon polygyny's founder, Joseph Smith, and a detailed description of the split between orthodox Mormonism and Mormon Fundamentalism. The paper also explains the general tenets of fundamentalism, which shares its roots with the official Mormon Church. A chapter on the Pinesdale worldview follows, a view which reinforces the male authoritarian nature of fundamentalism, yet allows women such a great degree of independence and freedom. By reading this chapter, it should become apparent how a male-dominated ideology translates into the real, daily events of women's lives. I argue that the belief system of both men and women is based on this "male" worldview--a worldview that was formed by a "male" God, revealed to a nineteenth century "male" prophet, and enforced by the "male" head of household. The next chapter analyzes the Pinesdale community in terms of socio-political structure, economy, and community life patterns. I then examine family structure and socialization, presenting a thorough look at the way a child is raised in the Pinesdale social structure. This chapter also analyzes sisterwife kinship and describes the courtship and marriage practices of Pinesdale. The next chapter deals exclusively with the relationships among women and how they use ideology, their kin ties with each other, and their common experience in polygyny to cope with day-to-day events. This chapter deals with the female realm as a contrast and a complement to the male realm of ideology and religious prestige.

The final chapter discusses female networking in Pinesdale in relationship to Leis' model of female groups and Murphy et al.'s model of female solidarity. I conclude this chapter and the thesis with comments on the formation of female groups in times of economic, social, and religious change. 


\section{CHAPTER I}

\section{THE HISTORY}

Pinesdale ideology and culture may seem strange and unnatural to outsiders. To better understand this ideology, one must first be acquainted with the beginning of Mormonism, Joseph Smith's revelation on plural marriage, and the split that occurred in 1890 between the official Mormon Church and the renegade group of "fundamentalists" who refused to abandon the practice of polygyny, forming their own line of authority to God.

\section{THE HISTORY OF MORMONISM}

Mormonism developed during the early nineteenth century, when millennial utopianism arose as a measure of rebellion against current civil or ecclesiastical law. ${ }^{1}$ In his study of nineteenth century Christian communes, Louis Kern describes three Victorian utopian systems--the Shakers, the Oneidas, and the Mormons--all of which utilize unusual, non-Victorian sexual forms of marriage. The Mormon form, polygyny, states Kern, provides a conscious ideational construct that is used as a tool to come to grips with social reality--the collective needs and beliefs of a growing number of "saints" (Kern 1989, Foster 1984).

Joseph Smith, Jr., the founder and leader of the Church of Jesus Christ of Latterday Saints, or "Mormons," as they are more commonly called, grew up during this period of millennial utopianism. At 14, Smith claimed he had seen God and Christ together in a

${ }^{1}$ A handful of these utopian groups adopted a "socially regulated sexual impulse" (Kern 1989) in order to resolve problems of needs, interests and beliefs. Among this type of experimental utopia lies Mormonism. 
grove of trees. He was told that Christ's church was not on the earth but that he would be instrumental in restoring it. Ten years later, in 1830, Smith organized a religion based on his numerous visions and on his translation of The Book of Mormon (B of M), a record engraved on golden plates of a chosen people who inhabited the Americas before the time of Christ. Smith was told in visions that there had been a great apostasy after the death of Christ's apostles and that the restored church, the Mormon Church, would be modeled closely after Christ's own church, which had been established nearly 1,800 years before.

Smith reported additional visions on the nature and form of this new church. In 1831, he announced the "Law of Consecration and Stewardship," which advised members to donate all their belongings to the Lord, through the bishop of the church. The bishop then returned a "stewardship" to each married male, who then turned over any surplus to the church. In other words, the bishop would collect tithes and offerings of various types-money, wheat, eggs, tools, etc.--and, in return, the male heads would receive a parcel of land to till, a cattle herd to care for, or some other type of "calling," which was of benefit to both the individual and to the community. This consecration eventually became known as the "United Order," which served to unify "a people fragmented by their individualistic search for economic well-being" (Arrington 1955: 2-3). Smith wrote that the Lord told him "if ye are not equal in earthly things, ye cannot be equal in obtaining heaveniy things" (D\&C 78:6), and that the Lord counseled that all properties be organized and established, "to be a united order, and an everlasting order for the benefit of my church, and for the salvation of men until I come" (D\&C 104:1). ${ }^{2}$ In paying a tithe, priesthood members would calculate 10 percent of all their family's income--including their wives' and children's--and donate this to the bishop. This cash or material donation was then used for

${ }^{2}$ Doctrine \& Covenants, a volume of Mormon scripture containing letters, directives, and selections from the revelations given to Joseph Smith. From this point on, I will refer to the Doctrine \& Covenants as D\&C. 
the building of temples and churches, for promoting missionary work, and for providing for the general welfare of the membership.

In general, Smith's church reflected many ideas derived from the New and Old Testament, such as baptism, temple worship, covenants and ordinances, washings and anointings, and "priesthood." ${ }^{3}$ Smith's concept of the Kingdom of God was very much like Israelite theocratic hierarchy, where God was at the head; man, empowered with the holy priesthood, was on the next level; and woman and children were at the bottom (Van Wagoner 1986). The Mormon God was seen as a married, polygynous being with human features and a progressive spirit. ${ }^{4}$ Smith, as a biblical student, became interested in its abundant references to the plurality of wives. He wondered if, like Abraham, he was supposed to take up additional wives to further his progeny (Embry 1987). In answer to his prayer, Smith received the Revelation of Celestial Marriage, or "the New and Everlasting Covenant," as it was sometimes called, where he was told to

prepare thy heart to receive and obey the instruction which I am about to give unto you; for all those who have this law revealed unto them must obey the same...If any man espouse a virgin, and desires to espouse another, and if the first give her consent, and if he espouse the second, and they are virgins, and have vowed to no other man, then is he justified; he cannot commit adultery with that that belongeth to him and to no one else (D\&C $132: 3,61)^{5}$

3 Priesthood, God's authority on earth, is based on the biblical idea of a Hebrew priest who mediated between his people and God by representing them officially in worship (Bible Dictionary, LDS Bible). Priesthood powers are endowed in the male members of society, and enable them to draw upon God's powers to heal and administer and bestow blessings. Holy oil is used, as it was in biblical days, as well as the laying on of hands. The difference in Mormon priesthood is that one must be married to attain the higher priesthood.

${ }^{4}$ Eloheim, or God, is a heavenly being that has a human body, and is married to a wife (or wives) who is considered by Mormons to be a "Mother in Heaven." The nature of the female half to God is not well explained or referred to in detail in the doctrine. The nature of God's marriage, whether it be monogamous or polygynous, is referred to in $\mathrm{D} \& \mathrm{C}: 132$. The interpretation of this marriage is unclear among Mormon theologians. The progressive nature of God is explained in The Pearl of Great Price, another Mormon scripture, which states that God was once as man is now, that is, God grew up on an earth like ours, and progressed through his trials and tests, just as we do. Man, thus, can become like God, through this same progression.

5 This revelation, not recorded until 1843, is believed by some historians as being written in an effort to reduce the opposition of Smith's wife, Emma Hale Smith (Embry 1987). The revelation was received, it 
The exact date of Smith's revelation on plural marriage is unknown (Quinn 1985). As early as 1831 , Smith had mentioned plural marriage as a possibility, stating that men would take up wives in the "same manner that Abraham took Hagar and Keturah; and Jacob took Rachel, Bilhah and Zilpah, by Revelation." (Phelps, as quoted by Van Wagoner 1986:4). Polygyny was considered by Smith to be the fulfillment of the law, the highest order a priesthood bearer had to go through on earth. When Smith received the revelation of plural marriage a few years later, he called it "the fulness of the gospel," claiming that celestial marriage (plural marriage) established an earthly pattern of the generations of the Gods (Journal of Discourses 1853, D \& C 132:29-37). Smith called for perfect obedience of the Saints by admonishing them to place themselves in absolute harmony with their leaders-complying with their guided direction. According to Orson Pratt, Smith said plural marriage would not be an easy practice but it would be the necessary step to attain the highest kingdom (Pratt 1854). Smith promised the males that in raising multiple, extended families they would develop the capacities to govern eternal worlds. Smith promised females they would acquire those same traits by subjecting themselves to the righteous rules of their husbands. In giving other wives to her husband, Smith said, a woman promised her husband that she would overcome jealousy; a man promised his wives that he would earn their trust. Love and confidence developed by keeping sacred all sexual relations and the man leamed to master his emotions and passions while his wives learned to trust in God, rather than depending exclusively on their husbands (Pratt 1854). According to Mormon historian Vance Allred, this family of a purified man and his virtuous wives was to produce a large number of children dedicated to God's service (Allred 1984). Brigham Young, the second president of the Church. The entire revelation is recorded in Appendix A. 
Relationships within nineteenth century Mormon polygyny were designed to "inculcate a reverence for godliness, a deference for righteous authority and a preference for spirituality" (Allred 1984). ${ }^{6}$ Ideally, men and women living in this type of spiritual system would be elevated above the cares of mortality, such as for clothing, food, and other comforts, and be planted firmly on the way of fulfilling the ultimate injunction of Christ when he commanded his followers to "be therefore perfect, even as your father in heaven is perfect" (Matt. 19:21). Because of a man's high priesthood calling, he could gain more wives, have more children, and build up his kingdom, which in turn, would promote his eternal status in godhood. This proved one sufficient reason for men to suffer the consequences of polygyny willingly. Another reason was that man's character would be polished through trials and hardships--Smith wrote that "a religion that does not require the sacrifice of all things never has power sufficient to produce the faith necessary unto eternal life" (Fulton 1970). Smith acknowledged the difficulty with which one might enter into polygyny when he claimed that an angel drew a flaming sword and threatened his life, if he did not comply (Allred 1984).

Polygyny did not become a public institution until after Smith's death, when Brigham Young, Smith's successor, moved the saints to Utah. Prior to that time, monogamy was outwardly sanctioned as the true form of marriage. ${ }^{7}$ From 1852 until 1890 , Young encouraged all male priesthood bearers to marry additional wives. Heber C.

6 Vance Allred, a Mormon historian, belongs to a large family of Allreds in and outside of fundamentalism. I refer to his 1985 thesis work on the hegemony of Mormon polygyny, not the work of Owen Allred, prophet of Pinesdale.

7 In 1869 Apostle Orson Pratt recalled that Smith told members that the principle of plural marriage was a true principle, but the "time had not yet come for it to be practiced" (Van Wagoner 1986:4). Mormon scriptures sanctioning the monogamous form of marriage were also revealed to Smith: "Thou shalt love thy wife with all thy heart, and shall cleave unto her and none else (D\&C 42:22); "It is lawful that [a man] should have one wife, and they twain shall be one flesh" (D\&C 49:16); and throughout the B of M (Jacob 1:15; 2:23-27; 3:5; Mosiah 11:2-4, 14). 
Kimball, who had 43 wives and 65 children, stated that a man owed it to himself to enter into the "principle."

I have noticed that a man who has but one wife and is inclined to that doctrine, soon begins to wither and dry up, while a man who goes into plurality looks fresh, young, and sprightly (Kimball as quoted by Embry, 1987).

For members of the early Mormon Church, polygyny helped to fulfill Adam and Eve's commandment to multiply and replenish the earth. Some historians, studying the early Mormon pioneer era, have stated that polygyny enabled men to have access to more women for lustful reasons (Kern 1989, Foster 1984), but this does not agree with recent studies of nineteenth century polygyny conducted by Embry (1987) and Van Wagoner (1987), who claim that Mormons adopted polygyny for religious reasons. ${ }^{8}$ In 1852, when Orson Pratt, a Mormon leader, publicly announced the practice of polygyny, he argued that members of the church could not receive the highest glories of heaven without entering into the "principle." Pratt also stated that polygyny helped control immorality, and that it enabled man and wife to "hold the scepter of power over a numerous progeny" (Embry 1987:42). Members of the church wanted to give "spirit children," the children in heaven that awaited physical bodies, the chance to come to earth and be tested. By marrying more than one wife, a man could increase his earthly kingdom three or four fold.

In the first 30 years of settlement in Utah, Mormon polygyny was practiced by a small number of the total population. In order to gain status and leadership positions within the church, a man had to marry more than one wife, and so, it was usually men at the top of the socio-political hierarchy who were polygynists, with access to more women, than those at the lower rung. More men refused polygyny than accepted it, and thus the notion of lustful males obtaining their harems for sexual pleasure does not fit the historic

8 According to Kern, it provided a religiously sanctioned rationalization for male promiscuity (Kern 1989); however, as one polygynist stated, there are easier ways to get women than to be married to them and provide economically for them and their children (Bronson 1982). 
picture. Young, the second president of the church, explained that plural marriage was introduced to the "Patriarchal order" not to please man's carnal desires, nor was it established to punish females, but to "raise up to His name a royal Priesthood, a peculiar people" (J of D 3 [14 July 1855]:266). It is evident, however, that polygyny in early Mormon culture was connected to power.

As a social institution in Mormon culture, polygyny provided controls that mutually reinforced each other. Mormon leaders, their sons, and men who served the church enjoyed opportunities to obtain plural wives by virtue of their priesthood calling. According to historian Burgess-Olson (1975), personal freedom and expression of talents were provided for the women who entered into polygyny. ${ }^{9}$ For both, there was the knowledge that one was doing all one was commanded to do, and would be blessed for it (Allred 1984). Charles W. Penrose portrayed Mormon marriage--celestial marriage, or the holy patriarchal order--as a privilege through which men and women were sealed together by the holy order of God..$^{10}$ The purpose of celestial marriage (plural marriage) was an abundant and faithful progeny. "They shall increase, worlds without end, in their prosperity, in knowledge, in wisdom, in understanding, in dominion, in glory" (Penrose 1918:16). Celestial marriage was for "time and all eternity" and "a necessary prerequisite for the attainment of the highest degree of glory in the celestial world," he said.

9 Vicky Burgess-Olson, in a study of the structure and dynamics in early Utah Mormon families, found that more than $50 \%$ of plural wives used their skills outside the home, in the marketplace (1975).

10 The keys to perform these sanctioned marriages are only in the hands of the President of the Church (Penrose 1918). 


\section{THE RENUNCIATION OF POLYGYNY}

In the late 1800s, public pressure from the federal government to abandon the practice of polygyny resulted in an official announcement from the Mormon Church. ${ }^{11}$ The Manifesto of 1890 , a document that prohibited the contracting of new plural marriages, was read to the membership at a Salt Lake conference by Wilford Woodruff, fourth president of the Church. At this point, one of the capstone beliefs of nineteenth-century Mormons became nullified, and those who had been the polygynous elite were now considered by the official Church to be a handful of powerless apostates. Historians claim that Woodruff was being threatened by the federal government to either stop practicing polygyny, or give up any chance of Utah obtaining statehood (Quinn 1985). Some state that Woodruff was giving precedent to the law of the land and monogamous church leaders over polygyny, which was said to have been the law of God (Allred 1984). When the Manifesto was announced, it is clear that Woodruff established priesthood control over Mormons to obey the law of the land, relegating polygyny to "a loathsome state" (Bradley 1989:2). In spite of the statement against polygyny, a great number of church officials continued the practice. By 1905, however, anyone still practicing plural marriage was ostracized and excommunicated by the official church (Quinn 1985).

The doctrine of celestial marriage articulated by Smith continued to be taught after the demise of plural marriage by groups now called Mormon "fundamentalists," "saints" who followed most closely the fundamental teachings of Joseph Smith, and who refused to discontinue contracting polygynous marriages. After the Woodruff statement on the abolition of polygyny, several Salt Lake men, in disagreement with the Manifesto, formed a secret pact amongst themselves to carry on the practice of polygyny underground. Some

11 In 1853, the United States passed the Morrill law against plural marriage. In 1882, the Edmunds law was passed to further harass the Mormons in the practice of polygyny. Then in 1887, the EdmundsTucker law to stop plural marriage was given to Congress (Kraut 1989). 
fundamentalists claim that only a few select people were capable of living the highest law, and so the Lord commanded Woodruff to collaborate with the law of the land. Brigham Young had warned the members of the early church that more men would be damned by plural marriage than saved by it, and so, it is believed, that the general church was not supposed to be forced to practice this most difficult law. Thus, mainstream Mormons would not receive the highest glory, but at least they would be safe in the main body of Mormon theology. Fundamentalism would eventually prove to hold the keys to the correct and proper authority of Mormonism, the fundamentalist group claimed.

The early underground polygynists, or "fundamentalists," were all LDS (Latter-day Saint, or Mormon) men who had been part of the leadership of the Mormon Church prior to the Manifesto, well educated in religious doctrine, and closely related by kinship ties to those who began the practice of plural marriage in the early establishment of Zion in Utah. So, in this light, they and their families were deeply connected to Mormonism and loved the church dearly. To this day, many fundamentalists claim to be "Mormons" and long to be associated with the mother church as "true" members.

The split between fundamentalism and the official Mormon Church has been one of the most confusing aspects of Mormonism to outsiders. Therefore, it will be helpful to distinguish further between the two cultures here. Both cultures originated with the church established by Joseph Smith. The fundamentalists, however, collectively protest the actions and revelations of the Mormon Church's prophets after the death of the third prophet, John Taylor. Fundamentalists claim that in the 1880 s, Taylor was approached about abolishing the practice of polygyny. Later, in 1886, in Centerville, Utah, while studying the proposed Manifesto which Woodruff later announced, fundamentalists believe Taylor was visited by the Lord and received a revelation stating that the New and Everlasting Covenant (plural marriage) was and is still a commandment of the Lord, and that in spite of the weakness of others, the Lord does not change and His word and His 
covenants do not change. ${ }^{12}$ Lorin $\mathrm{C}$. Woolley, who was attending the prophet, wrote that he saw a light from within Taylor's room and heard several voices. A meeting, lasting eight hours, was held immediately after the Taylor revelation where everyone present covenanted to dedicate their lives, liberty and property to the defense and support of the principle. This secret priesthood commission was made up of George Q. Cannon, John W. Woolley, L. John Nuttall, Samuel Bateman, Charles Wilkens, Charles Birrell, Daniel Bateman, Sam Seddon, George Earl, and L.C. Woolley. Taylor then set apart five men: Cannon, both Woolleys, Sam Bateman, and Wilkens, as the council of the priesthood to promulgate polygyny (Bronson, 1982). The official Mormon Church does not consider Taylor's revelation valid.

After Taylor's death in 1887, J. W. Woolley became the head of the fundamentalist priesthood, thus formalizing the split between the official church and the "underground" faction. Then Lorin C. Woolley, J. Leslie Broadbent, John Y. Barlow, and Joseph Musser, successively, became the leaders of the underground. When Musser became disabled and was not considered capable of leadership in the 1940s, considerable dispute arose between two opposing leaders--Dr. Rulon C. Allred, Musser's Salt Lake City physician, and LeRoy Johnson, who helped establish the Short Creek, Arizona, fundamentalist community, now known as Colorado City. ${ }^{13}$ Each leader claimed to be the

12 The full account of the 1886 Taylor revelation goes as follows: "Thus saith the Lord: All commandments that I give must be obeyed by those calling themselves by my name, unless they are revoked by me or by my authority, and how can I revoke an everlasting covenant; for I the Lord am everlasting and my everlasting covenants cannot be abrogated, nor done away with, but they stand forever. Have I not given my word in great plainness on this subject? Yet have not great numbers of my people been negligent in the observance of my laws and the keeping of my commandments, and yet have I borne with them these many years; and this because of their weakness, because of the perilous times, and furthermore, it is more pleasing to me that men should use their free agency in regards to these matters...I have not revoked this law, NOR WILL I, for it is everlasting, and those who will enter into my glory must obey the conditions thereof; even so Amen" (1880-1890 Revelations; original copy in John taylor's own handwriting, Sunstone Symposium by Ogden Kraut, 1989).

13 Johnson wrote a capstone speech in Colorado City, Arizona, in 1977, in favor of fundamentalism. The speech typifies many of the beliefs of present day Pinesdale. There are some contradictions between Johnson's speech and Pinesdale ideology, such as the misogynist undertones of female destruction, yet, by and large, the type of sermon given here is the same as one will hear while sitting in the pews of the Pinesdale chapel. The entire speech is found in Appendix C. 
true prophet; each stated that they held the keys of the authority of the high priesthood. Johnson claimed to be the "one mighty and strong," who was prophesied as bringing together the saints in the last days (D \& C: 85). Allred did not make this same claim, stating that he reserved this title for Joseph Smith, the first leader and prophet. This split resulted in the division of families and friends into two hostile fundamentalist groups--the Allred Group, more formally known as the Apostolic United Brethren, and the LeRoy Johnson group, established in Colorado City, Arizona. Other independent fundamentalists claimed their own particular line of authority to God, and refused to follow either Allred or Johnson. Today there are more than 30,000 fundamentalists in the United States, Canada, and Mexico, divided into more than 100 different sects (Van Wagoner 1986). ${ }^{14}$

In various raids and arrests from 1935 to 1955 , fundamentalist polygynists were arrested on felony charges in the United States. The largest raid took place in Arizona, in 1953, where almost 300 people were prosecuted and over 160 children and mothers separated. The last arrest took place in 1955, and since that time, fundamentalists, though still considered law-breakers, are free to live and marry as they wish. ${ }^{15}$

\section{PINESDALE FUNDAMENTALISM}

The AUB (Apostolic United Brethren) is the focus of this exploratory study. It was formed under the priesthood leadership of Rulon C. Allred in the 1940s, and has now spread in branches throughout Utah, with settlements in Montana and Mexico, totaling

14 According to Ogden Kraut, a Salt Lake City fundamentalist, there are probably 30,000 people who consider themselves Fundamentalist Mormons; however, there have been over 150 different break-offs from the Mormon Church, most of them being considered as fundamentalist in nature.

15 In 1955, the Utah State Legislature passed a bill appropriating $\$ 20,000$ to stamp out polygyny. As a result, Senator Langer of the U.S. Senate held a hearing in Colorado City. Sheriff's officers set up a road block on all trails leading to town, and 50 witnesses were subpoenaed to appear at the hearing. This was the last attempt to enforce the law regarding plural marriage (Scott 1989). 
approximately 3,000 people. Pinesdale, Montana is one of its biggest settlements with 700 people.

The town of Pinesdale, located 45 miles south of Missoula, originated in an attempt to find a refuge and haven for members of the AUB. On July 2, 1955, Dr. Rulon Clark Allred loaded his families (eight wives, 46 children) into cars and trucks, and left the State of Utah, after being warned by a member of the Salt Lake City Police that a raid was planned on his home on Highland Drive in Salt Lake City. ${ }^{16}$ Allred, while on the run from local Salt Lake City officials, searched for unimproved lands with timber to be used in building homes, a church, and a school. He hoped to find an area that was near the mountains with access to rivers and hunting and wood for stoves. In 1956, Allred had one of his men look over some property in the Hamilton, Montana area. They bought 20 acres on the East Shore Highway, eight miles from Polson and built a motel, as a subterfuge. Many Salt Lake City Saints sold their homes to prepare to move to Montana. Allred leased an old two-room farmhouse for a few of his wives, and tents were put up for the others. A few additional families joined the Allreds through the winter, living in large tents with rotten floors, outdoor plumbing, and mice-infested kitchens. In 1957, a few cabins were built around the motel.

In 1961, Allred purchased the Pinesdale ranch, 10 miles northwest of Hamilton, the same year that Attorney General Walter Budge of Utah tried to get a bill passed which would make it lawful to put in prison any woman who entered into polygyny and any legal wife who knew of and gave her consent to it. The bill did not pass. In 1964, construction on the Pinesdale private school and church began. Many of the houses now in use were built during this period. By 1989,700 people were living at the Pinesdale ranch in approximately 117 houses. Additional Utah branches are located in Salt Lake

16 Some of Allred's family relocated in Nevada, and some in Idaho. His brother, Marvin, later followed him into Nevada with a family. Owen, now the current leader of the AUB, located a family in Blackfoot, Idaho, and later moved them to American Fork, Utah (Scott 1989). 
City, Cedar City, Orem, and at a ranch called "Granite," near Callio, in the West Desert, where a 2,000 acre barley operation is stationed. Information on the Mexico branch(es) was not available.

The ideological framework, or world view, of the Pinesdale fundamentalists who belong to the AUB, headquartered in Salt Lake City, reflects both the theology of the early church and the official Mormon Church of today. It also reflects the majority of the beliefs of other fundamentalists groups who draw authority lines from different piiesthood sources, such as the Johnson Group, the Kingston Group, and the Alex Joseph Group. Extensive discussions of the distinctions between these religious factions will not be given in this paper. Instead, a brief summary of the important differences between mainstream Mormons and the AUB fundamentalists is presented below.

Pinesdale ideology and mainstream Mormonism share community sexual mores of modesty, cleanliness, and chastity. They share traditional, gender based sex roles to some extent, although it appears that more women in Pinesdale work outside the home, on the average, than do mainstream Mormon women. Additional socio-economic research on Mormon women will be needed to verify this. Children in both cultures are taught to believe in the Gospel of Jesus Christ, as depicted in the New Testament and other Mormon scripture, and are enculturated with the male-dominated ideology, based on Joseph Smith's revelations. Education in both cultures is highly valued, as is cooperation, the beautification of home and garden, and the importance of food storage. Both discuss the wickedness of the world and how one must be "in the world but not of it." Both tend to be very conservative, and vote against the liberalization of laws pertaining to homosexuals, abortion, and female equal rights. Both share the same religious origin, most of the same religious tradition, and many share the same ancestors.

The difference between mainstream Mormon thought and the Pinesdale ideology lies in the desire for Mormons to adapt, rather than preserve, as the Pinesdale "saints" do. 
Pinesdale fundamentalists promote the preservation of the original doctrine and basic concepts of the church as Joseph Smith, Brigham Young, John Taylor, and various other early apostles and prophets established it, including the principle of plural marriage. As fundamentalists, they view themselves and their beliefs as nonchanging, whereas they see the Mormon Church to be adaptive and adjustable to the world. God does not change his law to adapt to the times, say fundamentalists. Neither does God abandon his "new and everlasting covenant," plural marriage, as the mainstream church did. Pinesdale fundamentalists see themselves as part of the "mother" Church, yet with the privilege of possessing the "true" priesthood organization and authority. The Priesthood Council, as the male authority structure is called in fundamentalism, holds the keys to all correct sealings and ordinances. Conversely, fundamentalists state, the Mormon Church runs only partially on the true authority of God, and is viewed as more of a corporate organization whose function it is to preach the Gospel to the masses and teach them to learn more about the nature of God. Eventually, this knowledge will bring them into fundamentalism, which is the highest work and glory. Since the "mother" is considered the Church, the "father" is the priesthood in its true fundamentalist form. Many Pinesdale fundamentalists hope to reunite the two in a symbolic marriage some day, so they will again be able to go into the temples, and be considered valid Mormons.

Pinesdale fundamentalists also show displeasure with the Church's abandonment of the pioneer garment, which was abolished in President Heber J. Grant's day. This "priesthood" garment, as fundamentalists call it, is symbolic of the hierarchical organization of heaven and should not be changed. The fundamentalist garment is similar in markings to the official Mormon garment, with figures and symbols sewn in on various parts of the garment. ${ }^{17}$ It is all white, of cotton or synthetic material, and is the same in length as it was

17 Discussion of the purpose of the garment symbols and the representation of these symbols will not be included in this paper as they are sacred and secret to the people who wear them. Further discussion of the garment is included in Chapter 2. 
in pioneer days, reaching up to the neck, covering the arms, and most of the legs, and is always worn as an inner garment. Unlike it, the Mormon Church garment, also worn as under clothing, has changed significantly, by adapting, according to fundamentalists, to the fashions of the world. This modern form reaches high up on the arms, up above the knee, and has a lower neckline than the "old style" garment. This latter style is easily hidden under other clothing. The former style is not.

In other matters, Pinesdale fundamentalists also disagree with the Church's renunciation of communalism, or the United Order. They disagree about the Church's revelation allowing Blacks to receive the priesthood. Further, fundamentalists have restored the old rituals of blessing the sacrament with the right arm raised to the square, and serving the sacrament in glasses which are passed around. They also object to the building of temples outside Zion (America).

In spite of these doctrinal and practical differences, Pinesdale residents, like mainstream Mormons, still sing LDS (Latter-day Saint or Mormon) hymns, quote from the prophets, read the Ensign (the official inhouse Mormon magazine), hang pictures of Christ on their walls, teach their children to pray in the same manner as orthodox Mormons do, in the name of Jesus Christ, and live their lives according to the Mormon standard works: the Bible, Book of Mormon, Pearl of Great Price, and Doctrine and Covenants.

Fundamentalists quote much more from the Journal of Discourses (sermons of nineteenth century Mormon prophets) than Mormons do, but they also quote the current LDS (Mormon) Church leader and prophet, Ezra Taft Benson. Polygyny, however, presents the gravest point of separation, and this difference may never be resolved. Thus, though many Mormon leaders believe that a polygynous order will be established in heaven, some Mormon scholars think the Celestial Kingdom will be monogamous (England 1987). 


\section{CHAPTER II}

\section{WORLDVIEW: THE MALE IDEOLOGY}

In memory of our God, our religion, and freedom, and our peace, our wives, and our children.

BOOK OF MORMON, Alma:46:12

This thesis is primarily concerned with women, but as is often the case, it concerns women living in a man's world. The status of the woman is stated clearly, unequivocally, and strongly in the formal canons of Pinesdale culture--her position is inferior to that of the man, who holds the priesthood. This is a matter of official creed--male creed inspired by a male to be sure--reiterated at various points in the culture by elaborate myth, ritual, symbolism and firmly held values. The male creed sometimes bears a loose and confusing relation to reality, especially in regards to the plurality of wives. The men do not question their powerful position, nor do children growing up in the system, yet the women, when together, will sometimes make jokes about it, informally ridiculing the emphasis men place on their own power, or ignoring it when outside the confines of the chapel. ${ }^{1}$ Formally, priesthood power is recognized as being directly from God, and is respected by all women throughout the community. It is used, just as all other elements of a woman's life are used: her sisterwife's childcare services, the store's produce, the school for teaching her children, and a home to give her shelter. She usually will not deny the use of the priesthood powers, though she may not regularly call upon them. She will, however,

${ }^{1}$ Some women ridicule the male ideology, I surmise, because they secretly disagree with some aspect of the doctrine, they are opposed to its significance in the community, or they do not think it an important part of their daily routine. 
routinely call upon the female networking system because this directly affects her daily activities.

This chapter will consider the ideology of Pinesdale fundamentalism, in light of the male creed, where the prescriptions for behavior are structured on a hierarchical system of which women are an integral, but informal part. These prescriptions are based on deeplying beliefs that the Pinesdale colony expresses about the nature of their external world, and about the nature of their existence in that world. These beliefs are called "existential postulates," ideals which direct the behavior of a society, but are not solely effective in solving the problems of day-to-day living (Hoebel 1966). Along with the existential postulates are normative postulates which specify whether behavior is good or bad, proper or improper. In Pinesdale, the existential postulates represent the male hierarchical structure; the ideal and the formal culture patterns in society. The normative postulates represent the daily decisions made by all residents of Pinesdale; the "real," or informal culture patterns. Together these postulates provide individuals in society with a distinctive orientation toward the world around them and toward each other, they provide the community with a world view that establishes the rules of living that seem just and right to the residents of Pinesdale. To others, such as outsiders and nonbelievers, these same rules might seem distasteful, strange, and unnatural.

When analyzing the male ideology, one can see that it encourages the unity of Pinesdale women in the separation of male/female roles and spheres of influence. Men control the ideological and political aspects of community living, but women control the more basic aspects of day-to-day living. This chapter describes the foundation of the Pinesdale worldview, and in so doing, ironically, provides the factors that motivate women to form their own networking system. In analyzing the Pinesdale worldview, one can see that there exists a complementary/contradictory relationship between male ideology and female reality: priesthood and motherhood, the head and the body, the sovereign and the 
servant, the power and the support system for that power. A preview of the basic contradiction between these two elements of society are seen in the following dichotomy of the following ideological structures:

Patriarchy. While the ideal portrays the male as total sovereign over the subservient female, holding his priesthood power as leverage for her total obedience, the reality is that the female is her own sovereign over her children, her freedom, and her membership within the female network. She draws upon fundamentalist teachings to support her sovereignty. Men are actually "sovereigns" over their wives and families only once or twice a week, during their turn to visit; all the other days, the female is in control of the household. The male priesthood also provides a mark of differentiation for women. It causes them to group themselves together out of necessity to find an alternative name, such as "motherhood," and to seek religious asylum in their own company. They will not be "second class citizens."

Celestial Marriage. Whereas the ideal is that God proclaimed plural marriage as the holy marriage ordinance to propagate the righteous seed of a righteous man, a vehicle for transporting several righteous women to heaven, the reality on earth is that polygyny, which is "celestial marriage," provides women more leisure, female bonding, and children whom they rear the way they please. ${ }^{2}$

A Heavenly Order. While the kingdom of heaven is supposed to be an order of patrilineal descent, the reality is that bilateral descent is the earthly practice, and children are distinguished and associated more with their mothers than their fathers. In addition, the "rules of conduct," established by the male ideology (shown later in this chapter) are only achieved when it is the father's turn to visit. All other days, the mother has her own rules of conduct.

2 Women raise their children within the Pinesdale structure using their own example as the motivational factor. They have the opportunity to raise up a rebellious seed if they so desire, but more commonly will teach obedience and respect for community leaders to their children. 


\section{PATRIARCHY: KINGS AND KINGDOMS}

...they have entered into their exaltation, according to the promises, and sit upon thrones, and are not angels but are gods.

\section{D \& C $132: 37$}

The structure of male hierarchy in the patriarchal order in Pinesdale--the existential postulate of the group--is based on "priesthood" powers and authorities, to be outlined in Chapter III, Figure 3. This hierarchy is made up of a prophet and his priesthood councils and boards, all of which are under the supreme direction of two absolute supernatural beings: God, who created the universe and placed everything in order and harmony, and Jehovah, or Jesus Christ, who helped God form the earth, and who later came down to earth to give up his life for others' salvation. No man, woman, or child can cause events to happen, unless through the power of these two beings. Even the smallest childhood prayer is said to the Father (God) in the name of the Son (Jesus). All must strictly obey this male theological structure and dedicate their lives in the service of their "Father in Heaven," their God. Women are blessed for this obedience, and will be rewarded with thrones of their own, next to their husband's throne, to rule over heavenly kingdoms and peoples (D\&C 132).

\section{The Nature of God}

To better explain the nature of the Pinesdale male ideology, I will first discuss the nature of their God and the powers from God that form the priesthood. An important aspect of the theological order of Pinesdale is knowing the character of God himself, a personage whom man may someday resemble, according to fundamentalist, as well as orthodox Mormon thought. Joseph Smith, the founder of Mormonism, said that men must seek godhood, desiring to "know the only wise and true God;" learning how to be gods themselves and to be "kings and priests to God" (Follett Sermon as quoted in LDS Relief 
Society Guide 1988). Smith wrote that understanding the character of Eloheim, as God is more intimately called by the Saints, is crucial for understanding life itself. He stated that through comprehending God, man can better know himself, for God is, in effect, an exalted man. God was once as humans are now. Adam was created in God's likeness, and walked and talked with Him, as one man walks and talks with another, wrote Smith. Members of the Pinesdale community recognize a Heavenly Father and a Heavenly Mother, both operating on the level of godhood. In form, only the "Heavenly Father" is prayed to and praised. More and more, however, the fact that their God has a wife is being taught-most often by women. In addition, fundamentalists believe in the Trinity of God, that is, that God has two partners--the Son, or Christ, and the Holy Ghost. Though the Holy Ghost is an important part of their belief system, as a comfort and a conscience, it's placement in the priesthood hierarchy is somewhat confusing. It is a part of the godhood, yet it is not mentioned in connection with the direct lineage from man to God.

According to the Pinesdale worldview, when God created the earth, he placed man and woman, Adam and Eve, in the Garden of Eden with the commandment to never partake of the fruit of a certain tree. Eve, being beguiled by a serpent (Satan), ate of the tree. She did this consciously, in pursuit of knowledge and (in some interpretations) in pursuit of children. Adam and Even could not conceive of children unless the fruit had been eaten. Thus, Adam as her mate, was forced to eat of the fruit as well, and both were taken out of the Garden into the desolation of the world.

Pinesdale ideology further states that in the Garden, both man and woman were righteous equals. Both had power. Outside the Garden, both vie for power in their own ways--Eve to Adam, Adam to the world. The Apostolic United Brethren see polygyny as a way of restoring both man and woman's allegiance back to God, restoring the equal, regal status of the Garden. For the AUB, Abraham and Sarah were two people who restored the state of our primal parents while on earth, and serve as excellent examples for married 
couples beginning their "young" kingdoms. Rachel and Issac are also used in sermons as model spouses to encourage wives to give up selfishness, and husbands to heed the Lord's voice. $^{3}$

Fundamentalists adhere to the Adam-God doctrine, as described in Joseph Smith's King Follett Sermon (ibid. 1988), which states that Adam was the savior of the last world, and is now the God of this world, having performed the duties required for the next stage of his eternal progression. The savior of this world, Jesus Christ, will be the Adam-God of the next world, and so on. Pinesdale fundamentalism dictates that those born of polygynous heritage are by prophecy a chosen people, and are among the few direct descendents of Christ himself.

All Pinesdale residents must learn to be gods, the same as all gods have done before them, by "going from one small degree to another, and from a small capacity to a great one; from grace to grace, from exaltation to exaltation, until you attain to the resurrection of the dead, and are able to dwell in everlasting burnings, and to sit in glory, as do those who sit enthroned in everlasting power" (R.S Guide 1988). Men and women on this earth will die and shall rise again to be heirs of God and joint heirs with Christ, at which time, they will inherit the power, the same glory and the same exaltation, until they arrive at the "station of a god", and ascend the "throne of eternal power."

Before this earthlife, the head God (Eloheim) brought together the Gods (Jehovah and Michael, also known as Adam) in a grand meeting of the creation of the world. They formulated a plan to bring people to the world. Together, they created the heavens and the earth, or rather, they organized it, the same as a man would "organize materials and build a ship." God had materials to work with, just as man has his earthly resources, to begin building a world out of chaos (History of the Church [1978] 6:302-9). Joseph Smith

3 Much of this information on the biblical analogies to Pinesdale living came directly from interviews with residents of the Pinesdale community; what I have written is their unique interpretation of the scriptures. 
stated that the the immortal spirit and the resurrection of the dead are matters of great importance. God made people in His image and then He put souls into their bodies. The spirits He did not make; they were already in existence. The spirit of man is immortal; it dwells in a body for a short period and moves on. There was never a time when there were no spirits. It was in the spirit world that God organized the other spirits to enable them to advance themselves, like He advanced Himself. Smith stated that all men will receive a salvation, unless they have committed the unpardonable sins, which are rejection of the Holy Ghost after having known of its truthfulness, and murder. (Murder is a sin that is not forgiven by God.) The death that these die will be the second death, "Gnolom", to dwell in hell, in "worlds without end."4 There are different degrees of salvation, however. Only the most righteous will receive the highest glory. Smith's sermon continues, cautioning men against sin, stating that if they do err, Christ will allow them to repent. Those that "die in faith" are now in the celestial kingdom, which is the highest kingdom (King Follett Sermon, LDS Relief Society Guide, 1988).

\section{Priesthood}

The nature of the priesthood as a tool used to draw power from God to mankind is essential in understanding the male ideology of Pinesdale. Priesthood is a term that refers to the power of God invested in righteous men. Priesthood bearers are, essentially, agents of God. In some interpretations of Mormon doctrine, married women are empowered with these same gifts as well. ${ }^{5}$ In any case, the male members of Pinesdale participate in the political ranking of the sect's ideology; the female members usually do not. Similarly, the

\footnotetext{
${ }^{4}$ Incidentally, this aspect of control is effective to keep members from apostatizing. If they leave the sect after having sometime in their life given testimony of the Spirit, they will be damned.

5 I was told by one informant that the priesthood powers will someday formally be given to women, and that some women already have risen to this power and use it to bless their children in the absence of their husbands. The power that unmarried men in the lower priesthood have is less than the power that a mother who is married to a higher priesthood holder has in blessing her own child.
} 
men pay strict heed to the prestige factors related to the hierarchy, and the women, though taught to respect this hierarchy, pay little heed to these prestige factors in their day-to-day activities. ${ }^{6}$

As mentioned, the priesthood is the authority to act in God's name. Males receive this privilege by the "laying on of hands" of other members of the priesthood, just as Christ ordained his disciples two thousand years ago. At the age of 12 , a young man is ordained to be a deacon, then at 14 , he becomes a teacher, and at 16 , a priest. These lower ranks are in the Aaronic Priesthood. The higher level begins with age 19, when a young man becomes an "elder." One then becomes a "seventy," a term used to refer to the number of married men required to make up a "quorum," and then a "high priest." These higher ranks are in the Melchizedek Priesthood. One of the basic responsibilities of a priesthood holder is to insure that he and his family receive the ordinances for which they are eligible, such as blessings, baptism, etc. Only the male, as a priesthood bearer, can perform the ordinances. ${ }^{7}$

For Pinesdale fundamentalists, patriarchal priesthood authority has been divinely ordained and is explicitly set forth in the sect's doctrine. Joseph F. Smith, the fourth president of the Mormon Church, explained the position of a priesthood member plainly. It is this statement to which most Pinesdale men comply.

There must be a presiding authority in the family. The father is the head or president, or spokesman of the family....A home, as viewed by the Church, is composed of family groups, so organized to be presided over by the

${ }^{6}$ Priesthood prestige factors are recognition markers for political ranking in the religious sect and the community. If, for example, a man is a high-ranking priesthood official, such as high priest, there is more respect for that man than for one who is an "elder." Other prestige factors involve the amount of money a man can bring into the community through his surpluses. Elder Howard, for example, gains in prestige because of his successful fencing company.

7 This may soon be debated by women of the sect, as it is currently being debated in the Mormon Church. Often, Pinesdale women told me that when necessary they will bless their own children. This is a confusing issue in the community and, I believe, is a sign of a changing ideology. One informant said it was a sign of ignorance. 
father, under the authority and in the spirit of the priesthood conferred upon him.... The position which men occupy in the family is one of the first importance and should be clearly recognized and maintained in order and with the authority which God conferred upon man in placing him at the head of his household (as quoted by Widtsoe 1939).

In family relations, the fundamentalist, as well as the orthodox Mormon, is accorded the rights and duties of the "divinely established priesthood," both Aaronic and Melchizedek, and women can reach their salvation by becoming members of the sect, being repentant and baptized by male members who have the authority. For women, the full glory can be attained only through sacred rituals performed by male members who hold the priesthood, rituals such as marriage in the "new and everlasting covenant."

The priesthood is a right and an honor, "inseparably connected with the powers of heaven" (D\& C 121) which can only be controlled or handled by righteous persons. Only through kindness, pure knowledge and charity can the power of the priesthood be realized. Priesthood must be conferred properly and "all other authorities or offices in the church are appendages to this priesthood" (D\&C 107:4-5). The organization of the priesthood in light of its obligations and responsibilities can best be explained in the structure of the United Order, based on the Law of Consecration and Stewardship established by Joseph Smith. When Smith organized the Church, it is said that the Lord told him that one man should not "possess that which is above another" (D\&C 49:20), and that "if ye are not equal in earthly things, ye cannot be equal in obtaining heavenly things" (D\&C 76:6). This principle was a commandment just as plural marriage was a commandment; it was considered an "everlasting order" (Kraut 1989). The Order establishes a hierarchy of male priesthood members over the rest of the community; the economic implications of the "Order" will be discussed in Chapter III. ${ }^{8}$ The Order of Pinesdale, written in constitution form by Rulon

8 There seems to be a contradiction here between "equality," referred to in D\&C 76, and "hierarchy," referred to in the structure of male authority. The term "equal" in the scripture, however, is not equality among the sexes, but economic equality among men, meaning male members. In this way, there is no contradiction. The system is still prejudiced in favor of males. 
Clark Allred, Pinesdale's first prophet, is recorded in Appendix B. ${ }^{9}$

In summary, the priesthood that Pinesdale men hold has five official rights and privileges:

1) Leadership--the right to call people to positions, keep them in line with the teachings, delegate responsibility, and make important decisions regarding community and family welfare.

2) Revelation--the right to speak with God and be inspired to act on His behalf, such as whether to add a new wife to the family, or the announcement of officially sanctioned practices, etc.

3) Blessings--the right to heal and bless others in the name of his priesthood powers.

4) Specific Ordinances--the right to administer the Sacrament, command Satan to leave, perform marriages and baptism ceremonies, etc.

5) Administration--the right to gather family funds, the right to officiate in the Council of the Order, and the right to dictate all matters of family organization.

9 The United Order promotes order in the community, and makes use of the male hierarchical structure of priesthood authority (shown in Figure 1). In fundamentalist belief, this hierarchy is based on God's authority invested in the prophet and leader, Owen Allred. Allred, who leads those beneath him in the hierarchy, is under the guidance of Adam/God, and Jesus Christ. 


\section{CELESTIAL MARRIAGE}

For behold, I reveal unto you a new and an everlasting covenant; and if ye abide not that covenant, then are ye damned; for no one can reject this covenant and be permitted to enter into my glory.

$$
\text { D \& C: } 132
$$

An important aspect of the male creed is the law of "celestial marriage," or "the new and everlasting covenant (D\&C 132, in Appendix A)," more commonly known as polygyny. As it was in nineteenth century Mormonism, the primary purpose of Pinesdale polygyny is to raise up a righteous seed unto the Lord. ${ }^{10}$ Polygyny was said to be a divine principle "dedicated by the Gods for the perpetuation of life and birth of earths" (Musser 1944:102). According to Pinesdale world view, there are three good reasons to enter into plural marriage: 1) Old Testament prophets, such as Abraham, had plural wives, 2) plural marriage gives one access to eternal worlds as a god, and 3) Jesus and God both had plural wives (D\&C:132:28). ${ }^{11}$ After the creation of the world, God gave to man and woman a commandment to "multiply and replenish" the earth. This law of propagation is the firmest rule within the ideology of Pinesdale. God introduced marriage on the earth as a celestial, or immortal, institution. Man and wife should be "not twain," but "one flesh" in Pinesdale worldview. Each wife has the same opportunity to be "one flesh" with her husband, as Jesus was "one flesh" with his apostles--no matter how many wives a man has, he and each of his wives will be one (Kraut 1983). When this man-woman bond is formed, it is

10 Plural marriage also is the key to a new bride's status during this life and the next. Women must bear many children to keep the commandment of multiplying and replenishing the earth, but also, to allow the waiting spirits in heaven a chance to come to earth (Young 1947).

11 Many fundamentalists claim that Jesus married Mary and Martha, the two sisters of Lazarus (Kraut 1983). God's wive(s) are unknown, but it is believed by many Pinesdale residents that there are several Heavenly Mothers to one Heavenly Father. 
easier to form bonds between wives. When a family is united in all things, they are prepared to unite themselves with heaven and all are one with God.12

The most valued example of family unity is the story of Abraham, Sarah, and Hagar in Genesis. When Sarah, Abraham's first wife found that she was not able to have children, she decided to petition their servant girl, Hagar, to become his wife and have the children. Sarah did this because she was not willing to allow her husband to fail in having no posterity, which was promised him by the Lord. Sarah, in the worldview of Pinesdale, is seen to have been able to distinguish among the "most precious gifts of god"--children. She knew Abraham loved her, and so willingly conceded the glory of fertility to her maid. Sarah is a pattern for Pinesdale females in the structure. ${ }^{13}$

The male ideology subscribes to the belief that there will be wars and famines that will destroy many men in the near future. One of the purposes of polygyny, in light of this apocalyptic prediction, is to assure that the species will move forward at a healthy, abundant speed during the time of apocalypse. Women will be so numerous that it will be common to see seven righteous women cling to one righteous man:

In that day seven women shall take hold of one man, saying, We will eat our own bread, and wear our own apparel: only let us be called by thy name, to take away our reproach (Isaiah 4:1).

Polygyny also serves the purpose of washing away the filth of the "daughters of Zion," by turning them into plural wives, as recorded in Isaiah 4:2-3.14 One often hears in Pinesdale suggestions that if only polygyny were adopted throughout the United States, all the

12 When I asked if Adam was a monogamist or polygynist, one member said that since Adam had more than one rib from which to take a wife, he had several.

${ }^{13}$ Sarah later became pregnant herself, at the age of 90 , giving birth to Issac.

14 "In that day shall the branch of the Lord be beautiful and glorious, and the fruit of the earth shall be excellent and comely for them that are escaped of Israel. And it shall come to pass, that he that is left in Zion, and he that is remaineth in Jerusalem, shall be called holy..."--meaning, that polygynous women will be blessed above all other women. 
prostitutes would be eliminated. In short, polygyny became the catch-all solution for prostitution, infidelity, homosexuality, spinsterhood, childlessness, and various types of sexual sin (Bradley 1990).

The ideological structure, as defined in D \& C: 132 , seems to punish women more severely than it does men. Because of the ease of which women embrace the "principle," they are under a stricter obligation to obey its precepts. Men are said to be less enthusiastic about the "principle," and punish themselves through disobedience, without receiving any further authoritarian punishment.

And again, verily, verily, I say unto you, if any man have a wife, who holds the keys of this power, and he teaches unto her the law of my priesthood, as pertaining to these things, then shall she believe and administer unto him, or she shall be destroyed, saith the Lord your God; for I will destroy her; for I will magnify my name upon all those who receive and abide in my law.

Therefore, it shall be lawful in me, if she receive not this law, for him to receive all things whatsoever I, the Lord his God, will give unto him, because she did not believe and administer unto him according to my word; and she then becomes the transgressor, and he is exempt from the law of Sarah, who administered unto Abraham according to the law when I commanded Abraham to take Hagar to wife (D\&C 132:64-65). ${ }^{15}$

The patriarchal order of Pinesdale establishes certain checks against the sin of a man as well, which has its roots in the Old Testament. If a man was unworthy of more wives, his first wife stood as witness against him. In this instance, a wife acts as a "spokesperson" for God in rebuking a man who may seek wives for carnal and lustful purposes (Kraut 1983). The worldview further suggests that Pinesdale men who attend church and speak in favor of polygyny are men who were willing to live its laws--laws that gave men authority over their families and over "lesser men," such as blacks, who are

15 The female's sins here are an unwillingness to comply to her husband's decision to enter polygyny as well as her sexual association with any other man. If she does not comply, she will be destroyed; if she does not agree to a new wife, she will not have a say in who this new wife will be, which is the law of Sarah. 
unable to live the full laws. ${ }^{16}$ Thus, because all are to respect male authority, belief and support of the system is reciprocal, and a good investment on the part of males--it promotes more power in their own priesthood, and respect by women and children of that power. Women are taught not to be docile and submissive in the respect they have for their male leaders, but to speak out in favor of its powers, longing to be blessed by the Lord through these powers. Women must express a need for the priesthood, just as the men express a need for loving wives and mothers who will bear them many children.

The patriarchal ideology in Pinesdale fundamentalism promotes the use of scripture as the principal authority for proper relationships between men and women. As mentioned, an excellent example of this relationship is found in D \& C, Section 132, in Appendix A. Under this ideology, a man should guide his wife, and a wife should obey and be a "help meet to her husband." In some marriage unions, men take further scriptural advice from Paul who discouraged the speaking of women in church and important meetings [1 Cor. 14:34-40]. This rule is not universally adhered to, but there is an element of belief in the prescriptions for women by Paul within the male community. This seems to contradict the early statement about women avoiding a docile state in reference to their belief in the male hierarchy. Yet it becomes clearer when both prescriptions stem from the male authoritative structure. In light of this, they are not contradictory--the one complements the other. Since women are supposed to respect their priesthood heads, and strictly obey them, the following writing of Paul on the role of women is applicable:

This being so, she shall look up to her husband, provide for him, ask his advice, and do all with and nothing without such advice. If she does otherwise she leaves the order or level wherein she was placed by God, grasps after the sovereignty of the man, loses the favor of her Maker, and therewith the covenants which her husband made to her at their marriage (1 Pet. 3; Eph 5).

16 Blacks, according to fundamentalists, were given the choice before being born, in the Counsel in Heaven with God, as to whether they would be willing to live the higher law and accept the responsibility the priesthood brings with it. Their reply was, no we do not want it. This is why Blacks, say fundamentalists, are not allowed the priesthood, because they refused to accept it in an earlier life. 
These scriptures are guidelines for sex roles in Pinesdale. A woman will ideally look up to her "righteous" male head, so long as he is righteous. She respects a man who is hard working and loyal. When he isn't, she has every right to persecute, ridicule, and torment him under the law of the community. ${ }^{17}$

\section{THE ORDER OF HEAVEN}

In my Father's house are many mansions: if it were not so, I would have told you. I go to prepare a place for you.

\section{JOHN 14:2}

The Old Testament Kingdom of God was a political power that governed the House of Israel. Pinesdale fundamentalists believe that this power was restored to the earth by Joseph Smith. I was told that this holy kingdom will be established on the earth by the fundamentalists before it will be made in heaven. Because the kingdom is perfect, Pinesdale men and women strive to live within their families a perfect order, as God would want them to. This order was explained to me in the form of a metaphor. Each family structure is like a wheel, where the hub is the priesthood head, or the husband, who is the agent of God. The spokes of the wheel are the wives, each intrinsically connected to the hub, yet also connected to each other. The wheel functions properly when all spokes are straight and strong, tightly sealed to the hub. If, for any reason, the spokes or the hub detaches, the rim, which represents the family unit, will fall off and the wheel will collapse. ${ }^{18}$

17 According to Pinesdale doctrine, if anyone finds sin among them, they are to cast it out. This refers to the men of wives, as well. They have the right to "cast them out."

18 On a larger scale, this metaphor of order illustrates the Pinesdale community, where the hub is the "fullness of the gospel," i.e., the principles of righteousness, plural marriage, the United Order, etc., and the spokes are the individual members' contributions and commitments through their stewardships or callings. The rim is the net result: the social, economic, political and religious structure. If, for some reason, the hub is weak, the rim will deteriorate. 
The order of heaven, as a blueprint of social structure, correlates four different gospel-oriented principles into a workable system. It is made up of the following divisions: social, political, spiritual, and economical. The social element to the heavenly order is polygyny, the political element is the kingdom of heaven or government of God, the spiritual element is the priesthood, and the economic element is the United Order. This is how heaven is arranged, and how Pinesdale men and wives should live today.

Within a family, the Pinesdale worldview incorporates the same concept of order as it does in the community. This is best illustrated in the form of several rules of conduct and prescribed laws of behavior, established by the male ideological structure. Every priesthood leader desires that there will be peace, union, and cooperation among family members. When entering the principle, both men and women must submit themselves to a set of rules or guidelines, taken from The Seer, written by the nineteenth century Mormon apostle, Orson Pratt (1853). What follows is an abbreviated version of these rules; the entire document is found in Appendix D. The first set of rules pertains to men; the second, to women.

1) Any man who becomes a husband must obey God and consecrate all that he has to Him.

2) A man should choose a wife, not for her beauty, but for her talents.

3) Counsel and guide your wives in righteousness.

4) Keep the secrets of your wives.

5) Speak not of your wives' faults to others.

6) Avoid anger in your association with your wives and their children.

7) Give equal time to all family members.

8) Judge not your wives.

9) Assemble your family together often, at least once a week.

10) Use the Spirit to govern your family. 
For the wives, there are also rules of conduct:

1) Submit yourselves wholly to the counsel of your husband.

2) Seek not to manipulate your husband against your sisterwives.

3) Be a peacemaker in the family.

4) Speak no evil of your husband in the presence of others.

5) Aid your husband's other wives in sickness and in times of stress.

6) Correct your own children, and do not dispute with the children of another.

7) Instruct your children in righteousness.

8) Conquer and subject your children to obedience.

9) Use cool judgment in correcting your children.

10) Do not threaten your children or promise them anything.

11) Do not be a tyrant of the household.

12) Teach your children to honor their father.

13) Do not allow children to fight.

14) Be industrious in your habits.

15) Educate your children; girls in the domestic sphere, boys in the outdoors.

16) Do not be wasteful.

17) Endure to the end.

The male prescriptions for women's conduct in Pinesdale were summarized by a former fundamentalist prophet, Joseph Musser, in 1948:

Thy desire shall be to thy husband, and he shall rule over thee. In placing man at the head, he bearing the Priesthood, a law, an eternal law, was announced...man with divine endowments, was born to lead, and woman to follow, though often times the female is endowed with rare talents of leadership. But women by right, look to the male members for leadership and protection (Musser 1948: 134). 


\section{Woman's Place in the Order}

The story of Adam and Eve, mentioned at the beginning of this chapter, represents the transformation of two immortal, equal beings, into two separate, conflicting entities. According to Pinesdale theology, patriarchy and matriarchy, two corrupt versions of Adam and Eve, replaced the former unity the first couple experienced while in the Garden. Polygyny is the key to getting back to that united, equal existence, according to male ideology. Because Adam and Eve supervised each other, and instituted a system of checks and balances in their relationship, Adam was given no arbitrary power that Eve did not have access to as well. Eve was to heed Adam only insofar as he obeyed their Father. For Pinesdale women, this Adam-Eve scenario represents their role in the male structure most vividly. They are a check on their husband's righteousness.

An additionally compelling role for women in the male creed is that of raising a large, righteous family. Women are taught from childhood that the greatest virtue in life is to give birth to one of the Heavenly Father's spirit children. They are taught that "children are a heritage of the Lord, and the fruit of the womb is his reward" (Psalms 127:3). Women who cannot have children, and still live within the system, are bitterly reminded of the words of Rachel, Jacob's wife, who when she discovered she was barren said, "Oh give me children, or else I die" (Genesis 30:1). Women are also taught in the male ideology that they should allow the men to fight the physical battles of life and that the wife should "adorn the home, conserve the larder and render the habitation an earthly heaven where love, peace, affection, gratitude, and oneness shall abound" (Musser 1948: 134).

Eliza R. Snow, a nineteenth century "saint" who is much admired by Pinesdale women, and, who incidentally, was one of the Prophet Joseph Smith's plural wives, explained women's state in the male hierarchical structure in the following sermon:

We stand in a different position from the ladies of the world. We have made a covenant with God, we understand his orders and know that order requires submission on the part of the women. The Lord has placed the 
means in our hands, in the Gospel, whereby we can regain our lost position. But how? Can it be done by rising, as women are doing in the world, to clamor for our rights? No...it was through disobedience that women came into her position, and it is only by honoring God in all institutions he has revealed to us that we can come out from under that curse, regain the position originally occupied by Eve, and attain to fullness of exaltation in the presence of God. Queen and Priestess (Snow, LDS Archives).

The ideology of Pinesdale defines the female role in three basic instructive ways: 1) obey thy husband, 2) bear his children, and 3) work to make the United Order a success. The reality of female ideology, as captured in chapter 6 , suggests that these three requirements are limited in the total description of a woman's life in Pinesdale.

\section{THE FEMALE VIEW OF THE IDEOLOGY}

And Adam called his wife's name Eve, because she was the mother of all living; for thus have I, the Lord God, called the first of all women, which are many.

$$
\text { MOSES 4:26 }
$$

Behold the handmaid of the Lord; be it unto me according to thy word.

\section{LUKE 1:38}

Pinesdale women, while cognizant of and adhering to the male ideology outlined so far, have created for themselves their own versions of this ideology and structure which are uniquely meaningful to them. They do this in the form of stories about the glorified status of women in various forums--Relief Society, their homes, their work places, and the school. Rarely do these stories emerge while in the company of male residents of Pinesdale, and are not talked about in general religious meetings. These stories are described in more detail below. 


\section{Myth: Servant and Goddess}

Pinesdale women share myths, not so unlike the biblical miracles of which they often read, of how God has saved them from danger, given them the child they always dreamed of having, or caused a loved one to become well. ${ }^{19}$ These stories are accompanied by tearful testimonials of the "truthfulness of the gospel" and God's mercy. They are binding tools to unite opposing personality types, age barriers, or jealousies among sisterwives. If any women does not easily join these spiritual sessions with the accompanying tears and expressions of joy, she is thought to be a nonbeliever, and is not extended the same friendship and help in the networking system.

In these sharing of myth sessions, which usually take place during Relief Society meetings, and visiting sessions, women repeat the story Mary and Martha, the two dearest friends of Jesus (Luke 10:38-39). In fundamentalist belief, Jesus married both Mary and Martha, because he loved them both (John 11:5). And since the two sisters loved each other dearly, the trio became a loving eternal round. The character of Martha, a woman who was devoted to her home and family duties, is a canon for household magnificence for Pinesdale women. Mary, too, was given gifts--gifts of a different sort, which gave her the ability to conduct affairs outside the home. She is the model for women who work in the marketplace. These two sisters, devoted as they were to their talents, and to their families, were the perfect combination. Women learn that charity, above all other virtues, can bring them exaltation. Charity also will bring them closer to their sisters, building a "sisterhood" that is strong in force and number. It was because of Mary and Martha's tendency to serve others that Jesus was attracted to them in the first place (Kraut 1983).

19 Just as Queen Esther appeared before the king of Persia, facing death, so must all the Lord's handmaidens go when called, knowing that her sisters supported her and petitioned the lord in her behalf (Esther). Just as Mary, the mother of Jesus, and her cousin, Elizabeth, were united in their the news that Mary would bear the Only Begotten Son of God, Pinesdale women share news of joy of their expected child to their sisters (Matthew). 
Mother Eve represents another myth which women apply to themselves. Eve is the supreme example of righteousness. Pinesdale women believe that the world would be brought to naught without them--women are keys in the "priesthood arch of creation" (Nelson 1987). Adam held the priesthood. Eve was the mother of all living. They were a team. So, now, each wife may join with her husband as a partner unified in purpose (1 Corinthians 11:11). Eve was a mother, the mother of all living. And like Eve, each woman must welcome children into her life, nurturing them. She must be obedient to the commandment to multiply and replenish the earth. Above all, women are taught, that like Eve, they hold a power over their husbands--a power that is inherent in their eternal partnership. The everlasting priesthood principles, laws, and power depend upon a man and a woman; thus, a woman is a check upon the man in righteousness.

Women also tell stories of their pioneer past, when their own mothers, grandmothers, and great-grandmothers were humbled in raising their children under adverse conditions. In these stories, women are seen to be a powerful force in the settlement of the West. They are seen to be righteous stewards of their families, with a supreme influence over the lives of their children and those around them. The more vivid the details of hardship, sacrifice, and surrender, the better--to emphasize the strengths and rewards of the female "saints," in contrast to perhaps the historical fact of pioneer women's actual denigration at the hands of their husbands.

\section{Goddesshood}

In Pinesdale female ideology, polygyny is portrayed as the fulfillment of a divine principle. Women promote the cause of plural marriage, as it makes one more unselfish and willing to tolerate situations and people for a good cause. Learning to share becomes a heavenly art with women, an art that they perfect all their lives. Women are promised, if they endure to the end, that they will be rewarded with thrones, kingdoms, principalities, powers, dominions, glory, immortality, and eternal lives (D\&C 75:5, 128:12, 13; 132:19, 
24; Moses 1:39). These "kingdoms" are beautiful havens of glory where women sit on thrones alongside their husband and share the reign of power over their children and others in their respective kingdoms. The eternal perspective of the gospel helps women to understand their place in God's plan, to accept and grow from challenges, to make decisions, and to focus on their divine potential, according to female informants.

The mere existence of a goddess in a Pinesdale's pantheon does not necessarily suggest an exalted position for women, however. The privilege of goddesshood does not betoken female hegemony over men. On the contrary, the status of goddess is beneath the status of male "god." What is important about the myth of goddesshood, however, is how this myth affects the way women feel about themselves and the unity it brings to their relations with each other. One woman suggested that, as on earth, heaven will be set up with busy husbands (gods) attempting to rule several kingdoms, spreading their thin authority over a large sovereignty. And, also as on earth, women will be in charge of their own respective family kingdoms, being sovereigns over their own children. There is an apparent paradox in Pinesdale between the symbolic ascendancy of women and their social denigration, or inferiority. Yet, for women who believe in their potential as sovereigns of kingdoms, this paradox seems to go unnoticed, and is unimportant. Women will suffer for a good cause, and the cause of attaining goddesshood where all their children will be lifted up to heaven with them, is the greatest cause of all.

This polygynist belief is not unlike orthodox Mormon beliefs regarding women. In D \& C 121 , one reads that the rights of the priesthood are inseparably connected with the powers of heaven and that the powers of heaven cannot be controlled except in righteousness. This is also true of the rights of womanhood (Holland 1989). When each man or woman has kept his/her commandments in the priesthood and in motherhood, God will say, "Well done, thou good and faithful servant: thou hast been faithful over a few things; I will make thee ruler over many things" (Matthew 25:21). This is said to both man 
and woman and so, in this context, woman will be a sovereign of her kingdom. Neither man nor woman will succeed in his/her kingdom without the help of the other.

Pinesdale womens' role as a potential goddess on earth is a supportive one. Many believe that this subordinate position is temporary, and that soon, like Eve, they will rise to their full glory. In order to achieve this role, women study and prepare themselves enough to articulate to the world that they are not apologizing for strengthening the home, but are rather pursuing their highest priorities, personally, socially, and theologically. According to Pinesdale philosophy, to have any successful endeavor, one has to have order. Someone must be in charge. It just so happens that the male is the one chosen by God to be in charge. This is the purpose of the priesthood and the reason for a patriarchal form of government. One female member stated that because Pinesdale residents are usually more opinionated than the usual religious group, especially among co-wives, they must have someone to be the mediator. The husband is the one to mediate.

We are all living a hard principle and have strong opinions about how things should be done. We need a head. There would be chaos otherwise. The head says do this, we do it. That is effective rule. Our God is a God of order, and he requires that we be organized in the community and in the home. I need a guide in my life. In spite of my individuality and independent nature, I need the priesthood as that guideline. We are all free, but if you need an answer, go to your husband. Women and men have different jobs in life. Women are blessed to have children. The greatest calling is to nuture. You can focus your life around them. Men have the ability to provide for the family. I don't want to be a leader. Too much responsibility. Too much worry. I am independent in some things but for counseling, I rely on him.

In summary, the Pinesdale worldview includes the following:

1. Absolute authority resides in Eloheim, God the Eternal Father, and in His Son, Jesus Christ, omnipotent beings who created the earth and the heavens, provided a way for man to be tested on earth and return to their presence, and who share the sovereignty of the Kingdom of Heaven with, but give no visible recognition to, their wives. The progression of man, like the progression of God, Himself, is endless. 
2. Man must be like God and take up wives and build up an earthly kingdom, going through the trials and sufferings that God and Christ went through to gain godhood. Man's trials include being responsible for his wives and children, suffering persecution from the larger society, and enduring physical pain and financial loss. Woman must likewise go through trials: the trials of childbirth and motherhood, and the suffering of spirit. She will be rewarded with the heavenly sovereignty of her own kingdom, a kingdom which is shared with other wives, under the direction of the king, her husband.

3. Man and woman are redeemed in Christ, who died for them upon the cross, who has provided a pathway to salvation through suffering and obedience to God's commandments. All who live on earth will be resurrected because of Christ's gift, but only those select few who live the highest laws of God, i.e., polygyny, communalism, and serve under the supreme and holy priesthood, will receive the highest glories.

4. At all times the individual must be submissive to the will of God, as revealed through His representatives in the priesthood. Self-surrender to this will is encouraged. Only through obedience to the laws of God can one receive blessings and eternal life. A man must be obedient to God; a woman must be obedient to the counsel of her husband as he is obedient to His God, in righteousness. If a man is not righteous, she is accountable to her bishop, or her prophet.

5. What belongs to the Lord should be freely given; that is, all surplus and tithes should be willingly donated to the bishop for distribution back into the community. The Law of Consecration states that even if the bishop asks for a man to give his life, he should be willing.

6. Members should not smoke, drink, or eat to excess. Anything good for the body, in its proper season, should be eaten with modesty. 
7. Male dominance is reflected in the biblical tradition of Abraham and Sarah and is embodied in the relationships between the sexes and in marriage. Man is the leader in righteousness and is the example.

8. Above all, there is free agency. No one should force a member to live in a certain way, nor chastise him if he does so. One is free to live or not live the principles of the ideology. (It is rare, however, especially for males, for someone of a marriageable age to reject the "principle" and still remain in the community.) Note that agency is the "ideal" in Pinesdale and is not always achieved because of public ostracism and the need to cleanse the community of nonbelievers.

9. The ultimate goal of the community is to raise up a righteous seed and become gods and goddesses over this seed for eternity, establishing their own heavenly kingdoms, and giving the glory to the Father, making Him proud of them.

In this chapter, one can see that the behavior of men and women in Pinesdale is shaped by culturally defined divisions of theological standing--man on the right hand, woman on the left. It would appear that both sexes tend to maximize the benefits of their roles in the ideology structure and minimize the discomfort or negative aspects of these roles. Both are equal and opposite in this context, both complementary and contradictory. Both will distort the fundamentalist ideology according to their needs and desires, playing up certain parts and playing down others. For example, throughout the chapter, the ideology presents man as the "head" of the family, the "God" of his kingdom, and the "priesthood" member of society. For him, the ideology presents a place where his religious and familial authority is used to mold and counsel his family members--including his wives--into heavenly beings. Likewise, women, ideologically the receptacles of spirit children and the sovereigns of the household, will make use of their dominion of their children and their household. They will maximize the benefit of ideological humility for the reward of "celestial kingdoms on high." They will allow themselves to be symbolically 
dominated by men in order to achieve their own "exaltation" as goddesses and priestesses. In this way, each sex manipulates that aspect of fundamentalist ideology which most benefits their salvation and their needs on earth. Each sex is seen to be in charge of the dominion of a separate, but complementary realm. 


\section{CHAPTER III}

\section{THE PEOPLE}

Go ye, therefore, and do the works of Abraham; enter ye into my law and ye shall be saved.

$$
\text { D \& C } 132: 32
$$

Those principles which conform to the revealed word of God pertaining to reason, justice, judgment, mercy, love, and brotherly kindness shall be practiced and shall govern the conduct and the decisions of each man holding the Priesthood and every other member of the Order, remembering that the eyes of God are upon him or her, and that he or she is amenable to His righteous judgment.

\section{PINESDALE UNITED ORDER X:1}

The purpose of this chapter is to contextualize the occurrence of female groups within Pinesdale through an analysis of its people, its sociopolitical structure, its economic order, and its community life patterns--all of which are founded on the male dominated ideology of the Apostolic United Brethren, or Allred group. A brief analysis at the end of the chapter will demonstrate how these structures promote solidarity among women.

Pinesdale is nestled among several hundred Ponderosa pine trees on the eastern slope of the Rocky Mountains within the Bitterroot Valley, approximately 45 miles south of Missoula. The "ranch," which Pinesdale is often called, has a breathtaking view of the open valley floor and the opposite mountain range, the Bitterroots, and is located at the mouths of several small canyons. The location is perfect for a community desiring geographic isolation and protection (see Figure 1). The community meanders in and around the pines, and contains a few large openings where alfalfa and other forage crops are grown in the summer and where cattle graze on bunchgrass and wheatgrass in the fall 


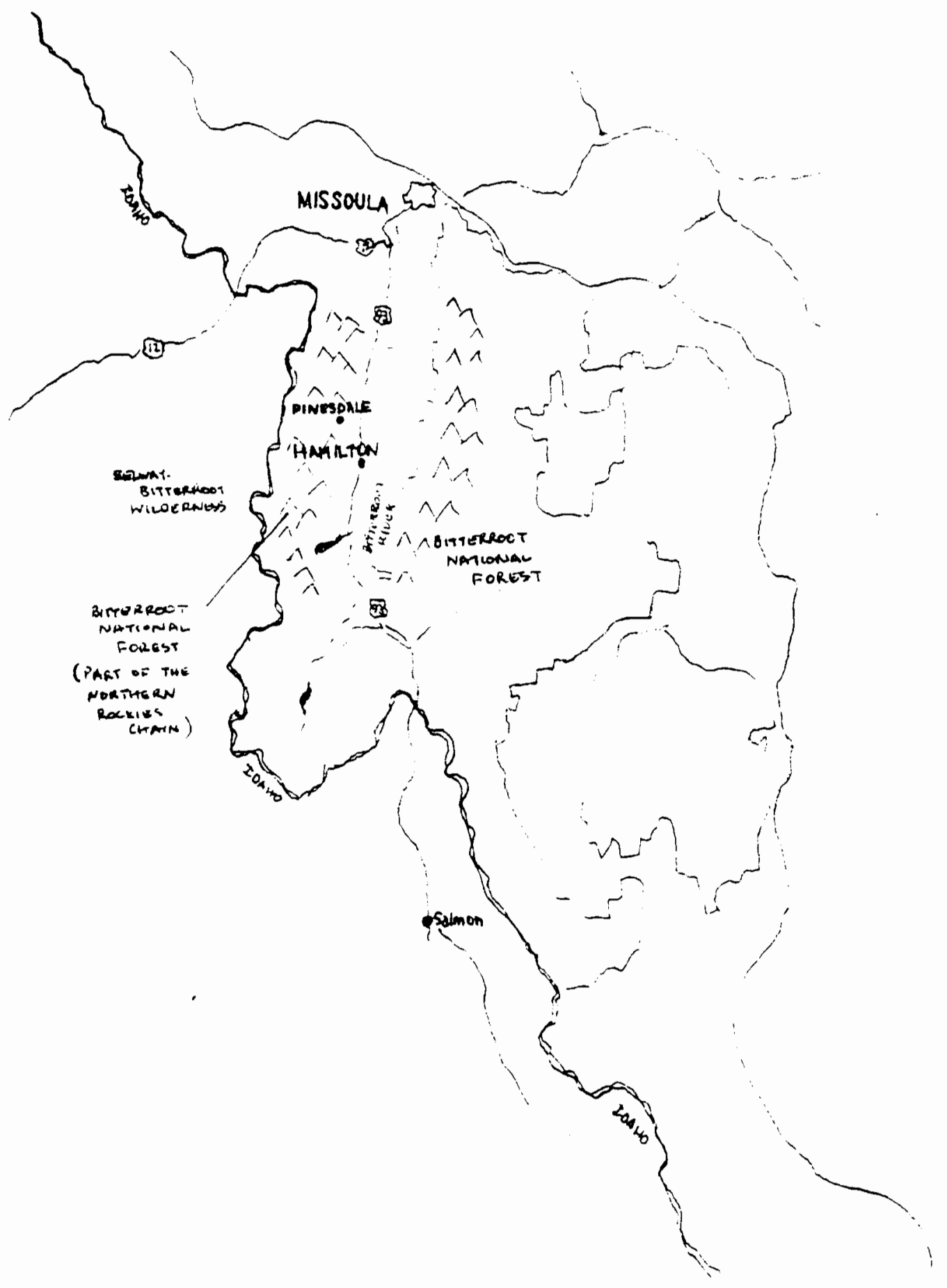

Figure 1. A map of the Bitterroot Valley, Montana. 
and winter. The community owns 100 head of black ballies (Hereford/Angus mix), several horses, a community mercantile, a gas station, a wheat mill, a bishop's food storehouse, several wood and metal workshops, a carpentry warehouse for cabinetry making, an all-inone church/schoolhouse, a power plant, a city hall, a fire department, and approximately 800 acres of land, 93 of which are in pasture. The majority of the houses are located-along with the Pine Mercantile, the school/church complex, a trailer court, and various wood and carpentry shops--in the center of town. Among them it is common to see clusters of houses belonging to one extended family (see Figure 2).

Pinesdale has an elevation of approximately 3,800 feet, an annual rainfall of 11 inches, and an annual snowfall of 33 inches. The land around Pinesdale is too poor and the rainfall too limited to produce cash crops of any kind. Individual families attempt to grow vegetables near their houses, while a communal garden is maintained six miles north of Corvallis, Montana, the produce of which is contributed either to the community storehouse or distributed straight to families. But these smaller gardens are not large enough to sustain the community with full-time inhouse produce. The colony will often lease additional acreage from absentee farm owners to use for cattle feed.

As previously mentioned, the people of Pinesdale are remnants of the original Mormon polygynists who settled in the Salt Lake Valley, Utah, from 1847 to 1890 . They live in matrifocally arranged residences, trace descent bilaterally, and the basic unit of the community is the extended husband-wives-children family. ${ }^{1}$ The 700 people--50 men, 150 women, and 500 children, are ranked according to their age, sex, and relationship to male

1 Descent can be confusing if one is talking of "heavenly" relations, as the Pinesdale community traces kin groups patrilineally in their view of the afterlife. This is significant in light of the fact that Pinesdale residents are attempting to live the "heavenly order" on earth. The term, "matrifocal," will be discussed later in this chapter. 


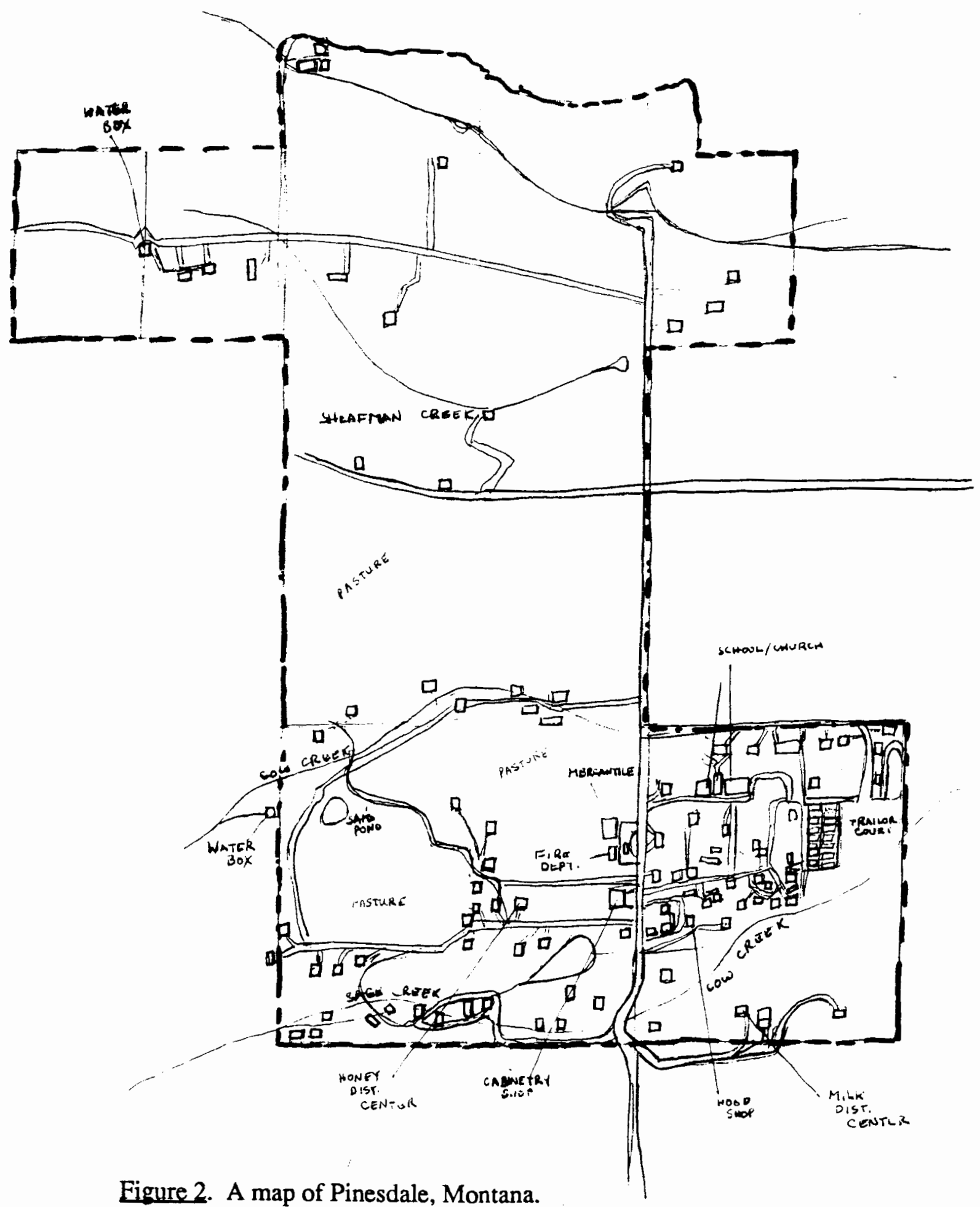


priesthood bearers. ${ }^{2}$ Women and children obey the male head of household, and the male head obeys the male leaders of the community. In turn, all members sustain the authority of their leader and prophet, based out of Salt Lake City, Utah, Owen Allred. The community practices plural marriage and attempts to live "the United Order," a utopian-like program which incorporates a Christian socialism which calls for the combined labor of the community, the elimination of extremely poor or wealthy members, and a system of redistribution that provides a high degree of security for the individual. ${ }^{3}$ All of these elements of the Pinesdale community reasonably satisfy both their spiritual and material needs. Yet, because of a recent economic recession in the area, the community is in need of an inhouse industry, such as a dairy, a poultry operation, or a toy manufacturing company of some type, which would boost their economic resources. Presently, they have not developed an adequate product or resource which would do so.

\section{THE SOCIO-POLITICAL STRUCTURE}

The sanctioned male authority of Pinesdale supersedes all civil authority when the laws of man interfere with the laws of God, although the community regards state and federal law as necessary and worthy of their full support in most cases. ${ }^{4}$ The General Council of the Priesthood, also operating out of Salt Lake City, is under the direction of the

2 Out of 200 adults, 50 are men who hold the priesthood and can vote on the general board of the town, and are members of the Council of the Order. That leaves 150 wives; a three to one ratio. There are 500 children, from ages $0-18$, most of whom have been raised in the private school system up until the age of 14 , when they attend public school. Women and children far outnumber men in Pinesdale. There are very few single females over the age of 18; and a small percentage of single males who are in the transition of either marrying in the community, or leaving it for work or school. Because of the scarcity of young, single adults in Pinesdale, they were left out of the general census.

3 James Hulett, in his study of early Mormon polygyny, stated that the sociological and social psychological aspects of this particular lifestyle promoted individual contentment and security $(1939,1940)$.

4 A large number of the members of the sect are guilty in a court of law of misdemeanor offenses in the State of Montana because of their polygynous practice, yet, in general, the community is extremely right winged-patriotic, and has a flag in every meeting room. Many are members of the John Birch Society, Women for the Constitution, and read Cleon Skousan's Freeman's Press. 
prophet, and serves as a watchdog on all branches of the AUB. More specifically, it guarantees that all plural marriages are sanctioned by God, as part of the celestial social order of the community, and that all transactions, financial and spiritual, are in line with the laws of the gospel. Each baptized member of Pinesdale is under the direction of the Council of the Order, which is made up of each priesthood head of family, and takes instruction from the General Council of the Priesthood. Those under the age of eight, and adults who have not yet been baptized, are not considered members of the community, but are merely welcomed as visitors, without significant status. An ecclesiastical/governmental board of seven male members also serves to enforce certain laws of the community. A general board of every male head of family, which meets once a month to hear the recommendations of the seven-man board, aids the seven-man board in carrying out instructions, and forms committees to complete projects. The seven-man board is an elite group of respected men, who perform a judicial function in the community. For all intents and purposes, the general board and the Council of the Order are interchangeable; in other words, the same people sit on both organizations. Church and state, however, are united in almost every aspect in Pinesdale, as all those with civic duties are active, believing members of the Order, having made holy covenants of obedience to Allred and the General Council of the Priesthood. For example, the sheriff and his deputy are swom in by civil authorities, yet they are church-going "saints," and adhere to the law of the gospel above the law of the land. The town also has a fire department, a town council, and a board of education. The same church and state juncture applies to these organizations as it does to the sheriff's department. There is, essentially, no difference in purpose. The "civil" board of seven members meets once a month to work with the general board on community decisions, such as how to handle the water distribution, what to do about juvenile delinquency, and what to do about Jane Smith's frozen pipes. Some of their responsibilities trickle down to the town council, the board of education, or any other 
informal civil committees formed to take care of specific problems, over specific jurisdictions.

Women have no official voice in the sect, are ineligible for top leadership positions, and do not usually participate in formal community policy, with the exception of the town council and the school board. ${ }^{5}$ Pinesdale women participate officially in the sect by being present at church to confirm and support the actions of the male hierarchy, and by joining in the prayers, sermons, and singing rituals on Sunday. They do hold leadership positions below the level of priesthood authority, such as Relief Society president, Young Women's advisor, Sunday school teacher, town council member, or school board member. They also comprise the largest group of registered voters in the town.

The official leader of Pinesdale is the Bishop, though he must answer to the Council of the Order, as well as to the General Council of the Priesthood and the Prophet. Under the Bishop are two counselors who help conduct meetings and join him in the "laying on of hands," an ordinance performed by members of the Holy Melchizedek Priesthood to heal the sick and bestow blessings on the needy. ${ }^{6}$ Two members of the higher council inhabit Pinesdale, and hold a higher priesthood than the Bishop. It is the Bishop's task to exert his authority wisely in making decisions that affect the congregation. He refers all weighty matters to the two members of the General Council that are present. His religious duties require that he conduct church services and perform civil marriages and funerals. He must also hear confessions, and administer punishment for sins. He is also "steward" over the community storehouse, which stores goods for the needy. It is his responsibility to see that no one goes without food or shelter. It is also his task to watch

5 There are two women on the town council and four men. One woman is the secretary and the other is a full voting member. There are three men on the school board and two women: one teacher, one secretary.

${ }^{6}$ As will be discussed in Chapter 2, the Holy Melchizedek is the higher order of the priesthood, above the Aaronic order, which is held by young men and boys under the age of 20 (LDS Church Priesthood Manual, 1988). 
over the internal distribution of funds for families and projects. He collects the tithes and offerings of the membership, and assures that all money is accounted for. He is also one of the spokesmen for the fundamentalist way of life outside Pinesdale.

In summary, the bureaucratic organization of the community, as illustrated in Figure 3, is as follows:

1. The prophet or leader of the priesthood is Owen Allred, of Salt Lake City, Utah.

2. The 10-man General Council of the Priesthood, two of whom reside in Pinesdale.

3. The Council of the Order, made up of all priesthood holders.

4. The bishop of the congregation and his counselors.

5. The individual priesthood holder, who is also head of the family.

6. The wives of this priesthood holder and their children.

On the level of civic organization, there is a smaller hierarchy which is all under the purview of the Council of the Order. It includes:

1. The seven-man board.

2. The general board, synonymous with the Council of the Order.

3. The town council.

4. The board of education.

5. The fire and police departments.

6. The postal service and notary public.

\section{Stewardships and Family Structure}

Each member in the bureaucratic organization of Pinesdale is awarded a "stewardship" which is a type of calling or duty. This stewardship gives them jurisdiction-both small and large--over some aspect of the United Order. In general, these 


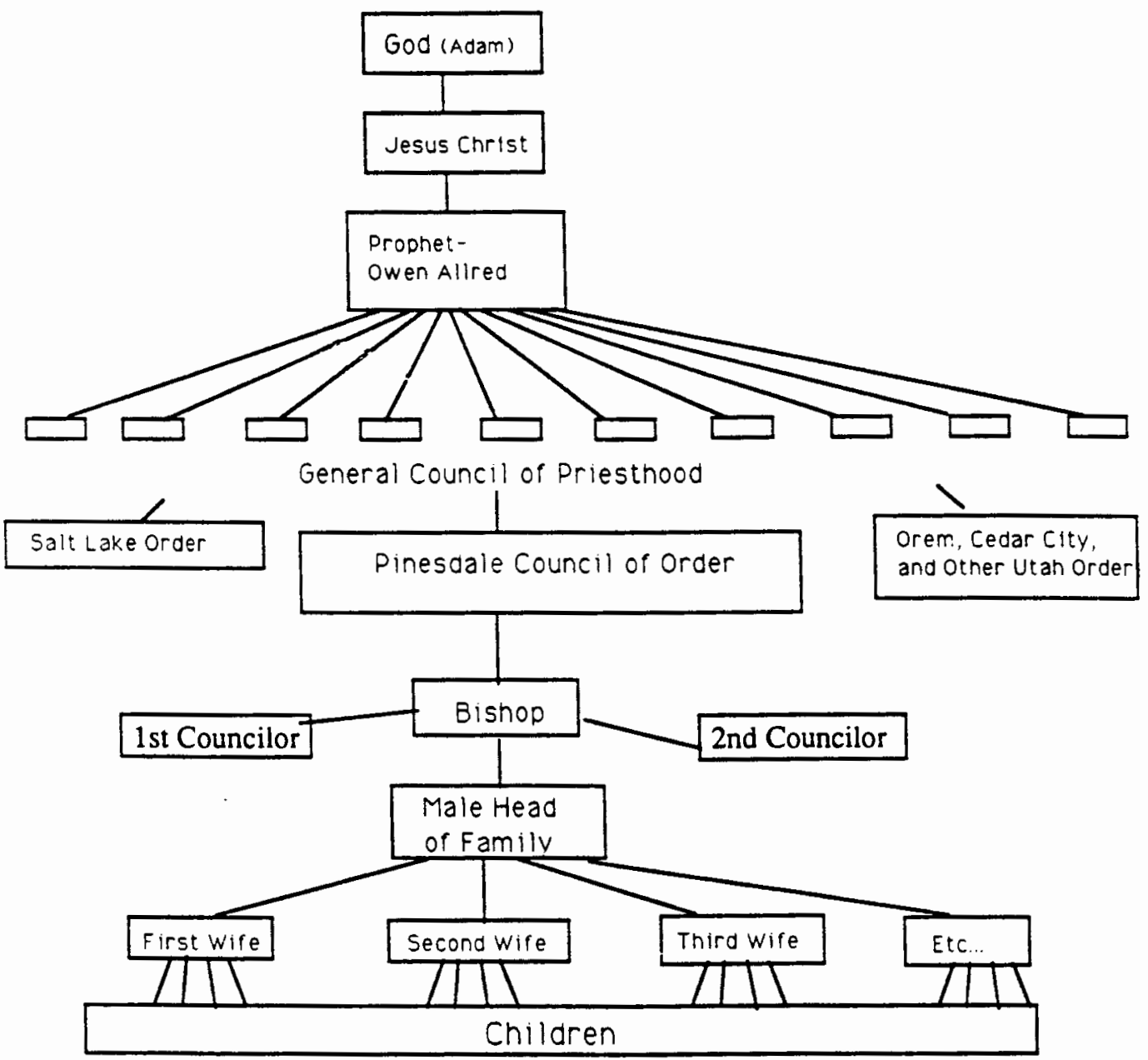

Eigure 3. The Pinesdale priesthood hierarchical structure. 
stewardships are unpaid roles in the community. One man's stewardship is to collect goods for the Bishop's storehouse. Another man's calling is to insure that all marriages are sanctioned by God, or informally, to oversee the courtship practices of the community. Women have stewardships in the home, as mothers of their children, and often, in the community, as teachers, nurses, and caretakers of specific tasks such as the communal distribution of eggs, honey, or milk. One woman is steward of the Pines Mercantile, the community's general store. She orders all produce and bulk dry goods, and arranges to have them shipped from Stevensville, 24 miles north on Highway 93. Another woman's duty is to deliver all the babies in Pinesdale. She works long hours, visiting four or five women a day, trying to insure that all babies born are healthy and strong. Another woman's job is to sew and organize all religious articles of clothing. ${ }^{7}$ In this way, the community socio-political structure ideally resembles a smooth running machine with various parts, each part sanctioned by the hierarchy of male authority.

The community, as a machine, requires the complementary union of male authority and female networking to run smoothly. The "priesthood," which is God's authority on earth, is held by the men, but is maintained and supported by the system of female networking. Women must form these supporting systems among themselves. The cooperation of women--both economic and emotional--is officially validated in fundamentalist theology. Since the men are seldom at home, (approximately $30 \%$ work out-of-state during winter), and the residence is primarily female dominated (men rarely spend more than one day at a time in one household, but rotate to and from each wife's residence as visitors), women are in a position of economic, emotional, and social

7 I was told two separate statements about the "priesthood garment" which many members wear. One man indicated that there were numerous people who wear the sacred garment of the sect, as there is a woman specifically called to repair and sew these garments. Another member said that only those persons who have gone through the Mormon temples--which could be any number of former members, or current ones who still hold temple recommends--are still wearing the garment. Temple recommends are official cards that allow one to enter into the orthodox Mormon temples all over the world. 
interdependence. ${ }^{8}$ The wealth of the family determines the arrangement of "sisterwife" (cowife) residence. Some wives share one home with separate bedrooms; others have their own home built next to their sisterwife's home. It is common to see clusters of sisterwife houses; the apparent theme in house building is to arrange wives' residents in order for women to have access to their family economic network system. A more complete description of residence, kinship, and married life will follow in Chapter IV, under Family Structure.

The average number of wives per man is slightly more than three; thus, one wife will, on average, cook for and sleep with her husband approximately twice a week. In the case of one man with eight wives, six of whom live in one household, each wife would sleep with her husband approximately once every one and one-half weeks, though she may see him on a daily basis. It is common for the wife to cook and care for her husband when it is her turn to sleep with him. Essentially, the wives raise their own children, rotate in teaching them and other children in the community private school, and budget their own incomes [often one man can't supply enough food and clothing for three or more wives so most women $(75 \%)$ work outside the home either part time or full time to provide for their families]. Each woman's budget is usually separate for her individual subfamily, though many commodities are shared among co-wives, as discussed in the next section. Men are required to give their wives equal parts of their income, according to the number of children in household. Working wives redistribute their income in the family, through the male head. The women also provide a social support network among themselves which allows them more freedom and enjoyment and less work per woman per family. In this kind of networking system, the amount of labor in a household or family of several wives is

${ }^{8}$ Residence is defined here as "matrifocal" (Smith 1956), as households are organized around women who control the economic resources in the home to a large degree and influence those within that home, i.e., children, visiting husbands, etc. The nuclear units of mother-plus-children may also constitute independent units, as in the "matricentric" families of the Caribbean; or may be linked together, as in African polygynous societies where each co-wife and her children constitute a separate household. 
diminished with the increase in number of wives. In addition, the women share in childcare, bulk shopping, healthcare, and home maintenance.

\section{THE ECONOMIC ORDER}

Behold, mine house is a house of order; saith the Lord God, and not a house of confusion.

D \& C 132:8

Coupled with plural marriage in fundamentalist belief is the United Order, an institutionalized program of sharing communal wealth, pooling of labor and resources, and drawing on that pool according to need. The purpose of the Order is to minimize privileged position and private gain. As one shares spiritual gifts, material gifts naturally follow, said one member. The formal beliefs about material items are that they are all "gifts from God" for the well being of his servants on earth. Ideally, man does not "own" anything, but is steward over it. An individual cannot come closer to God unless he gives up his possessions, as suggested in Pinesdale member's reference to Matthew 19:24: "It is easier for a camel to go through the eye of a needle than for a rich man to enter into the kingdom of God." The ideological implications of the United Order were discussed in Chapter II. The practical enforcement of the Order is found in the Pinesdale United Order document, compiled by the former prophet, Rulon C. Allred, reproduced in Appendix B.

The United Order can be defined in five parts: 1) consecration of tithes and offerings; 2) surrender of time and energy; 3) communal distribution; 4) storage and rotation of new and used goods; and 5) provision for the poor and needy. An illustration of how the United Order works is found in the procedures for entrance and commitment to the community. Restrictions are placed on incoming members so that they are aware of the great commitment involved in living the highest law. Most of these restrictions are in the 
form of material loss of property and goods. Another vital aspect of joining the ranch is one's ability to live the principle of plural marriage without flaw. According to one informant, many men who join the AUB prove to be incapable of living "the principle," the law of plural marriage. I was told that many move to Pinesdale for the lifestyle, to get away from he world, and to bring their children up in a good, up-standing community. ${ }^{9}$ Even though some few do come for the wrong reasons, it is rare for "gentiles," or nonmembers, to slip through the priesthood process of entrance. The following is a list of the steps toward obtaining membership:

1) Consecrate all one has and give it to the bishop, in other words, give up all material possessions and donate these items to the community for distribution to all members.

2) Commit oneself to the principle of plural marriage, promising to someday add a wife to one's family, if one don't already have one.

3) Organize one's family, promoting order, cleanliness, and obedience--the success of the communal order depends on the success of the family order.

4) Gain the permission of the Prophet, and or a member of the General Council of the Priesthood, in writing; personally confirm one's commitment to the community before arriving in Pinesdale.

5)Reserve a tenth of one's gross income as tithing to be sent to Owen Allred in Salt Lake City, for redistribution in the form of programs throughout the sect.

9 The man who explained the entrance process to me joined the community nearly 20 years ago, when he and his wife Julie were converted to the sect. They already had several children, and once they arrived, were hesitant to add a wife to their family. They later added Alice, Sarah and Beatrice. Julie has nine children of her own, Alice has six, pregnant with her seventh, Sarah has one (she would have had more but contracted cancer), and Beatrice has two. Julie told me she and her husband had once been strong members of the Mormon Church and said she was at first skeptical about sharing her high school sweetheart with other women. She says it's just a matter of becoming unselfish--a matter of sharing. 
6) Commit to give all of one's future income to the bishop--the bishop will then return only those expenses--money for clothing, school costs, home improvements, utilities, medical, food, and tithing--needed to survive.

The storehouse, as mentioned in the beginning of this chapter, is an important aspect of the Order. Dave Bond, an assistant to the Bishop, runs a thrift/junk shop outside of Hamilton. He is also the Bishop's agent in the storehouse and organizes the distribution and storage of goods. The storehouse is a building in Pinesdale that houses new and used items that may be of use to someone in the community. Some of these items come from Bond's own shop. These include appliances such as washers and stoves and other items such as foodstuffs, toilet paper rolls, and clothing. The foodstuffs are usually delivered to the Pine Mercantile or held in the storehouse for whoever needs them. The bulk items include flour that is ground from wheat at the mill, honey from the Howards' beehives, and quartered beef taken from the community herd--all of which is stored in the Mercantile or the storehouse. Tithing can be paid or given "in kind," meaning, in items and goods rather than money, such as turkeys, fruit from the orchards, goat milk, and whey. "In kind" donations are given to the Bishop for storage or distribution to those who need it.

For Pinesdale, the best example of the United Order is the Pinesdale Academy, which teaches children ages 2 to $12 .{ }^{10}$ The school runs on a budget of $\$ 48,000$ a year, including all labor, supplies, library, film, and instruction materials, all of which comes from community/family surplus and donations. The neighboring Hamilton school, a secular public school with fewer numbers of children, is budgeted at $\$ 350,000$ per year. Teachers get approximately $\$ 20-\$ 40$ a month in stipend pay, but this amount is used to help prepare lessons or buy extra supplies needed in class. The library, containing a large

10 Though the Saturday work projects performed by the male members of Pinesdale are also included in the activities of the Order, these male tasks are somewhat less thoroughly run and performed with a less continuously steady number of volunteers than is the school. 
assortment of religious and academic materials and films, runs on $\$ 50$ per month. The school board has successfully collected an average of $\$ 20$ per month per child from nearly every household (96\%), and is saving for new supplies and video material for their recently purchased television and VCR equipment. Although the school building and its land are owned by the community, with no recurring debts, the school board reserves an allotted "rent" payment for community emergencies. This rent money is taken from the budget in order to prove that the school is efficiently run. The school's programs include:

Montessori/kindergarten, a nursery, the IOWA Basics program (a standard achievements test which compares the progress of children in Iowa), and Chapter One, a federallyapproved program to help the under achievers. For children with birth defects, there are also special programs at the school. These programs are state subsidized. Birth defects in the community are below $2 \%$. Out of 500 children, only one has Downs Syndrome, and two are retarded. ${ }^{11}$

The women cooperate in order to run the school properly. Like the Relief Society run by its president and counselors, the school is a network of women helping each other to complete its goal, quarter by quarter. Teaching is mostly voluntary (teachers are given a stipend of $\$ 20$ to $\$ 40$ a month for some expenses; labor is free). An excellent example of the female network in the school is found in the nursery program. One nursery instructor has two preschool-aged children. She is currently teaching her sisterwife's child, while her sisterwife tends her younger children. Often the motto in this school network arrangement is, "if you'll babysit my kids, I'll teach yours." Another woman in the nursery takes care of her sisterwife's two children in exchange for bread each week. While one tends, the other bakes. I was told by one informant that the female network at the school is a "family" of women caring and teaching their own children or those of their sisterwives, who are,

11 This is surprising considering the large number of women who bear children after the age of 35 . This fecundity, again, is attributed to the will of the Lord by community members. More significant than the childbearing age, however, is the length of childbearing years--from teens to ages 30-45. 
essentially, their own. In this way the parents know that their kids are in good hands, said one member. The cooperation among women in the school will be described further in Chapter V.

In addition to the school and the storehouse, the United Order is exhibited in church bazaars held in the fall, where goods and foods are made and contributed for sale to the rest of the community. The money goes to the Relief Society or the priesthood for future projects and benefits. There are also fairs, carnivals and dime-a-dip dinners held to pay for medical bills for the ill, or to help a mother whose husband is out of town and does not financially support his wife and children. The Pinesdale children often host a talent show and all pay a quarter which goes to buy clothing for someone. These projects are usually initiated by the female network.

In spite of the obvious advantages of living in Pinesdale--a good school program, effective religious socialization, and political autonomy--informants admit that the town has been unsuccessful at living the full Order. One of the problems encountered by new converts is the failure of the United Order to provide a comfortable living for all members of the ranch, a problem which could be solved with the acquisition of an inhouse industry. ${ }^{12}$ Other problems emerge in the area of "obedience" to the rules of the Order and the willingness on the part of residents to share their time and labor. The residents are encouraged to shop only at the Pine Mercantile, the only community commercial enterprise, to support it financially. They are also encouraged to pay a ten percent tithe, and contribute any surplus to the community funds. These funds pay for school supplies, help families in need, pay for some store expenses, water and construction expenses, and various other items. Yet, there are some families who don't pay a full tithe, or give freely of their accrued surplus. Nor do they unanimously contribute labor for projects or goods that they

12 Presently, residents of Pinesdale are living at poverty level, that is, approximately $\$ 9-\$ 12,000$ per subfamily. 
no longer use. Some agree to pay the tithe, but refuse to contribute free labor on work project days. This inconsistency in giving and committing, said one informant, will cause the economic order to collapse.

Much of the United Order's strength lies in the informal arrangements among sisterwives that help them to better manage their finances. The allocation of family economic resources is based on the number of children per wife per husband. Ideally, each head of family is responsible for assuring that all of his wives are caring and providing for their children. In reality, because of his frequent absence from home, it is up to each individual wife to manage her household and provide for her children what is not already provided them by their father. In order to accomplish this, she relies on the female network that exists among her co-wives, and the larger economic network that exists among all female community members. An analysis of the family economic resources and household management will follow in Chapter IV under Family Economy.

\section{Production and Resources}

Community and family income in Pinesdale is largely derived from the construction and building supplies industry in the Bitterroot Valley, which allows most of the male members to find work in which their fathers trained them. The monetary donations from the community and the wages of wives comprise the next largest financial resource in Pinesdale. For maintaining male employment in the construction industry, the Order has an effective apprenticeship system where young men and boys watch and help their fathers work with wood, machinery, and building materials. The rest of the income resources of the community are spread over a large body of employees--both male and female--who work mainly in blue-collar and non-professional jobs. A list of these jobs is located later in this chapter, in Figure 4. To supplement incomes, several families own agricultural projects and items such as poultry sheds, raspberry bushes, potato cellars, and greenhouse produce. Additional resources include more than 20 homes and buildings, several large 
pieces of machinery, and a variety of donated goods that are "consecrated," or donated, by members entering the community.

The Pinesdale Ranch was purchased by Rulon Allred not only as a haven for the Saints from the law (or as a hideout to practice polygyny), but as a place where they could cut down trees and build their own homes, and use the natural resources without charge. They soon found the soil difficult to till, and the prospects of growing a cash crop were dim. They built up a dairy and chicken industry which provided economic stability for a while, but after a few years, both projects were discontinued because of labor costs. ${ }^{13}$ As already noted, a significant amount of the community's resources are maintained by the financial tithes and surplus contributions of the Pinesdale membership. These tithes are sent directly to the center of the AUB, Salt Lake City, then redistributed to a larger number of members. Because of this, individual family surplus donations much more significantly aid the community's financial status than tithing. These family surplus donations comprise the amount above tithing and living expenses of the family. This money goes directly to the community. Only the roads in Pinesdale are funded by the state. Everything else comes from community donations. ${ }^{14}$

Community labor is another large resource. Work parties of male members of the community gather every Saturday to construct houses and buildings, work on the water line or power plant, harvest alfalfa, pick berries, or whatever is needed that week. Often, men and boys will gather at any time on any day to complete emergency projects. The

13 Originally, all community labor was donated freely. Because of the inflation of feed costs and longer hours of labor required to deliver and distribute feed, more labor was needed to offset the expenses of working both the dairy and the poultry operations. Fewer residents offered free labor, and so the two industries folded. A few years ago, residents were encouraged to place a bucket or two of food scraps outside their doors on a certain day to be picked up and fed to the chickens, but fewer and fewer people were willing to do this, and the operation shut down.

14 Howard is also the town's mayor and said that Pinesdale is the last incorporated city in Montana. They have had to "jump through a lot of hoops," he said, to obtain this privilege: maintain a certain number of registered voters per ward, keep records of all financial transactions and assure that all members are law abiding citizens, that is above the misdemeanor of polygyny. 
women meet every Thursday for work projects which include quiltmaking, sewing bedding and clothing, canning fruit, and repairing and constructing general domestic items, such as rugs, storage units, and planters. Most items made by the Relief Society will either be distributed through the Bishop's storehouse or held at the Pine Mercantile for sale. Labor projects in water supply, fire department, and building maintenance are all voluntary. A sign-up sheet in the church is used to keep extra funds and labor flowing from members back into the community. In terms of more hours spent on community projects, women, who are more likely to stay in the Pinesdale during the day, are able to complete more community work a week. Men work hard one or two days, usually a Saturday or a weekday that they have taken off, to complete all their community projects.

All or part of one's personal assets must be donated to the AUB, promulgating a financial interest in a permanent residence and lessening the chance of one's returning to a former vocation. For example, the mayor of Pinesdale, Louis Howard, had a thriving fencing company and several thousand dollars invested in gold. Before his arrival in Pinesdale, he sold his fencing company. He gave all of his money, including the gold investment, to the former prophet, Rulon Allred, keeping only enough to sustain himself and his wife and four children. During the past 20 years in Pinesdale, he has rebuilt his fencing company and employs a handful of Pinesdale residents, contributing his surpluses to the community.

All the land in Pinesdale is held by a communal trust administered by Owen Allred. People wishing to live in Pinesdale must petition Allred and the General Council of the Priesthood for permission to settle there and either build their own house or inhabit an already standing one. All buildings and improvements have to be left behind if the member leaves the group. That is the condition of entering the communal order. As with the Mormon Church, and most religious sects in the United States, wealthier members, such as Louis Howard, obtain higher ranking or status according to the amount of money they earn 
and contribute. He is respected because of the wealth that he can share with the community.

There is no health insurance in the community, so home remedies using herbal medicine are common. The women gather these herbs at the ranch, or order them from a naturopathic supply company in Idaho, from which they concoct teas, salves, and poultices for most medical problems. ${ }^{15}$ There is access to hospitalization and medical services; however, because of the costs involved, these facilities and services are considered a last resort. In this respect, the home remedies prove valuable. They also help cut the cost of medical bills. Many members see a Dr. J. B. Swafford, a chiropractor, from Hamilton, for illnesses. The local cures are passed down from mother to daughter, from sisterwife to sisterwife, and involve an extensive network of information and experimentation. ${ }^{16}$ Between these home remedies and the healing powers implied in the priesthood, there are few occasions to call the doctor.

\section{Human Resources: Labor}

For the most part, Pinesdale's sexual division of labor follows that of mainstream American society. The difference is that in Pinesdale there are far more women than men. By nature of their large numbers, more women are employed in the workforce than men--a ratio of 2 to $1 .{ }^{17}$ It is much more difficult to pinpoint just how many women work inside

15 One member told me Pinesdale women used to have herb-scouting parties to gather yarrow, spearmint and other herbs. They then dry them for all wives' families.

16 Some local cures include yarrow tea for colds, plaintain as a salve for diaper rash, Shepherd's purse to make the blood clot in delivery, and com silk, parsley and juniper for kidney problems. Tansey is used for menstrual cramps and as an insect repellent. Mullein is used for earache, and diaper rash and general ailments. Comfrey is taken for diarrhea, dysentery, and general irregularity. Women use both infusions and decoctions (where the root is mashed and strained). Burdock root tea and sassafras is used for acne, slippery elm for vomiting. One folk remedy used was a soothing potato and banana poultice for second degree burns. One would cool the skin with cold wet towels, then apply potatoes, thinly sliced, and then frozen bananas.

17 Since 75\% of the female members of Pinesdale are involved in some non-domestic form of employment in and outside of the home, that totals 112.5 out of 150 women who are involved in some sort of working task in addition to their motherhood calling. All 50 men are employed in addition to their religious callings. The ratio of working women to working men then totals approximately 113 to 50 , or 
Pinesdale as outside. In a sample of 20 working women, I found that $45 \%$ were involved in a full-time position such as nurse, secretary, school teacher, clerk, accountant, etc. Yet among this $45 \%$, only $30 \%$ earned full, competitive salaries outside Pinesdale. The others, many of them working at the school, store, or post office, were full employees of the communal system, receiving less than $\$ 40$ a month. The other $30 \%$ of part-time workers (which makes up the $75 \%$ female workforce, indicated above), are involved in both community and marketplace jobs, approximately, 10\%-community, and 20\%-marketplace. This makes it difficult to trace the exact contribution of female labor to family income because of the overlap in full-time, part-time, inside and outside employment. Calculating the exact value of community labor to the community, as well as household labor to the family has always been a difficult task. There is no question of the actual value that the ranch places on these women and their duties, but then again, there is no real way to compare them to a competitive, full-time salaried worker, either. It is clear that fewer Pinesdale women work full-time than work part-time and community-type jobs, enabling more women to share the tasks of managing their households with other women, than men are able to share their occupational tasks with other men.

As stated, most men are skilled in construction, metal and wood working, and other blue collar trades. These men work long hours, almost entirely outside of the community, and in some cases, move out of state for the winter to secure work. Male high school students are part-time members of the local work pool and may be assigned specific tasks such as cutting wood, cleaning tools, or repairing machinery. They gather at the church two Saturdays a month for communal projects which include labor on the water boxes, new buildings and houses, and machinery. The husband's primary role is the one of provider, yet the role is extended to the task of being the spiritual and theological receptor

2.25 to 1 . What all this means is that women far outnumber men in the workforce in the community and in the marketplace. They are significantly adding to the family income because of this work, strengthening their female solidarity and interdependence in the process. 
from God to his family through the priesthood. Along with their employment, the men must contribute free labor to the community projects requiring skills in building, farming, buying, selling, and record keeping. They must also contribute time and energy to political and religious meetings, such as the Council of the Order, the Sunday early morning priesthood meetings, and the blessings and ordinances of anyone in need throughout the week. ${ }^{18}$ The fact remains, however, that most of their waking hours--8-10 hours a day-are spent at their place of employment, away from the community, their wives, and families.

Pinesdale male and female earning power can be seen to be quite different, but complementary. Many women (100\% of the total number of Pinesdale women) work in some context or other, whether it be at an outside, high-paying salaried job, at a community low-paying school position, or at home tending children and managing the household. Women are obviously not in the same class as males in terms of occupations which earn regular salaries, but because there are so many women in the community, the hours they do earn are significant in illustrating their economic interdependence and contribution to family income and community stability. On average, Pinesdale women work 25 to 30 hours per week on either community type or marketplace work. On average, a Pinesdale man works 40 to 55 hours per week at his job and 5 to 15 hours per week on community and church related jobs. These figures show two things: 1) women have more leisure, and 2) because of their large numbers, women also spend more time, collectively, in community, home and job labors, than men do. ${ }^{19}$

18 Ordinances in the Pinesdale ideological structure are blessings and special rituals conducted only by high ranking priesthood bearers. They are usually official rituals such as baptism, marriage, and succession of children into young adulthood, and young adults into adulthood. These ordinances will be discussed later in this chapter and in Chapter 4.

19 From the hours given above, it can be figure that women, working 25 to 30 hours per week, multiplied by the $75 \%$ female workforce number of 113 , contribute from 2,825 to 3,390 work-per-week hours, while men, numbering 50 , working 40 to 55 hours per week, contribute only 2,000 to 2,750 workper-week hours. 
A list of the ten most common male and female jobs, taken from a sample of 120 individuals, in and outside the community is shown in Figure 4. An inside job is usually in the form of a low or unpaid stewardship. The outside job is a salaried, hourly-waged, or bid-project job, either part-time or fulltime. Sometimes the employment and stewardship overlap, as with retired persons whose employment is their stewardship--but most of the time, these categories are discrete. In evaluating male and female forms of employment it becomes obvious that women dominate the workforce in their numbers, if not in their total range of skills and salaries.

In general, women are responsible for all aspects of domestic economy, including housework, cooking, washing, tending the garden, etc. Women also are responsible for learning any skill that may enhance the life of their children, as well as themselves, such as education, art, music, literature, drama, nursing, midwifry, teaching, etc. In this way, Pinesdale women resemble the early Saints, i.e., polygynous women who did a little bit of everything. In the words of Brigham Young, an early Mormon polygynous prophet, women were:

useful not only to sweep houses, wash dishes, make beds, and raise babies, but that they should stand behind the counter, study law or physic, or become good bookkeepers and be able to do the business in any counting house, and all this to enlarge their sphere of usefulness for the benefit of society at large. In following these things they but answer the design of their creation (Widstoe 1939:335).

Women must also often perform home and yard maintenance jobs that are normally performed by strong men. One women said that because her husband was gone so often she had to put on her own front door, fix the sink, and repair certain mechanical devices of the home and the car, all by herself. She said this was common among Pinesdale women.

So far, this chapter has provided a basis for analyzing the occurrence of female groups in terms of socio-political and economic structures of Pinesdale. The contribution of these features to the formation of female groups will be developed further, in Chapter VI. In analyzing the socio-political and economic structures of Pinesdale, I can see several 


\section{MALES}

\section{OUTSIDE EMPLOYMENT}

1. House construction

2. Wood working

3. Metal working

4. Fence and pipe working

5. Parts sales and maintenance

6. Mechanical repair

7. General sales

8. Truck driver and distribution

9. Appliance installation and servicing

10. Agricultural--farming or ranching
INSIDE STEWARDSHIP

1. Council member

2. Father

3. Spiritual counselor

4. School Board

5. Police Department

6. Town Council

7. Janitorial

8. Water maintenance

9. Fire department

10. Priesthood calling

\section{FEMALES}

\section{OUTSIDE EMPLOYMENT}

1. Teacher

2. Nurse

3. Clerk

4. Secretary

5. Bookkeeping

6. Food sales

7. Clothing sales

8. Computer operations

9. Government worker

10. Social services
INSIDE STEWARDSHIP

1. Mother

2. Community school teacher

3. Home maintenance

4. Religious instructor/advisor

5. Food and goods distributor

6. Record keeping and budgeting

7. Nursing community ailments

8. Food preservation

9. General childcare

10. Religious administrator

Figure 4. The ten most common male and female jobs. (Categorized by employment and stewardship.) 
contributing factors appearing. The male-dominated religious and governmental bureaucracy provides an opposing male authority structure from which women separate themselves, initiating their group building. In order for women to join ranks in any society, they must find commonalities, whether these commonalities are born through oppression or subjugation, or whether they are born of liberation and exultation. Commonalities may also be, simply, common interests in similar tasks and experiences. It is my observation that Pinesdale women unite because they do not hold political or religious power in the community. Thus, women who are dominated by their husbands, build bonds with other women who are likewise officially dominated. The evidence to support this premise lies in the behavior of women when with their husbands and other members of the male hierarchy, and in their behavior when with other women. In the first case, women are much more restrained to perform in certain ways, giving recognition to the male authority structure. In the second case, when alone with other women, a woman displays more physical and emotional freedom, without the constraint of authority or formality. In addition, the United Order, though a part of the male authority structure, mainly benefits women who more easily share material goods and services on a day-to-day basis and who more regularly care for their families, rather than on weekend projects such as the men experience. ${ }^{20}$ It is known throughout the community that women more practically adhere to the rules of the Order than the men, and achieve an economic interdependence because of it. Examples of this occurrence are described in detail in Chapter V. Because the school is run on an almost all-female cooperative network, and because women more readily form sharing networks among other women, than men do among other men, it is recognized that women are more successful at living the Order. Pinesdale women also gain in economic strength through their expert management of

20 Though most women work, a large number of them still work within the community in the form of low-paying stewardships, such as teaching, storekeeping, food and household goods distributing, etc. In this way, their work patterns and visiting patterns overlap. With men, they do not. 
household resources. Because they share tactics and "rules of thumb" for running a tight ship, each woman is able to feed and clothe her family successfully with the limited money available on to her monthly budget. Women also gain economic interdependence by working in the marketplace, contributing modest salaries to the extended family income. Because women are the largest number of workforce laborers, their economic contribution to the family is a significant factor in female status.

The next section will describe the community life patterns of Pinesdale, illustrating how life evolves from day to day, week to week, and how each member of society is affected by these activities and events.

\section{COMMUNITY LIFE PATTERNS}

The last section examined how Pinesdale's socio-political and economic structures provided a basis for female association. This section will investigate how polygyny and women's spatial and temporal living patterns affect the formation of female groups.

\section{Polygyny}

Polygyny functions in Pinesdale to increase membership in each family's "kingdom," as will be discussed in Chapter 4 , and is a vital aspect of community life, as it represents one of the capstone religious beliefs of the sect. Yet, polygyny also functions to bring women together in a working, visiting, worshipping, and gossiping network. Polygyny is widely practiced in the community--nearly every adult man and woman above the age of 18 belongs to a plural marriage. Polyandry, the marriage union of one woman and two or more husbands, is strictly forbidden. In studying Pinesdale polygyny, and when interviewing those who practice it, one is aware of both the advantages and the inconveniences associated with this outlawed form of marriage. The inconveniences are many. Men and women are committing third degree felonies by practicing polygyny, and must always expect public ridicule and, possibly, official persecution. Many men and 
women live dual lives--in the larger society where they deny any involvement in polygynous unions, and in Pinesdale, where they preach polygyny as the only true form of marriage, worshipping their God in their own particular way. Marriage unions of a man with additional spouses are held in secret rooms, away from public scrutiny, and women rarely take more than two or three children with them at a time when shopping in Hamilton, so as not to attract attention. Other inconveniences include the lack of privacy and solitude for men. Men often work long hours at a job and come home to additional duties as parttime father, and mediator, and as a priesthood bearer, with ecclesiastical duties in the community. These duties leave them with very little time for themselves. According to one informant, men experience more ailments and stress related disorders than do women in Pinesdale. For women, the disadvantages are obvious. They must share their husband sexually, economically, and emotionally with several other women, splitting his time and money between several different sets of children.

There are, however, many advantages to a polygynous lifestyle--advantages which help to explain why polygyny is conducive to the formation of female associations in Pinesdale. These same advantages would not necessarily apply to Chinese, South American, or African polygyny. Polygynous women, by sheer force of their numbers, often register informal complaints against husbands and leaders, which place the minority males at a disadvantage. Polygyny brings from two to eight women into a marriage union, strengthening the collective position of the female in the family, as well as in the community. ${ }^{21}$ For example, with several women in one family, emergencies of various types are more quickly attended to, as it is more likely that an adult will be there to handle the situation. If any problems arise in the family, such as economic loss, illness, or dissatisfaction, means to solve these problems are available through several sources. Thus, one woman who needs more money will tend another wife's children so that she, in turn,

21 The most wives per husband in Pinesdale is eight, the least, is two. 
can work. Another woman, who is ill, may have to quit her job and have another wife take care of her children temporarily.

In Pinesdale, as elsewhere, polygyny also lessens the possibility that women will experience a sense of closeness with men because is reduces the time actually spent with them (Leis 1974: 233); Pinesdale women are more often seen with other women than with men. What this ultimately means is that men have less information about things that matter most to the community residents, such as daily living activities, birthdays, programs, emergencies, courtships, and various other concerns. In addition, polygynous married men must constantly be involved with wives; a polygynous woman has some respite from her husband, and therefore more freedom to interact with other (female) community members (Leis 1974).

\section{Spatial Patterns}

The relationship between behavior and the physical environment is important in a study of female groups. The following analysis, as expressed informally by Pinesdale informants, illustrates this relationship. In Pinesdale, where hundreds of tall, Ponderosa pines surround the living space of its members, high on the bench of several strong, tall mountains, spatial patterns reflect psychological patterns. Pinesdale is a haven against religious persecution, and a frontierland for the development of natural resources. The strength of the mountains is symbolic of the strength of the member's religious convictions, based on the "only true priesthood on the earth." The shelter of the trees is to cloak Pinesdale residents in the Spirit of Christ, where no evil thing can penetrate. The distance from town is to provide a gulf between themselves and the wickedness of the world. All of these physical elements of separation and isolation are also conducive to the formation of female groups. Since women are more narrowly confined within one neighborhood, they are allowed more occasions of visiting, cooperating, gossiping, and uniting--in daily activity and religious belief. 
Further analysis of spatial relationships showed that there is the creation of an alternative reality among Pinesdale residents, resulting when one is physically separated from friends, society, and the worldly frame of reference in which one functioned before entering the community. There is partial isolation from the rest of the world--physical, mental, and spiritual isolation. Men and women entering from the world usually sever all connections they had before they became members. Some correspondence with family members and friends outside the colony occurs, but many relatives and associates disown Pinesdale residents for a time. ${ }^{22}$ The longer the isolation from former acquaintances and from the outside world continues, the more sense of one's own reality within the community develops. This isolation makes the world outside seem fantastical, and even an awful, sinful place to community members. My observation is that this perception of isolation is effective in providing women with psychological security and protection from the "evils of the world."

Home Environment and Social Identity. The home is a symbolic representation of the social relationships manifested in spatial, psychological and interpersonal elements (Werner, Altman, and Oxley 1985). For Pinesdale women this representation has special significance, as they are the residential cores of their households. The home represents the strong foundation a woman has in the community as primary caretaker for her children's welfare, and as the major decision maker in the domestic sphere. Though she may share a home with another wife, it represents her stability, identity, and status at the ranch--it is her home, after all, not his, though the husband may have helped finance and built it. For the man, who visits various homes during the week, hanging his coat in a different closet every night, the home is less stable, and more of a temporary shelter and place to eat, sleep

22 One woman told me that when she and her husband joined the community, her parents refused to call or visit her for five years. The parents had heard untrue rumors about sexual orgies taking place in Brother Havener's cabinet shop and that those who visited the polygynists sometimes never returned. After five years' time, however, the parents visited their daughter and her seven children, and were delighted to find the rumors to be false. They now make a visit once a year. 
and visit his family. Women have invested more time, energy, money, and emotional attachment in the home. In short, the home is the "matrifocal" compound where a woman dominates the lives of her children and manages her affairs with the aid of her co-habiting wife(s), or oldest daughter. ${ }^{23}$

In Pinesdale, housing arrangements are formed three basic ways: 1) all plural wives live in the same house, sharing the same personal "dwelling" space of the kitchen and living room, but having separate bedrooms, 2) two or more wives live in the same house and have separate apartments, or 3) each wife lives in a separate home. Generally, the housing arrangement depends on the monetary resources available and the value a man places on a particular wife and her stage of life. For example, the senior wife lives in the largest home, and the second, third and fourth wives live in smaller homes or compartments, depending on family income. Though a large percentage of wives live two to a home, more women are finding ways to establish their own private spaces even if the living conditions are poorer than while living with their sisterwives--such as a trailer home, or one-room cottage. ${ }^{24}$ Women's shared economic need, rather than their friendship or "like" of each other, takes precedence in determining where Pinesdale women will eventually live, determining the proximity of their houses, the evidence of which will be presented in Chapter V.

The Pinesdale home itself has no solid architectural prototype, but does have a few characteristics which identify it as a polygynous home. It is usually quite large, either a

23 Residence here is defined as "matrifocal" (Smith 1956), as households are organized around women. My use of the term is associated with Nancy Tanner's work in West Africa (1974), where the focal point of familial and communal activities surrounded the mother and her home, and where the mother's power and authority grew stronger and her sphere of influence expanded as the male's economic contribution decreased, just as in Pinesdale.

24 In light of co-wife avoidance studies in Kenya, among the Gusii, the Kipsigi, and the Luo (LeVine 1962), the greater the forced contact or physical proximity between in-laws or those in similar relationships, the greater their hostility or avoidance, and the more prevalent the use of mechanisms to create a psychological separation between them. 
spacious duplex, where one or two wives can live side by side with a connecting door, or it is a contemporary, block home with a mother-in-law apartment, attic area, and/or basement space, so that one house can provide for two to four different sub-families. Ideally, when economic worries are over for the "saints," each wife will have her own house, where boundaries of nonshared items--the bedroom, the wedding trousseau, special photos and memoirs--are not invaded by other wives, or their children. Privacy boundaries, such as bedrooms, dressers, closets, and bathrooms, are built up among wives to protect their own unique relationship with their husband. At times, depending on need, these boundaries may be crossed. Because it is common to have two wives living under one roof, women find ways to deal with boundaries, and the proper times to break them down. If the house is small, such as the old school shack that Sheila inhabits, or the unfinished barn-shape shelter that Margaret inhabits, then there is barely enough space to house one wife, her visiting husband, and the six to eight children that live with her. ${ }^{25}$

Generally, most wives do not share the same living quarters or "dwellings," though they live in the same household or household cluster. For example, the second wife may live for a while in a room in the senior wife's house and then move into a built-on apartment or duplex in that house. ${ }^{26}$ The three families I visited each had two wives living under one roof, separated by floors or walls. The "dwelling" a wife inhabits is located in a compartment within the house, such as a duplex, an apartment, or a studio with its own bathroom, kitchenette and bedroom. A child or two may share the bedroom with their mother when their father is away, moving to the couch or another bed when he is home.

25 On average, with 500 children at the ranch, 50 men and 150 women, mathematically, there are approximately 7 children born per wife.

26 Most often, right after marriage, the majority of wives live in the same house until a second dwelling or apartment can be found or built. The community may help provide a home or apartment for a wife that has none, such as the case with Sheila, who was forced to leave her husband and co-wives in Salt Lake because of a lack of space. The community helped her relocate in a tiny, one-room school shack, not far from the school. 
Again, as with other cultures, a husband is expected to divide his time equally between families and establish some pattern of visiting each home. ${ }^{27} \mathrm{~A}$ husband must adhere to the visiting schedule if he wants to keep his wives happy. Most of the time, missing a night or two will not make a difference to a wife, but if she feels her husband forgot her, or preferred another over her, then she will demand a visit. There is a sense of expectation when the father comes home and when he chooses to be with one wife over another, and sometimes a sense of relief when he is gone (Embry 1987). ${ }^{28}$

Religious and Social Events. Pinesdale husbands have to determine diplomatically which wife to take to church and to social events. Most attend with all of their wives and children, attempting to sit with all surrounding them on the same and adjacent benches. At times, one wife, who may be hosting the husband that day, will stay home to prepare the meal. The husband will then attend church with his other wife or wives. Sometimes one can see all the older children sitting with friends and one man sitting with two wives on each side and a few small children on laps. In church and other social events, wives pose as a check on the husband's scheduling and usually are successful at reminding him of whose turn it is to go to the dance or the movies or out to dinner. Often, if it is a big community social, all the wives will attend with the husband, and all will take turns dancing and socializing.

In examining church attendance, I found that involvement in religious matters and the adaptation of worship in the homes is a good determinant for devout membership in the Order. One must prove one's commitment to the community by attending regularly church meetings and social events. Religious activities in the home, such as family and individual

27 In African families, each wife has her own hut and cooks independently, while the husband in regular succession will live and eat with each of his wives. The husband divides his sleeping time equally among his wives too (Boserup 1970).

28 As will be discussed later, all members are involved in the preparation for the father's homecoming. There is much work to be done in this preparation. Many activities are forced into a small amount of time, and, like a vacation, one is anxious to return to the routine schedule. 
prayer and family programs, are spatially important. In other words, how one positions oneself in relation to others and to the home environment is symbolic of devotion and respect during the ritual. For example, how one kneels, moves one's head, or holds one's hands is representative of his or her sentiments toward the ritual. Family devotional services are conducted by the mother or the father, where the children gather around the adult and join in prayer, song and scripture reading. ${ }^{29}$ All family members kneel facing the Salt Lake temple at prayer. When praying for an individual event or person, the family members kneel or stand in a circle with either hands clasped or hands raised to the square. One's physical position during this prayer is symbolic of unity and the faith of the members of the circle. These prayers are considered the most effective means of healing and comforting. Family prayer continues in the same physical manner whether the father is present or not. It is symbolic of all rituals and events that take place in the household during his absence, in that all are enforced by the mother.

\section{Temporal Patterns}

Pinesdale theology teaches that there is a right order for everything and time for every act. Consequently, time functions to organize Pinesdale activities and social relationships. Time is a significant factor in how men and women group themselves, especially when women's routines overlap and enable them to meet, work, worship, and gossip. The daily schedule involving all the members of the community is patterned by prayer, work, lunch, work, dinner, family program, prayer, and sleep. It is a rigid schedule and varies only in the sharing of tasks among sisterwives. For example, if one sisterwife is needed at the school for a day, called to attend a meeting, or is ill in the hospital, her sisterwife will see that her children follow through with the day's rituals. The weekly schedule involves childhood and youth, priesthood and Relief Society (women's

29 If the father is not present, the mother will conduct these sessions. When he is present, he will always be the one to conduct, as he is the priesthood head. 
group) meetings and builds up to a climax on Sunday, for early morning priesthood meeting, Sunday school, and Sacrament Meeting.

Pinesdale residents combine the sacred and the secular in their world, as represented by their handling of the police department, town council, and school board. There are, however, special occasions when a distinct separation of this world and the higher realm, or spiritual existence, is recognized in the temporal patterning of the community. Prayer is one of those times. When someone is praying, all become silent and respectful of that prayer. Prayer is a sacred ritual to communicate with the Father through the Son, and is performed at least seven times on weekdays, and 11 times on Sunday. Weekday prayers include: early moming community prayer, breakfast-family prayer, school classroom prayer, lunch prayer, dinner prayer, family, and individual evening prayer. This number increases if there is an auxiliary meeting during the week, such as the Young Women's, Relief Society, or Primary. It is also common for a man and a wife to kneel in "partner" prayers before saying their individual prayers. Sunday prayers include: breakfast-family prayer, opening and closing Sunday school prayer, lunch prayer, opening and closing meeting of the Sacrament Prayer, the two sacrament blessings, dinner, and family prayer. Other sacred times are during rituals and ceremonies of community significance, such as the passing of the Sacrament (when all are supposed to think of Christ), baptism, marriage, and death. Priesthood blessings and ordinances are considered sacred. Any sudden inspiration or revelation that the Spirit may bring to a person at any time during the day or night is also considered sacred. (This same sort of Sabbath day regimen is not entirely foreign to orthodox, active Mormons.)

Daily Schedule. Pinesdale daily patterns flow in a constant rhythm from morning to night that can be best described in the following scenario of my first day in the community: 
The December morning sunlight poured in the east windows of the schoolhouse, sending long shafts of yellow into the basement room. It is 7 a.m. and the community prayer has begun.

"Our Father in Heaven..."

The words are repeated by all. "Our Father in Heaven..."

"We are gathered here as thy children to kneel before you in gratitude for the restoration of thy church. And to thank you for all you have given us. We ask, dear Father, a blessing on our efforts, on our homes, and on our children--that they may remain strong in thy gospel..."

The light from the sun creeps slowly across the room, and the figures of men dressed in work clothes, women in housecoats, and children in school clothes and pajamas--all kneeling with bowed heads--come into view. The figures--mostly men, widows or women with grown children, and children, are kneeling with their bodies facing the south, toward the Salt Lake City temple, several hundred miles away.

"And Father, bless us with thy Spirit, that we may keep strong. (Cough). Bless Brother Owen and the Priesthood Council. Bless the Bishop and his councilors. Bless Sister Rachel that she may get over her ulcers. And Father, bless all those in need of thy care. Help us to better serve thee, we pray, in the name of Jesus Christ, Amen."

The elderly lady who said the prayer clears her throat and all rise. The figures become alive with movement, light, and chatter, all moving toward the front door, and back to their homes. Some go by foot in the wind-blurry snow, and some by trucks and cars, already warmed by the initial early-morning start. The sun is touching on the Ponderosas on the west hillside now, spreading upward onto the benches of the Bitterroot Mountains, shedding light on the whole valley below. A few dogs bark, and children's laughter comes from he direction of the Mercantile, where a snowball fight is taking place. All over town, mothers are building fires in their wood stoves, and breakfasts of grits, or creamed wheat, and eggs are about to be served. The smoke from the fires swirls upward from the houses, disappearing into the morning sky. I hear the grate of a snow shovel on sidewalk in front of the schoolhouse. The sunlight hits the top of Look Out Point. The Pinesdale day has begun.

Daily community life in Pinesdale is influenced by the momentum of work, worship and ritual. Each daily act--including the community morning prayer--is a symbol of the enduring belief in the afterlife, and a belief in God. Community life is influenced by a number of ideological and sociological factors associated with the Old Testament. There is an attempt among believers to base their lives upon scripture, duplicating the biblical life of Abraham, Sarah, and her sisterwives, Hagar and Keturah. ${ }^{30}$ The Abraham-Sarah

30 As will be explained later in Chapter 4, Abraham was an Old Testament prophet who was promised by God that his seed would flourish and reach phenomenal proportions. He was told that this seed was the foundation of his kingdom in heaven. Abraham's wife, Sarah, though barren, was able to give Abraham this seed, through the conception of her sisterwife, Hagar (Genesis). 
union, as described in Chapter II, is the prototype for familial and communal relationships within the boundaries of the Pinesdale ranch. People join the sect to better fulfill the law of Abraham in an environment conducive to raising children and worshiping in isolation from the world. Yet, once one arrives, having convinced the sect's leaders of one's commitment, Pinesdale seems somewhat more like any rural Mormon town in Utah or Idaho, than the biblical City of Enoch about to be taken up to heaven.

Within the temporal setting of the community, individuals are ranked by age and sex: 1) nursery children, 2) kindergarten children, 3) grade school children, 4) youth, 5) adult, and 6) elderly. Each age set has its own daily schedule. Most mothers are up an hour before both their children and their visiting husbands in order to start the wood stove, begin preparations for breakfast, sew on buttons of workshirts, straighten the house, and do the laundry. When the children and husband get up, they all go to community prayer at 7 a.m., and return for breakfast. The husband works long hours from 7:30 a.m. to 6 p.m. at his respective job, and mothers, depending on whether they work outside Pinesdale, are busy chauffeuring children to Montessori or grade school, going on errands to the store, or on their way to work, from 7:30 a.m. to 9 a.m. From 9 a.m to noon, women's tasks vary from food preparation and preservation, to shopping, cleaning, and visiting other women. Those who work outside the home have differing schedules, mostly remaining at the work site until 5 p.m. A full day's schedule of an average Pinesdale woman is given in Chapter V.

At noon, all the children meet in the school's upstairs cafeteria, pray, and eat their homemade lunches, usually sandwiches on wheat bread and a piece of fruit. At home or at work, men and women take time to eat something, always giving a prayer of thanks before beginning their meal. Beginning at 3 p.m., children are let out of school and go to their homes, or to play at a friend's house, or go skating on Sam's pond. Some children have piano lessons at Sister Kay's house; while others do extra school or church projects, such 
as practicing for the Christmas Pageant, and come home just in time to do their chores before supper. On Tuesdays after school children from 3 to 13 go to their children's meeting, Primary, in the chapel side of the school/church structure, where they sing songs and hear stories about the early pioneer polygynists. They may also do crafts and carry out any project the priesthood asks of them, such as building the playground, or painting a fence. At 6 p.m., the family kneels in prayer and gives thanks for the dinner they are about to eat. After dinner, from 7 p.m. to 9 p.m., children and mothers relax and enjoy each other's company by reading stories, watching an old movie, or singing around the piano. The family sermon is held around 9 p.m., a prayer is given, and all children go to bed. After all the children are asleep, the mother may finish her chores, or more likely, talk on the phone or visit a friend for an hour or two before sleeping.

When father comes to visit, the daily family schedule is altered to allow more attention to be given to his needs and wants. A nice meal is prepared with all the children helping to make the dinner go well. Rarely are leftovers served when "Daddy" comes home. All are on their best behavior. A discussion of doctrine usually follows the meal, after which there is a catch-up interrogation of the children regarding the activities in which each child is involved.

Weekly Schedule and Sunday Complex. During the week, several auxiliary meetings are held for all age sets to teach them doctrine and to keep leaders and parents abreast of each individual's "progression in the gospel." These meetings usually combine both the spiritual and the utilitarian. There is always a prayer, usually a scripture, and some form of gospel-oriented sermon. Then there is a project to do, or secular activity to conduct. The first meeting of the week is the seven-man town board meeting at 7:30 p.m, Monday, in the schoolhouse cafeteria. The following Saturday, the general board of all priesthood members will meet at this same time and location, to discuss the decisions and suggestions made at the seven-man board meeting. The young men of the community meet 
on Monday nights as well, attending Boy Scouts or Priesthood Meeting at 7 - 8:30 p.m., whichever applies to their age set. These meetings are usually more doctrinal than those for girls--that is, more time is spent on discussions of priesthood honors and duties--usually ending in some kind of project, such as building a fence in the summer time, or carrying boxes from the store room in the winter.

On Tuesdays, at 4 p.m., the Primary children meet in the chapel and then in the individual work rooms of the school/church. ${ }^{31}$ The Young Women meet separately in the chapel on Tuesday nights at 7:30. This meeting for girls, ages 12 to 18 , begins with a scripture reading and a formal ceremony of prayer and song, after which all leave for classes where crafts, sewing, embroidery, cooking, and other homemaking arts are taught.

Wednesdays are busy days for children. There are afterschool practices for Christmas pageants, musicals and dances for which to decorate and prepare, piano lessons to practice, and miscellaneous projects to be completed, all usually ending by suppertime. After supper, starting at 7 p.m., Family Home Evening is held, where all co-wives and their children meet at one wife's home on a rotation basis to sing songs and read scriptures. The father is in charge of the meeting, and all surround him in chairs or on the floor, attentive to his counsel. He may decide to read from Section 132 of the $\underline{D \& C}$, or tell a story about his great-grandpa and the time he fought with Butch Cassidy, after which he will go around the room to each child, time permitting, and ask for a talent or a scripture, or some kind of statement. It is the only time during the week he has to really get to know his children, and so on these nights, children don't go to bed until late. After the talents are given, refreshments, a combination of "goodies" from all wives--usually punch and cookies or brownies, are served.

31 The Primary program was organized in the early days of the Mormon Church to give young children religious instruction during the week. Primary children usually sing as a group in Sunday meetings, and put on plays and pageants during the year. 
On Thursdays the women's organization, the Relief Society, meets at 7:30 p.m., where homemaking projects of all sorts are completed. For holidays such as Christmas, crafts and decorations are made. When someone is sick or in need, an entire week's meals will be prepared and frozen for later use. Often, after the initial song and prayer, women will bring out their knitting or sewing while one woman preaches or reads a story about pioneer women. This is quite enjoyable, and serves to unite the women in purpose and in talents. Refreshments of a sugary nature are always served after the lesson or project, during which time several minutes of candid gossip and conversation take place among the women, further uniting them in friendship and conscience. Fridays are "free" days for the community. On Saturdays, the men meet together in front of the church to conduct a general board meeting and work on any project that is in need of completion: house construction, pipe leakage, etc. At 1:30 p.m. the Relief Society "Treasure Chest" is opened, which is a room full of household goods, baby items, clothing, toys, and tools for sale at a very low price. This money then goes for the materials for a future Relief Society project.

Sunday, "the day of rest," is, ironically, one of the busiest days for both men and women. At 6:30 a.m., the men and boys 12 years and up rise for early morning priesthood meeting at the school at 7:15 a.m. Usually, at 9:30 a.m. the entire community attends Sunday school, with an afternoon meeting of the Sacrament and a one and one-half hour sermon at 2:30 p.m. Pinesdale sermons are given by lay persons called to give a "talk" or persons from the audience called to give a spontaneous message. Some Sundays, the prophet, Owen Allred, visits from Salt Lake, and so a two-hour sermon is usually held at 9:30 a.m. with no Sunday school. A choir practice is held at 4:30 p.m., and some times the Boy Scouts are called to meet after the meeting, depending on the week, usually in the late afternoon. In the evening a youth fireside starts at 7:30, where a special guest will 
confront an issue related to adolescence, such as drug abuse, or premarital sex.

Refreshments are served afterward.

Sunday school is a meeting of instruction where the entire congregation meets in the chapel for a few songs and scriptures, and then separates into age set group classes, with the adult class remaining in the chapel. Above the pulpit, hanging on the wall, is the theme of the community, the title of liberty of the stripling warriors of the Book of Mormon, found in Alma 46:12: "In memory of our God, our religion, and freedom, and our peace, our wives, and our children." 32 This motto is present at all meetings and represents the belief of the community to outsiders, such as reporters or relatives. A prominent woman of the community, Patty Hatch, also a member of the school board and president of Young Women's, teaches the adult sermon in the Sunday school meeting. When I was in attendance, the sermon was on the sickness of the sect: how evil is spreading within, and how a greater knowledge is kept from many because of their wickedness. It went as follows:

If we can get converted to faith in Jesus Christ, all else will fall into place. Faith makes an anchor to the hearts of men. Through faith we will be able to work harder, and eventually, to see Christ--this is what we want most. Man in and of himself can't produce good things. Only through Christ can the best things happen. By faith we become the sons and daughters of God, the meat of the gospel. Yet, once we take upon the name of Christ, and then sin, we will be damned. We must have total belief in Christ. If we listen to what He says, we have the milk of the gospel. Polygamy and United Order do not alone equal eternal life. Brother Owen wants to give us meat, but we will choke on it. The milk is listening and treating wives with respect, and doing good to others. But there is more to life than milk...

The meeting of the Sacrament at 2:30 p.m. is conducted by the Bishop or his counselors. It begins with a song from the Mormon hymnbook, and then a prayer to invite

32 This same slogan was used at every meeting of the original fundamentalists in the early 1900 s, inspired by Joseph Musser. The scripture is found in a story about Captain Moroni, a brave religious soldier, who wrote the slogan upon his coat, fastened it to the end of a pole, praying unto God "for the blessings of liberty to rest upon his brethren, so long as there should a band of Christians remain to possess the land" (Alma 46:13). 
the Spirit to enter into the meeting. Then, another hymn is sung, and the Sacrament is blessed and passed. The Sacrament prayer blesses the bread first, and then the water, stating that the bread is the body and the water is the blood of Christ, and by eating of these elements, one can renew one's covenants to Him. The ritual involves two young priesthood members who kneel at an altar-like table, where one gives the prayer for the bread, and the other for the water, each raising his arm to the square, symbolic of the correct way to God. The bread is served on small trays by Priests, the third and highest level in the Aaronic Priesthood, and then several glasses of cold water are passed around. (This Sacrament ritual is very much like the one practiced by orthodox Mormons with the exception of the glass being passed around, the physical position of prayer, and the priests, rather than deacons, blessing the Sacrament.)

After the Sacrament, the conducting counselor asks several men, women, and children to come up to the pulpit, consecutively, and "bear their testimonies" of the truthfulness of the gospel. "Bearing" one's belief is a folk term which implies that one will bear witness of the truth, or cause a testimony to be born, to others in the the meeting. Testimonies are a formal recognition of belief in the community and are a vital part of the reinforcement of community life patterns, as are prayer, and acknowledgement of inspiration. Children at a young age are asked to participate in this ritual, in order to give them positive feedback for believing in the system. The meeting is closed with a song and a benediction.

Eternity is another important aspect of temporal patterning in Pinesdale. The fundamentalists, like orthodox Mormons, believe that this earth life is "but a speck on a long eternal line." "We have always existed and we will always exist," explained one member. Residents of this earthlife were all together in the heavens, in the presence of the Father, where many agreed to be tested on earth and receive the blessings of the Celestial Kingdom. This eternal perspective, as described in Chapter II, is spoken of in daily speech 
and action patterns. For example, children are taught to be patient, and that "one thousand of God's days is but one of ours." Men and women who claim to be struggling are counseled to think of the eternal bliss they will experience after this life. All are constantly reminded that God's time is eternal, and all encompassing.

\section{Emigration and Immigration Patterning}

Another important aspect of community life patterns is the constant immigration of female members into the community, and the constant emigration of male members. How is it that there are three to four wives per husband? Where do all these women come from? There are several ways to explain the discrepancy in the number of females to males in Pinesdale. In the first place, it is common for most young women raised in the system to remain in Pinesdale. This is well known in the community and is documented in this study. In the last three years' graduating high school classes of females, more than $95 \%$ remained in the community. The other 5\% either moved to another branch of the same sect to marry or live with relatives, attended college or became employed outside Pinesdale. This large number of returning females to the community is significant in the overall number of wives for the marriage pool. Another important factor is the significant number of female to male converts to the sect who then move to Pinesdale. On a number of occasions, I heard informants speak of mothers, aunts and female friends who converted to fundamentalism because of divorce, widowhood, or "spinsterhood." It is common for Pinesdale women who become converted from the Mormon Church such as Patty, Sarah, and Connie, to bring in another member of their family, usually a sister or cousin, into the sect as well. Sarah, who converted with her husband, she taught the fundamentalist teachings to her younger sister, Jean, who soon afterward joined the sect and moved into the same household as her sister. In addition, another significant factor in female immigration is the informal exchange in young adults that occurs among the branches of the Apostolic United Brethren sect. It is common for young women from the Salt Lake City or 
Orem branches to meet a male member from the Pinesdale branch who is visiting Utah. Marriage unions usually result from such meetings. And lastly, a few Pinesdale women joined the Pinesdale community without their husbands for economic reasons. In one situation, two wives who had been living with two other wives, their husband, and all of their children, in a Salt Lake City home, relocated in a trailer home and an old renovated school shack in Pinesdale, because there was no more room in their husband's home.

Explaining the emigration of male members of the community is somewhat more difficult. It is common knowledge in the community that young males show more dissatisfaction with Pinesdale lifestyle than young females. This occurrence will be explained in detail in the following chapter. It is important here to understand how significant are the numbers of males that leave as compared to females. In the last three years of graduating high school classes of males from Pinesdale, more than $30 \%$ either left the sect's belief structure, or left the community to marry elsewhere. There is also a tendency, though rare, for an adult male to leave Pinesdale in search of work elsewhere, taking one wife with him, leaving the other wives to be cared for by the community. He relocates in another city, either sending money or not, depending on his financial situation. Another, more plausible solution to the problem of why more men leave the community than women is because most of the men work jobs outside Pinesdale, and so the pull away from the group is stronger for these men. Men must be susceptible to the messages they hear from outside society which tell them that these outside occupations run counter to the belief systems of the community or to fundamentalism. Women who now work in increasing numbers outside the community must similarly feel these same sorts of pulls, although because the outside society reinforces their domestic relations and motherhood obligations, they are able to have both a job and a family with the help of a sisterwife or two. It is the help and companionship of this sisterwife that lends a certain attraction to 
women. If they left, they might be forced to choose between their job or their family, letting one slide to build up the other.

In summary, Pinesdale community life patterns promote female groups in the following ways. First, as was described in the above section on polygyny, women who enter plural marriage outnumber men three to one in Pinesdale, they have more leisure because of less domestic work per individual, and are relieved from their duties as wife several days a week. ${ }^{33}$ Further, women are better able to support each other because of close proximity to sisterwive's living quarters. They experience more daily and weekly association because the spatial organization of the day and week enables them more frequent visits. And lastly, sisterwives more often than not are related through kinship ties and therefore, build closer, stronger bonds with each other.

33 Singh et al. (1987) conducted a study of the value of work-at-home and contributions of wives' household service in polygynous families and discovered that the work load per wive is lowered as the number of wives increases. The overall family productivity increases, but the individual wife has more leisure than she likely would in a conventional American marriage. 


\section{CHAPTER IV}

\section{FAMILY STRUCTURE AND SOCIALIZATION}

This chapter describes the structure of family life and the rigid socialization of children and adults in the fundamentalist environment. It will discuss how Pinesdale socialization and education reinforces the male authoritarian nature of fundamentalism, but at the same time, allows women a great deal of independence and leisure. It will view how girls are drawn into their mother's world as extra domestic helpers from the age of 12 and 13 until their own marriages. It will look at how young men usually marry girls closer to their own age for their first wife, but with each additional wife, the gap in ages between bride and groom widens. Most importantly, this chapter will focus on those aspects of family life and socialization that most affect the formation of female groups.

\section{THE FAMILY}

The structure of the family is a vital element of Pinesdale society. The anthropological definition of this structure, however, can only be said to be of a "polygynous" nature. It is obvious that large families are common and that these families are produced from the marital union of one male and two or more females. But to empirically state that family structure is made up of a certain prototypic residence, or a nonvariable descent type, would be erroneous. In Pinesdale society the range of family residence and descent is varied, to say the least. For example, one wife may live on her own away from her husband in her own nuclear, single-parent type family. She may even live in another city or state from her husband. Other wives may live all in the same house in the same city, seeing their husband on a daily basis. One would then call this structure 
an extended family. There are numerous instances of familial arrangement that fit in between these two extremes. As was stated in Chapter III, in Pinesdale, a polygynous women typically spends much of her married life in the same household with at least one sisterwife, or another woman of the community--usually a blood-related sister, cousin, or mother. The male members of these households are not permanent residents, but visitors to and from this household. Therefore, residence here is non-rigidly defined. It is neither solely matrilocal, nor patrilocal. It is neolocal, as some women may live with their husband's or their own kin after marriage, creating residence around their own marital unit. Yet, in my estimation, Pinesdale family residence, is more clearly defined as a "matrifocal" type residence, than any other documented type in the literature, as previously mentioned. The extent to which each co-wife lives separately from her own children is directly dependent on her living arrangement with her other wives. ${ }^{1}$

Likewise, descent is a variable entity in family structure. On earth, Pinesdale society recognizes the same bilateral kinship that most American society practices, acknowledging both the male and female kinship network. In heaven, however, and under the ideological structure of the both family and community, this is not the case. Pinesdale residents acknowledge only the male kinship network in the afterlife, where unmarried daughters will remain with their father's kin group, and married daughters will join their husband's father's group. So, in effect, Pinesdale family structure utilizes both bilateral and patrinineal descent systems, and both nuclear and extended "matrifocal" residence patterns.

${ }^{1}$ Because wives may live in their own compartment within the home of their sisterwife, in their own home, or in the living space within the home of another woman, the way the children are separated from their step-siblings varies with each wife. On average, the children share rooms and special items with their own siblings, while sharing other rooms and items with their step-siblings, in the same household. Even in the case where one woman has her own house, her children share certain items, such as toys, some clothes, etc., with their step-siblings in another house. This sharing makes the boundaries between siblings and step-siblings very weak. 


\section{Family Economy}

Family economy, as opposed to community economy, is also vital in an analysis of Pinesdale family structure. The allocation of family resources, as was mentioned in Chapter III, is based on the number of children per wife, per husband. The ranch has established an ideal budget, which allows a fair distribution to all members of each household: $\$ 1 /$ per adult/per day, $\$ .75 /$ per teen/per day, and $\$ .50 /$ per child/per day. It is up to the husband's discretion whether the wife budgets her own family income or he prepays certain items before giving her a portion of his income. It is more common for the wives to handle their own household budgeting, however, making most of the decisions for how the home is run without the husband. The husband, ideally, is in charge of determining the community surplus to be given to the bishop, and requires that all family income go directly to him. In most cases, the wife receives back less than what she herself earned at her job since all money is handed over to the husband for equal distribution. In this way, though the wives manage their own households, the male head of the family is in charge of any money that comes in or goes out. ${ }^{2}$ The senior wife of each family may be appointed by the husband, or on her own initiative, apportion the goods to all, with the cooperation and consent of the sisterwives. In most cases, however, all wives meet on an equal basis, usually once or twice a week, to budget and apportion the goods for each of the wives for that week or month. The goods in this case are only those goods which have been decreed as "shared" goods. In some families there are less shared goods than others, depending on finances and particular needs. For example, one wife, whose children are frequently ill may require speciality items which must be purchased out of her own budget. She is therefore compensated in cash for the food or supplies she does not receive from the

2 Though the husband, as a priesthood bearer, is required to hand the surplus over to the bishop, any of the wives may help him keep records, tally up the numbers for him, or handle all the money up until the point of delivery to the bishop. This is true of Sarah, a professional accountant, who handles all of her husband's finances for him. 
other wives. The system is extremely egalitarian, and according to one informant, results in relatively few quarrels about food or goods. I did notice, however, that in the distribution of goods two, three, or four ways, some wives may get fewer provisions or dollars than others and get cheated out of a low-running item. This often happens over a long period, one wife told me, and is corrected through communicating certain needs that have been ignored or forgotten among sisterwives. For example, when one women has mistakenly received only three gallons of milk for the week when normally she gets four, she will either borrow one from her sisterwife, or be compensated for it in extra cheese or eggs.

A common tactic to save money used by many wives who are able to organize their own budgeting, is to try many different natural cures before taking their children to see a non-fundamentalist physician, using the resultant money saved for food or clothing. In times of illness, people are devoted and come together with money, prayers, or attention. A wife will usually ask a sisterwife to come to her aid when she is ill. ${ }^{3}$

In analyzing one women's monthly budgeting, I discovered how much a mother relies on the female networking system and the communal storehouse to feed, clothe and care for six children. Hannah Harris, the mother in question, used a family budget sheet to keep track of any income and expenses that she incurred during the month in caring for her five children (Figure 5). On it Hannah would categorize all of her monthly expenses: tithing, clothing, food, recreation, gifts, necessary items, miscellaneous items, and family. Incredibly, her expenses from October 17 to November 30, more than one month's time, totaled barely $\$ 76$. This amount is her portion of her husband's salary after being split three different ways. The items on which she spent money vary from postage stamps to cough drops, but on the whole, are items which involve children, school, or recreation.

${ }^{3}$ One account stated that when one woman contracted cancer, her sisterwife stayed with her night and day until she died. 


\begin{tabular}{|c|c|c|c|c|c|c|c|c|c|c|c|c|}
\hline & A & $B$ & C & $D$ & $\bar{E}$ & $F$ & $\bar{G}$ & $\mathrm{H}$ & 1 & $j$ & $K$ & L \\
\hline 1 & FIGURE 2: & \multirow{2}{*}{\multicolumn{8}{|c|}{ MONTHLY HOUSEHOLD BUDGET SAMPLE - NOV.-DEC. 1990}} & & & \\
\hline 2 & & & & & & & & & 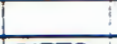 & \multicolumn{2}{|l|}{ 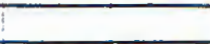 } & \\
\hline 3 & ITEM & INOOME & EXPENS & BALAN. & TITH. & CLOTH & ROOD & IREC & GIFTS & INECES & IMISC. & FAM \\
\hline 4 & & & & & & & & & & & & \\
\hline 5 & cash & 12.54 & & $12.54 !$ & & & & & & & & \\
\hline 6 & babysitting & 3.25 & $0.25 !$ & 15.79 & 0.25 & & & & & & & \\
\hline 7 & tithing & & 0.33 & 15.46 & 0.33 & & & & & & 0.25 & \\
\hline 8 & stamos & & 0.25 & 15.21 & & & & & & 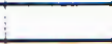 & & \\
\hline 9 & babysitting & 8 & & 23.21 & & & & & & & & \\
\hline 10 & iithing & & 0.8 & 22.41 & & & & & & & & \\
\hline 11 & babysitting & 26 & & 48.41 & & & & & & & 0.25 & \\
\hline 12 & tithing & & 2.6 & 45.81 & 2.6 & & & & & & & \\
\hline 13 & red ribbon & & 0.25 & 45.56 & & & & & & & & \\
\hline 14 & insurance & & 19) & 26.56 & & & & & & 19 & & \\
\hline 15 & library fine & & 0.02 & 26.54 & & & & & & i & 0.02 & \\
\hline 16 & picture reprints & & 0.65 & 25.89 & & & & & & 1 & 0.65 & \\
\hline 17 & picture paybacl & 0.65 & & 26.541 & & & & & & & & \\
\hline 18 & lehips, zingers & & 1.28 & 25.26 & & & 1.28 & & & & & \\
\hline 19 & apple juice & & 0.5 & 24.76 & & & 0.5 & & & & & \\
\hline 20 & school play & & 1 & 23.76 & & & & 1 & & & & \\
\hline 21 & school pictures & & 14 & 9.76 & & & & & & $\$ 4$ & & \\
\hline 22 & Ireasure of tru & & 2.5 & 7.26 & & & & & & 2.5 & & \\
\hline 23 & babysitting & 2 & & 9.26 & & & & & & 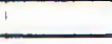 & & \\
\hline 24 & tithing & & 0.2 & 9.06 & 0.2 & & & & & & $\because$ & \\
\hline 25 & babysitting & 3 & & 12.06 & & & & & & & & \\
\hline 26 & tithing & & 0.3 & 11.76 & 0.3 & & & & & & i & \\
\hline 27 & hamburger & 1.24 & 9.24 & 11.76 & & & & & & & $\vdots$ & \\
\hline 28 & pantyhose & & 21 & 9.76 & & 2 & & & & & 1 & \\
\hline 29 & babysitting & 2.08 & & 12.56 & & & & & & & & \\
\hline 30 & lithing & & 0.28 & 12.28 & 0.28 & & & & & & & \\
\hline 31 & Imen's cologne & & 1.78 & 10.5 & & & & & 1.78 & & & \\
\hline 32 & bracolel & & 2.97 & 7.53 & & & & & 2.97 & & & \\
\hline 33 & lorange juice & & 0.65 & 6.88 & & & 0.65 & & & & & \\
\hline 34 & hamburger & & 3) & 3.88 & & & (3) & & & & & \\
\hline 35 & dorink & & 0.35 & 3.53 & & & 0.35 & & & & & \\
\hline 36 & frias & & 1.68 & 1.85 & & & 1.68 & & & & & \\
\hline 37 & drink payback & 0.05 & & 1.9 & & & & & & & & \\
\hline 38 & grape juice/pie & & i.68 & 0.22 & & & 1.68 & & & & & \\
\hline 39 & speech paymt. & 3 & 3 & 0.22 & & & & & & 3 & & \\
\hline 40 & primary show & & 0.22 & 요 & & & & 0.22 & & & & \\
\hline 41 & cough drops & 0.4 & 0.4 & & & & & & & & 0.4 & \\
\hline 42 & babysitting & 3 & & 3) & & & & & & & & \\
\hline 43 & tithing & & 0.3 & 2.71 & 0.3 & & & & & & & \\
\hline 44 & kitchen towel & & 0.7 & 2 & & & & & & $i$ & 0.7 & \\
\hline 45 & choc. cherry & 0.69 & 0.69 & 2 & & & & & 0.69 & & & \\
\hline 46 & shoos & 10 & 10 & 2 & & & & & & & & \\
\hline 47 & & & & & & & 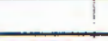 & & & & & \\
\hline 48 & TOTALS & 77.971 & 75.97 & 21 & 4.81 & $13 !$ & 10.4 & 1.25 & 6.43 & 38.5 & 1.57 & \\
\hline
\end{tabular}

Figure 5. A monthly household budget sample for November 1989. 
This leads me to believe that the staple goods: food, shelter, and clothing, are acquired through some other source. In Hannah's case, the female network provided her with most of these staple goods and services. Since Hannah's income is extremely limited (her husband is a garage door installer), her food budget relies on wheat ground by the communal mill, brown rice purchased in bulk quantities by several women, communal honey, and milk which is distributed at a discount price by her neighbors. She has quite a few shelves of canned fruit, which came from a united effort of several wives in both the Salt Lake and Pinesdale group, and various other foodstuffs purchased at bulk. She also relies on beef products purchased from the community herd. Hannah's wood is gathered locally, or purchased at a low, bulk rate. The wood for most of the community is usually delivered by a large truck to various wood sheds throughout the community to allow for easy access by every family. Women also go regularly to rummage sales year-around in the Hamilton area, finding all kinds of household "treasures" for very little money. 4

When analyzing the family budget, it is important to remember that Pinesdale is operating on a partial communal system. Because no one in Pinesdale pays either rent or mortgage payments (all land and and homes are communally owned), and in light of the fact that there is no medical insurance to pay, no central heating (all homes are heated by wood stoves) or outside water bills, the monthly expenses for one family can be quite low. Pinesdale has the lowest tax base in the state, and there are no city taxes. The water used in each home is gathered from the natural streams and rivers of the mountains into two water boxes near the mouth of two canyons. Each extended family is charged $\$ 10 /$ per family for water per month. At present, only one-third of the town is paying this amount; the rest are getting their water free. As Figure 5 indicates, the largest expense for families are items for the children, such as school pictures, basketball uniforms, a dress for the prom, a special

4 One day Julie, a woman I lived with at the end of my stay in Pinesdale, showed me around her house. She claimed that most every appliance, tool, utensil, and several pieces of fumiture were found at rummage sales. This is how she maintains the home with a low budget, she said. 
treat, etc. There are many items that are shared communally, such as household appliances, clothing, baby items, furniture, stoves, televisions, beds, and garden tools, which are stored and distributed on a rotation basis. As mentioned, most wives buy bulk products at discount warehouse stores and split them three to four ways, but this convenience may not be possible in the future due to a lack of bulk items in the market. ${ }^{5}$ They pass clothing down through the ranks in all three families and share every item in the household. Childcare is among the most valued sharing item to be shared. In fact, one woman said that sometimes her young children can't figure out which mother is their real mother. "It doesn't really matter anyway," said the women. "We are both his mother. He calls us both "momma."

While staying with Hannah, I was able to help prepare and consume each day's meals for little over a week. The following is a description of the food served per meal during that time. For breakfast, meals ranged from grits with eggs, milk with biscuits, and for special occasions, Swedish pancakes with lemon juice. Lunches, eaten at school or work, comprised a slice or two of wheat bread with a thin slice of cheese or butter and jam. On Sunday, which happened to be "fast Sunday," when members restrain from eating but one meal a day on the first Sunday of the month, we were served a late lunch of tomato soup and a slice of bread. In light of the fact that all members had fasted all morning and most of the early afternoon, this single Sunday meal seemed especially spare. Since there was no supper served in the evening, the afternoon meal was the only meal of the day. ${ }^{6}$

\footnotetext{
5 Recently a huge supermarket chain has been built in Hamilton, called Super One, which has bought out all the other stores, including many of the bulk food discount stores in the area. They have underpriced most of the stores they haven't bought out, including the Pine Mercantile, and have lured many Pinesdale women to their store. In the future it will be more difficult to buy bulk items, unless women want to drive to Missoula or to distant farms and discount warehouses.

${ }^{6}$ I am not in any way saying that these mealtime patterns are cruel or inhuman. Pinesdale residents are healthminded and insure that their children are eating no more than what they need to maintain a healthy constitution. I am pointing out that food is not a priority for most families, as it is in much of American culture. No snacks are served between meals, or in front of the television. And on one Sunday a month, only one scant meal is served, as this is the day of fast.
} 
The varieties of week-day suppers included: lima bean soup and wheat bread for one meal, noodles and gravy for the next. Hannah often supplemented these meals with fruits or a vegetables. Milk was commonly served as the beverage at every meal. Hannah's budget allowed for little grocery shopping. This shows her reliance on bulk items, purchased together with other women, and garden items, stored in the cellar, such as carrots, onions and potatoes.

Within family structure, it is also important to conceptualize the kinship structure and acknowledge divorce, contention, and family break up. Because Pinesdale residents draw their spouses mostly from within the community, there is an element of inbreeding that distorts the kinship lines drawn from one person to the next. Affinal ties are just as important as consanguineal ties in Pinesdale society, as they represent the celestial alliances a family makes with another. In spite of the incidence of inbreeding, there is another element present in Pinesdale that suggests that marital ties are more commonly formed among families of sisters and female relations than among brothers and male relations. The following analysis of kinship among sisterwives, conducted in a study of one prominent Pinesdale family, serves to illustrate this point.

Kinship Among Sisterwives. As indicated in the beginning of this chapter, women are the residential core of the household in Pinesdale. They form clusters of kinswomen through affinal and consanguineal ties, but also ties of sisterhood in the gospel. Women are usually related to their sisterwives even before marrying into a family, being sisters, cousins, or aunts and nieces to each other, as well as being sister-in-laws, or affines. Because of this, their bonds with each other are more tightly woven than if they were married as strangers into their husband's kingroup.

To illustrate the close kin ties women share with their own sisterwives, as well as other women of the community, I have drawn up a small genealogy of the common ancestor of several Pinesdale residents, Joseph Lyman Jessop. This is found in Figure 6. 


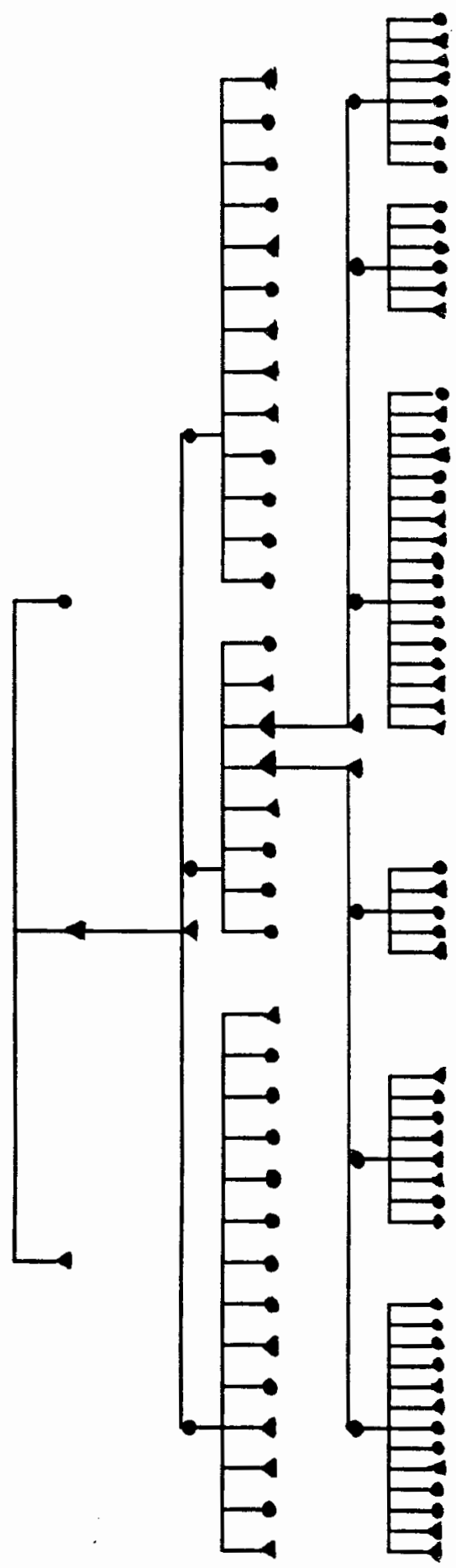

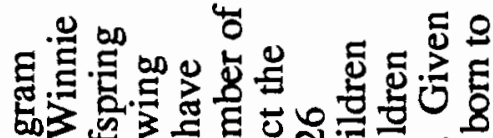

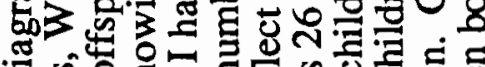

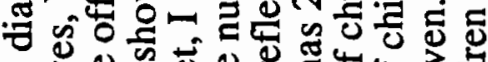

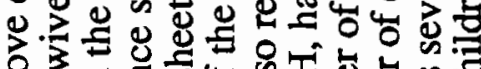

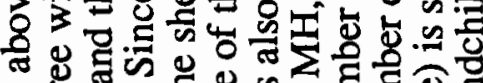

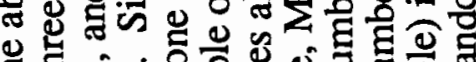

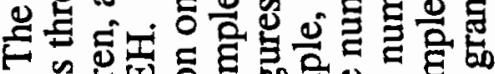
象四

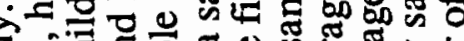

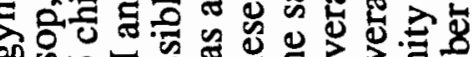

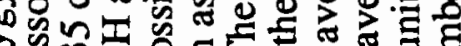

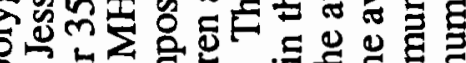
年 co

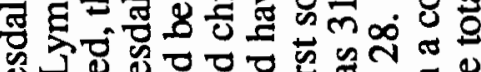

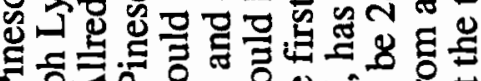

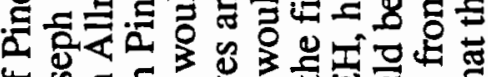

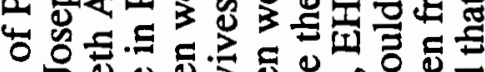

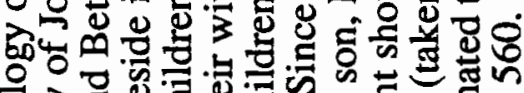

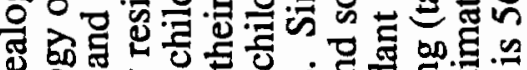

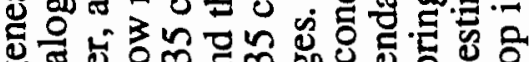
of 8

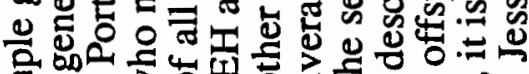

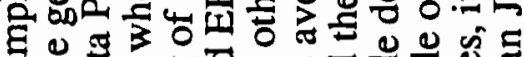

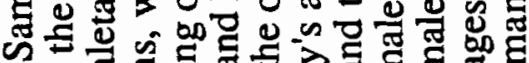
的 g.

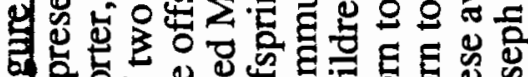

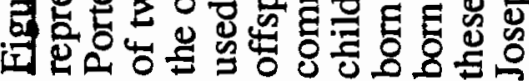


For the Harris and Olson families, who intermarry constantly, kinship association is somewhat confusing. Beth Harris' children are some of Mary Olson's children's closest friends as well as their cousins and aunts and uncles, simultaneously. Because Beth and Mary are natural sisters, as well as sisterwives, their children have become cousins to each other, yet at the same time are brothers and sisters through their father. Because some of the older children's offspring are the same age as their brothers and sisters, these children have become aunts and uncles.

The genealogy of Joseph Lyman Jessop's family, as well as the Harris/Olson example of intermarriage, illustrates certain marriage patterns among these polygynous communities. I further derived information on these patterns from interviews and additional genealogical research. I observed patterns of men marrying sisters, brothers marrying sisters, and cousins marrying two separate sets of cousins. Sororal polygyny is by far the most common form of consanguinal marriage. The marriage of cousins to the same man is the second most common form. For example, in Pinesdale, Melvin and Matt Harris married Hannah, Jean and Deborah Hanson. Rulon Allred, the former prophet, married Mary and Melba Clark. Mark, Rulon's brother, married three Harris sisters-Louise, Matilda, and Ruth--and Larry Harris, married two Martin sisters, Carry and Elizabeth. Three Paterson boys married three Parson girls, and Tom Clark married his cousins, Rachel and Kathy Peterson. An example of sororal and cousin polygyny is given in Figure 7, which also serves as an excellent illustration of sisterwife kinship.

The significance of kinship among sisterwives is that women living in the same proximity as their female relations reinforce each other and protect each other's interests, whether emotional, economic or religious. The physical association with others--especially family--means living near people who believe the same way you do.

Family Breakup. I was told that without the cooperation and religious vision of Pinesdale wives, contention, jealousy and eventual breakup of the family would arise. If a 


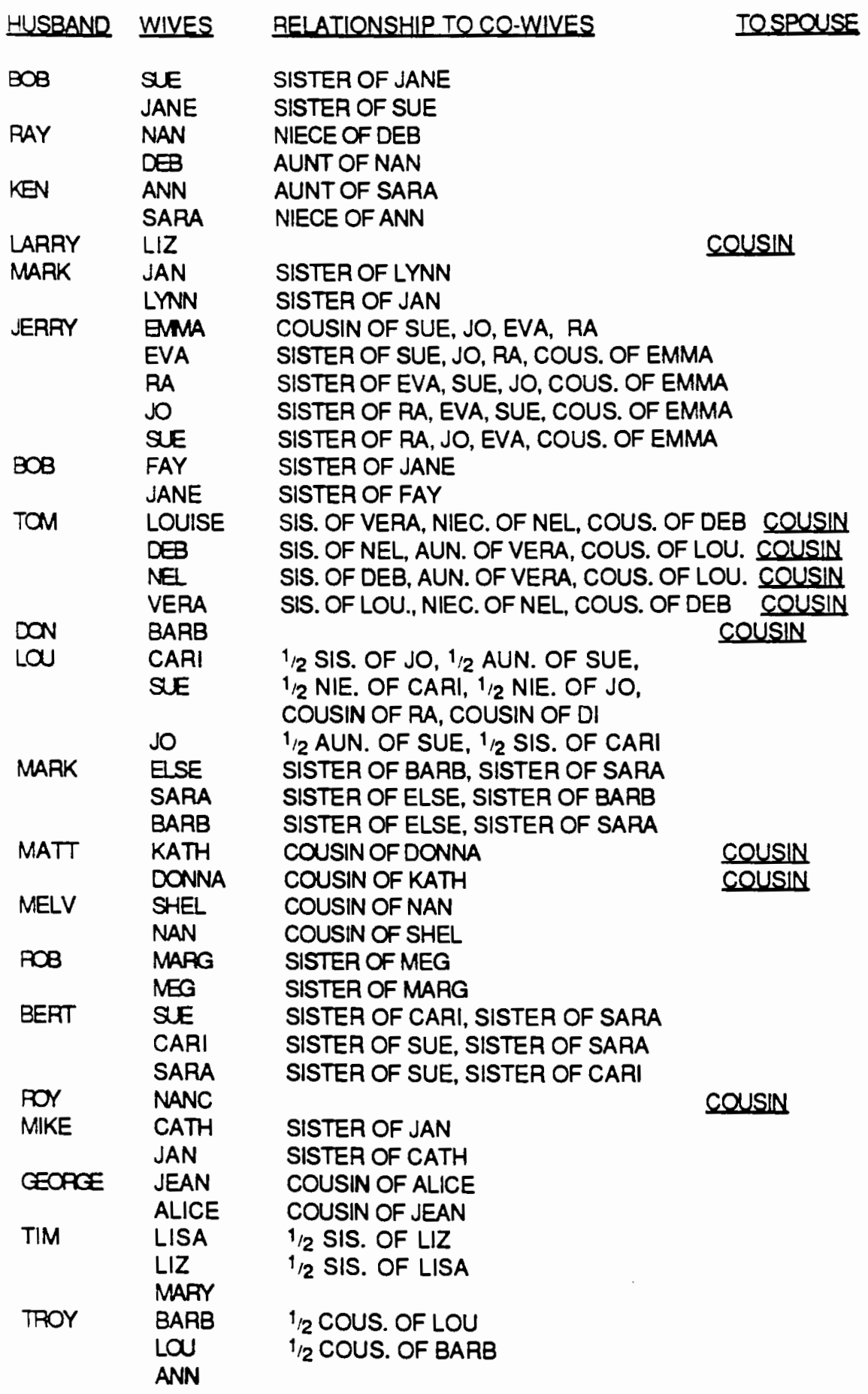

Eiqure 7. Sample chart of co-wife kinship ties. This sample represents the marriage pool randomly picked from one man's progeny, Joseph Lyman Jessop. There are some instances of nonkin ties with co-wives, though rare. It is by far more common to see kinship ties among co-wives prior to their marriage to their husband. These pre-affiliated blood ties are significant in female bonding. 
squabble occurs, couples are petitioned by their belief in the principle to iron out their differences for their own salvation. Yet, there are incidents of divorce, however small in number (2\%). One common reason for splitting up is the lack of living space, where with families who all live under the same roof, wives and children find solace only in their overcrowded bedrooms, and no large communal area is to be found. Each quickly grows apart, adapting to the independence of their rooms, and factions occur between siblings, wives, and especially husband and wives. Mostly, though, the divorce is a result of incompatibility between husband and wife. Divorce rarely occurs because of differences between sisterwives, since there are ways to avoid a sisterwife.

\section{SOCIALIZATION}

Train up a child in the way he should go; and when he is old, he will not depart from it. PROVERBS 22:6

I love Daddy, he loves me. We love Mommy, yessirree. She loves us, and so you see. We are a happy family.

\section{MORMON CHILDREN'S HYMN}

Pinesdale socialization produces a psychological and sociological conformity which marks the community as a distinct religious group and makes it difficult for people to either move into or leave the group. This conformity makes it hard for members to blend into the world. For example, the community's members attempt to dress in popular clothing, but they seem to stand out in their gentleness, their separateness, and occasionally the modest and inexpensive way they dress. Women are often seen with hair longer than usual, either pinned up close to their heads, or tied in back. They wear long pants or dresses, with the hem below the knee by at least four inches. Men dress in a rural, "smalltown" fashion, with bill caps and country jackets. They are sometimes seen with one middle-aged woman 
and one younger woman in town, as if a married couple were taking their babysitter on an "outing." Pinesdale children are recognized by their striking resemblance to each other, their same last names, and their tendency to group themselves together. When teachers outside Pinesdale point these similarities out, the children are taught to reply, "No, he's not my brother, he's my cousin." It is not uncommon to see several women together shopping, decorating the lunchroom for a dance, preparing food for a community meal, or gossiping in front of the post office. Women are seen together more than men because women more often travel in the same daily working circles, whereas men are more often alone in their work, away from the ranch, away from each other. Most of the time, an outsider does not perceive the actual life patterns and socialization activities of Pinesdale residents when they are seen at a high school concert, play or basketball game. Ranch members are extremely secretive and nonsocial, keeping the expressive aspects of their lives limited to the confines of their homes, church and community.

Pinesdale socialization functions to perpetuate religious belief and community commitment. It is a consistent, continuous process, building up to three peaks in the life of the individual. These peaks are: baptism, or membership into the sect; marriage, or the "everlasting covenant" with God; and death, or entrance into the kingdom of heaven. Socialization during childhood prepares one for baptism and marriage; socialization during adulthood reinforces commitment and prepares the individual for death. The pattern of socialization is remarkably consistent throughout the community; deviancy is rare, but does occur in the adolescent and young adult stages, mostly among males. ${ }^{7}$

I hope to illustrate in this section how certain mechanisms in the socialization of females help to maintain their membership within groups throughout their lives. Logically,

7 I was told of more incidents of young men leaving the sect than young women, and when I recorded the number of young adults ages 18 to 24 , the females far outnumbered the males. 
in order to understand female socialization, the socialization of the male must be included, since the one affects and pushes against the other.

\section{From Birth to Two Years}

The purpose of plural marriage, as shown in Joseph Smith's revelation and as stated in Genesis, is to "multiply and replenish the earth," and to provide a home for the chosen spirits that are waiting to arrive into a family kingdom. Therefore, the more children born to a woman, the more blessed she will be. Birth control, abortion, and abstinence for any other reason than lactation, pregnancy, or menstruation are forbidden. Children are raised in extended families--made up of nuclear units of each wife and her children--and are brought into the community school system at the age of 2 or 3 , depending on the parents. School training involves Montessori instruction at ages 2-3, kindergarten at ages 4-5, and 1st through 6th grade, ages 6 through 12. A small group of junior high age students are taught in the community, but after grade school, most children are bused to a "gentile" school in Corvallis, 12 miles to the east.

Within a celestial marriage union, sanctioned by the proper authority, children are gifts from God. And children of polygynous marriages are promised to be the strongest, most intelligent children of all God's kingdom (Allred 1985). ${ }^{8}$ In spite of this, there is no formal recognition of a pregnancy by the community. When a women finds out that she is pregnant, there is merely an informal recognition among the women that "so-and-so's" time has come and she will be needing their help. It is uncommon for husbands to modify their routines to help when any of their wives are pregnant. With approximately $40-50$ children born per year, pregnancies are all too frequent for the community to take special notice.

One man with three to four wives will average 18-32 children. This means an average of 6 district.

${ }^{8}$ Pinesdale has one of the largest number of honor roll recipients, athletes, and student officers in the 
to 8 children per woman. In light of these statistics, men would be altering their actions constantly if they were to aid their wives during confinement.

Pinesdale mothers give birth in the home. Prenatal care and medicine is provided by the town's midwife, who, on average, visits five to six women a day in her home. She bills the family for most of these costs, usually totalling no more than $\$ 75$, though the ranch usually pays for any additional costs. The midwife herself receives no income for this service. During the actual delivery the woman's sister or sisterwife will attend her. A priesthood bearer, usually the husband of the mother, is also present. Since childbirth is known among Pinesdale women as being one of the bonds that lasts among them, this service will most definitely be reciprocated when it is her turn to deliver and recover. The postpartum mother is cared for by the midwife and close relatives or sisterwifes. The new mother's work is alloted to either her sisterwives or to women who are available to take her job and her religious and community assignments.

More than $95 \%$ of Pinesdale births are delivered by the town's mid-wife. She has given birth to 17 of her own children, and delivered more than 600 community children. She was taught naturopathic obstetrics by the former prophet, Dr. Rulon Allred, watching him deliver natural births since she was 14 years old. The midwife is on call 24 hours a day, preparing for visits, check ups, nutritional analyses and deliveries. During the latter, she demands that a priesthood holder be present at all times in order to give blessings if needed. ${ }^{9}$

${ }^{9}$ This is symbolic of how women's powers are demonstrated in the patriarchal system. Here is a woman who essentially does the task, or miracle, herself, without the help of men. But in order to draw on the Spirit and the powers of heaven, she must have a priesthood backup. The priesthood, in the eyes of Pinesdale residents, is the power of God. Only through men who hold the priesthood can healing powers and other powers be channeled--unless, of course, a man is not around, then a women who is connected to a man with the priesthood (by celestial marriage) can call upon those powers herself. So in a way, it is just the opposite of what you would find in some African societies, where women hold a religious magical power, while the men do most of the tasks. On the contrary, in Pinesdale the men do all the blessings and ritualistic tasks. 
The midwife's birthing procedure, though not directly related to the child's socialization, is an important factor of the mother's socialization, as she will be spending many years of her life giving birth, and helping others give birth. I will, therefore, briefly describe this procedure below. The midwife will often manually reach in and turn the cervix to the front, if tipped, as part of the birthing procedure. She said that this technique is unheard of in hospital obstetrics, but it works wonderfully for her. She requires mothers to take vitamins and exercise through their pregnancy, and to drink a quart of raspberry tea and/or comfrey every day. This helps prevent hemorrhaging and aids in the delivery. She also has the mothers eat alfalfa for vitamin D during pregnancy. For toxemia, she uses snake grass, corn silk or parsley. If she has "a bleeder on her hands," she gives them bioflavinoids, which are the white part of the grapefruit or orange or lemon. If a woman is hemmoraging, she bestows a healing prayer upon the woman, and asks for the priesthood to administer to her. ${ }^{10}$ She then has the mother drink blue cohosh, Caulophyllum thalictroides, which helps clot the blood and also helps the placenta. Chinese herbs are also used in hemmoraging. She manually massages the uterus after the birth to stop the bleeding. She also binds the mother after birth, using a towel or other wrap around the uterus. She folds the towel in front and so it will weigh down the uterus. She learned this from Rulon Allred, and swears by it, but says that no other doctor uses this practice.

An important aspect of the socialization of children begins even before they are born. Women desire children. They seem to know that a specific child, boy or girl, is waiting to be born into their family. They must bear that particular child, as they have had visions of it, and know it to be their very own child. ${ }^{11}$ The bond between a mother and

10 Administering is giving one a blessing by laying priesthood holders' hands upon the head of an ill one, and stating "by the power that we hold, I command you to be well." Sometimes anointing oil is used.

11 The midwife spoke of the afterlife where her two dead children, both stillborns, talked to her son in a vision while he was in the hospital. She told me she had been worried that they hadn't received a spirit into the body before leaving the body at death. She worried that the children had not literally become "hers," that is, her own heavenly children who would join her in the afterlife. Her son while in the hospital saw both of the dead children, as adults, standing before him and described exactly what they looked like. She 
child is a vital part of the socialization of the child. Mothers look forward to their coming into the world, as it is a status marker for them, and they will be highly valued by their husband and the town if they are productive. Mothers speak with pride when telling the number of children they have, for it is their most blessed achievement in this life. The sect believes, as the Mormons do, that this child has been transported from the presence of their Heavenly Father, from the state of an "intelligence," or spirit of intelligence with no body, to the state of a baby's body, fresh from heaven. So, as a child grows, though he is still loved, he loses that innocent, blessed state. For most women, bearing children and watching them grow in the gospel is the consummation of all their earthly wishes. If a woman happens to become barren or infertile before her heavenly quota, she may experience a nervous breakdown, or depression. ${ }^{12}$ One woman, who had been trying for years to have a second child, put her energies into her work at school to avoid confronting her barrenness. In some cases, it is felt that the best way to care for this depression is to bring another wife into the family, one who will bear many children who both can share and care for. With the death of a child, the best remedy is said to have another one. Thus, it is not the men who push for more children, although they desire them, but the women who want them, "for in children shall they receive joy," as quoted from a Pinesdale sermon.

Because of the help of her sisterwife or other female friends, the mother is able to devote herself completely to the infant's care during the first months of the child's life. Later, as she participates more fully in her work, she will leave the baby with a daughter, sister, or sisterwife, or leave her with the women who run the school nursery. At this time, the pattern of the child's life meshes more closely with other "mothers" and the

felt comforted that she did not have to go through additional births to bring the two children she knew to be waiting for her, to the earth. She also felt that she had already brought them to their testing ground.

12 "Heavenly quota" refers to the number of children a man and woman have either discussed having, or what a woman sees visions of having. As noted, women often have "feelings" or "visions" about certain children that are waiting in heaven to come down specifically to her family. 
community structure. As the child grows it will learn to love these other mothers (sisterwives, teachers, relatives), having spent a great deal of time under their care.

Religious training begins around age 2, at the table, when a mother folds a baby's arms and asks it to bow it's tiny head to pray with the others for the meal. This prayer training occurs at morning, evening, and all other meal times. Religion for the young child early on becomes a ritual, associated with food, as a child will learn to automatically fold it's arms and bow it's head when hungry, and at the instant anyone calls for a prayer, at church or at home. A baby's first prayer at night will be simple and will be modified slightly throughout it's life:

Heavenly Father, thank you for this beautiful day. Thank you for Mommy and Daddy. Thank you for all my blessings. Please bless me to do what's right. In the name of Jesus Christ, Amen.

Along with prayers, songs are taught early to young children, at home, at nursery, at Sunday school, and Primary. The mother begins teaching these to her baby while rocking it to sleep and continues to sing them to the child at worktime or playtime. These Primary songs are basically hymn-type ditties for children about the Savior and his love for children, such as "Jesus Loves Me This I Know," "Jesus Once Was a Little Child," and "I am a Child of God." By the time the child is three years, he or she is able to both sing a few songs and pray by itself without the help of its mother. The child is now ready for more instruction.

\section{Conformity: From 3 to 5 Years}

Discipline for a young child begins when he or she hits back--at playmates, siblings, or parents. Punishment is not usually physical since a verbal reprimand from the mother will send him crying to his room. Most children are taught that they must obey their parents at all times and that their greatest joy is to please their mother. When children quarrel over an object, the object is removed. When children fight, they are told to "kiss 
and make up." When a child refuses to share something, to do his chores, or take his part in community and family work, he is refused a meal. All or most of such disciplining is taken care of by the mother, as she is usually the parent present at the time. When the father is at home, he may hear about the incident and inflict further punishment, but usually, he wants to share good feelings during the limited time he has with this particular family, and will not act too harshly.

Pinesdale mothers seldom take their young children with them when they engage in community work, or work in the marketplace. Even when doing errands or making visits, it is rare for a mother to load all of them in the car and travel into Hamilton since this would attract undue notice to herself. One informant said "it's just too much of a hassle!" The mother will leave them instead at home with an older child or sisterwife. Consequently, the child seldom goes outside of the colony, and "going to town" becomes an adventure. Because of this, children tend to look at "gentiles," or nonmembers, with great curiosity and find certain of their behaviors repulsive, such as cigarette smoking, swearing, or drinking. The child is encouraged in this repulsion and urged to behave properly, and soon loses his fascination with the "wicked" world outside.

In raising young children, sex differentiation tasks are strictly enforced. The rules of conduct supported by the male ideological structure provide guidelines for this sextyping of children. The full document is shown in Appendix D, and has been discussed in Chapter II:

Let mothers educate their daughters in all kinds of domestic labor, teach them to wash and iron, to bake and do all kinds of cooking, to knit and sew and to do all other things that will qualify them to be good and efficient housewives. Let fathers educate their sons in whatever branch or branches of business they intend them respectively to follow. Despise that false delicacy which is exhibited by the sons and daughters of the rich, who consider it a dishonor to labor at the common avocations of life (Rules of Conduct, \#25, Pratt 1853). 
Pinesdale girls work inside at cooking, cleaning and sewing, and outside with foodproducing tasks such as pulling weeds, and digging up potatoes. Daughters help their mothers with washing, ironing, and other chores, training to be future wives and mothers. Ideas about professional careers are uncommon, but ideas about jobs and making money to support the family income are routine. By watching their mothers work at extra jobs and learning contemporary work skills, such as secretarial, accounting, store clerking, or nursing, daughters also learn to follow in non-traditional roles. Fathers, in turn, reenforce sex differentiation in boys through exposure to masculine-type tasks and activities. They take them on fishing and hunting trips and along with them to work on the car, or work in the tool shed. Boys' chores include caring for cattle, carrying firewood, and moving machinery. They develop an early love for mechanical and carpentry work by watching their fathers install a kitchen cabinet in a newly built home, repair the valves on a water box, or run the saw mill. In terms of total time spent at work, sons help their mothers more than they do their fathers, since they must help clean their rooms, fetch wood, and take turns taking out the garbage. Yet, overall, boys usually gravitate toward the tasks that their fathers, as men, perform, and harbor a dislike for housework.

Because a mother spends most of her time with her children, and knows them so much better than her husband, she often prefers, overall, their company to his. ${ }^{13}$ For a husband with three to four wives, which is the community average, having approximately seven children per wife, there is little father-individual child time alloted in his busy schedule. Often a father will come home exhausted from work, seeking quiet refuge, and find a house full of kids with "Daddy" on their minds. He may seek a quiet conversation with his wife, rather than discuss all of his children's problems and activities in the first

13 The Pinesdale woman is compelled by her solo-parent condition to make confidants of her children. In a study of father's relationships with Mormon polygamous children, Embry noted that in a sample of 63 children, both monogamous and polygynous, 41 percent of monogamous children were close to their fathers and only 22 percent of polygynous children were close to their fathers (1987). 
five minutes. Some children get more regulating and instruction than others. For example, when a man visits his first wife's children, he knows them better, they are older, and he expects more of them. When he visits a second wife's children, some of whom may have been born by the women's dead husband or by a man she divorced, he may be restrained in disciplining and bestowing spontaneous affection. ${ }^{14} \mathrm{He}$ hesitates crossing the boundaries of her established authority over the children. To children, fathers are always busy with one thing or another. Frequently, when it is "Daddy's" special night home and all are sitting around the table, he is suddenly called away to bless so-and-so, or help with some community priesthood problem or project.

Montessori Instruction. From age 3 to 4 , the children begin the day by sitting on a red-taped square in the middle of the room, while the instructor tells them a story about Jesus, showing pictures of the Savior in different settings: in the garden of Gethsemane, on the cross, talking with young children, and at the Last Supper. Children sing hymns and are lead in prayerful exhortation to love one another--the same prayer they will repeat for the rest of their lives. They then have a Bible story, a geography lesson, and then they "choose work," picking out a project with which to occupy themselves for an hour. In Montessori, the basic philosophy is to teach a child to be independent at a young age. With so many children in the household, and more on the way, it is deemed best to socialize a child early on to be a self-reliant contributor rather than a drain on their mother and others in the family. Thus, both boys and girls are taught to fix their own lunches, fill their own beverages, and even to sew their own buttons on their shirts. They also help make beds, fold their clothes, do the dishes, and scrub the table. This instruction does not always survive the sex-typing instruction the children receive at home and in later school years. Boys begin to avoid household tasks, as their fathers do.

14 It is common for women who have been divorced or widowed while in the orthodox Mormon Church to be converted to fundamentalism. 
The child's transition from home to school is eased by the fact that he sees other children and other adults at church at least twice a week and has so many brothers and sisters of his own at school with him. It is rare that a child from Pinesdale is a loner, as from very early in life he is taught to seek out, get along with, and care for others. In this light, it is not surprising that many young children eventually become involved in high school basketball, track, glee club, and student office. Some children, however, find themselves at odds with the system from the beginning. Young kindergarten children who miss their mother will sit on the bench defiantly and chant, "You're not my mother. I want my mother." Since the child must submit to the teachings of his parents and teachers, he may act frustrated for a while, but ultimately he learns that obedience and acceptance are the best policy, and gradually he comes to tolerate his lot.

Kindergarten Instruction. In kindergarten, from ages 5 to 6 , the child learns about the gospel, about the alphabet and numbers, and how to incorporate himself into his peer group with whom he will remain for the rest of his life. At this age, in most of the United States, children learn to stand apart from their peers, compete, and miminize their contact with other children in order to develop their individuality. In Pinesdale, individual belief and character are also important, but the child is constantly placed in a setting that maximizes his identity both as a member of a group, and as a member within a heavenly order. Kindergarten, and the church environment, teach the child cooperation and the need to respect the authority structure of the community. The kindergarten child is expected to be obedient and begin to learn how to behave as he should in conforming to the rituals of the church/community. He says his prayers, cleans his room, and completes his chores. At five, a child must learn to be quiet in church; he must sit still and be attentive to the sermon. At six, he must begin to familiarize himself with the sect's scriptural canon which includes the King James Bible, the Doctrine and Covenants, the Pearl of Great Price, the 
Book of Mormon, and various sermons from the prophets found in the Journal of Discourses.

In summary, the most intensive socialization in the life of the individual occurs between ages 3 to 5 . During that time he is vigorously taught that obedience is the only way to be happy. Once he learns to conform to the rules of the community, he is rewarded by his parents and teachers, and is ready to prove himself by participating as an active member of the sect.

\section{Grade School and Performance: Ages 6 to 12}

During grade school children are counseled to take the knowledge and talents they have been given by God and use them to benefit the community and their families. Children are encouraged to talk, when asked, in church, to recite scripture, to run errands, and to work on their own. Any money they earn is handed over to their father, who then hands it over to the bishop. Most of the child's day is spent under close supervision by someone in authority--teachers, principal, or a parent. At recess, however, she is unsupervised and spends time with her peer group or brothers and sisters. The children play in a large playground which they helped design and build. There is an elaborate swing set and slide, several basketball courts, a baseball diamond, a soccer field, a volleyball net, a jungle gym, hop scotch and four-square grids, and sand piles. Early childhood friendships are formed at playtime with brothers and sisters, and cousins and friends from the larger community. These close ties will continue into adulthood when brothers will be the leaders of the next generation of colony members, and sisters will marry within the community so as to help each other.

Peer pressure among age sets is an effective tool for propagating the laws of the Order. By exploiting the desire for acceptance, doubts about the Order's practices are overcome by offering a sense of belonging to an affirming community. Believing is a high staus marker among children ages 7-8, as they prepare for baptism which marks their 
official entrance into the sect. At this age, children are taught to have unquestioning obedience to fundamentalist authority. During grade school the child's actions are directed through praise or punishment without the use of conscience and guilt as motivators to act. Guilt is a factor in regulating their actions to some extent, but is more common with the older youths, who are more often taught to repent for their wrongdoings. Children here are involved in trying to please by memorizing scriptures, doing well in school, singing loudly, and obeying their parents, thus, furthering themselves in the system of achievement. Often, young children of 8 to 12 are asked to come up to the pulpit in front of all the community on Sunday to say a few words about their "testimony" in the form of an extemporaneous speech. This keeps children prepared spiritually and makes them conscientious about the sect's activities.

Children, ages 6 through 12, spend the majority of their time at the school/church complex. As mentioned, they have after school projects and duties to perform in addition to the homework and lessons they must complete before the next day. The Pines Academy is run by two men--Brother Doug, the principal, and Brother Bary, the vice principal. Under them are the female volunteer teachers and clerical workers. There are thirteen teachers: one-5th grade, three-6th grade, two-4th grade, two-3rd grade, one-2nd grade, two-1 st grade, two-kindergarten, two-Montessori, and two-nursery teachers. There are also a few specialty teachers for dance, music, P.E., and art. Time schedules for teachers are flexible and run on a year-round quarter system. School begins in the fall and lasts from August 1 to October 1, after which there is a harvest break. School is reconvened from October 20 to December 20, after which there is Christmas break, and so on. This gives the teachers and students a "new lease on life," according to Brother Doug. When they come back, the teachers are refreshed and ready to teach with "added vigor." The quarter system also allows women to take time off for childbirth and recovery, as there is always someone in the community who can substitute for a few months. 
All classes begin with prayer and the pledge of allegiance to the flag. There may also be a small vesper's program with a scripture and a song, depending on the instructor. Children rotate from class to class, just as in other school systems, learning about math, art, social science, English, and religion in one day. At noon, the children gather in the upstairs cafeteria for lunch. All bow their heads and bless the food before eating it. Since the children bring sack lunches to school, they often share or exchange sandwiches and treats with their best friends. School ends at $3 \mathrm{p} . \mathrm{m}$. with the tolling of the last bell of the day.

At age 8, the child goes through his second religious ritual--Baptism (prayer is considered the first religious ritual). He/she is examined by the bishop beforehand to assure that the child has been taught about the grave responsibility he is taking on, and then a date is set for the baptism. A spot is chosen, usually Sam's pond, and the child is taken, dressed in white, to walk into the water with his/her father, or another member of the priesthood. $\mathrm{He} / \mathrm{she}$ is then immersed completely for a few seconds and taken out of the water. The priesthood bearer who officiates, usually his father, bestows the baptism ordinance by the power of his personal priesthood, in the name of "the Father, the Son, and the Holy Ghost." This takes place on a Saturday. On Sunday, dressed in his/her finest, the child is "confirmed" a member of the sect by the "laying on of hands." At 12, the child is again interviewed by the bishop and during this meeting recites several scriptures chosen for him. He/she also recites "The Articles of Faith" of Joseph Smith found in the Pearl of Great Price, listed below. These basic tenets of the Mormon Church are utilized by the Pinesdale community as guides throughout their lives and are often repeated during sermons as reminders of how one should structure one's belief system.

1. We believe in God, the Eternal Father, and in His Son, Jesus Christ, and in the Holy Ghost.

2. We believe that men will be punished for their own sins, and not for Adam's transgression. 
3. We believe that through the Atonement of Christ, all mankind may be saved, by obedience to the laws and ordinances of the Gospel.

4. We believe that the first principles and ordinances of the Gospel are: first, Faith in the Lord Jesus Christ; second, Repentance; third, Baptism by immersion for the remission of sins; fourth, Laying on of hands for the gift of the Holy Ghost.

5. We believe that a man must be called of God, by prophecy, and by the laying on of hands, by those who are in authority to preach the Gospel and administer in the ordinances thereof.

6. We believe in the same organization that existed in the Primitive Church, viz. Apostles, prophets, pastors, teachers, evangelists, etc.

7. We believe in the gift of tongues, prophecy, revelation, visions, healing, interpretation of tongues, etc.

8. We believe the Bible to be the word of God as far as it is translated correctly; we also believe the Book of Mormon to be the word of God.

9. We believe all that God has revealed, all that He does now reveal, and we believe that He will yet reveal many great and important things pertaining to the Kingdom of God.

10. We believe in the literal gathering of Israel and in the restoration of the Ten Tribes; that Zion will be built upon this [the American] continent; that Christ will reign personally upon the earth; and, that the earth will be renewed and receive its paradisiacal glory [heavenly reward].

11. We claim the privilege of worshiping Almighty God according to the dictates of our own conscience, and allow all men the same privilege; let them worship how, where, or what they may.

12. We believe in being subject to kings, magistrates, in obeying, honoring, and sustaining the law.

13. We believe in being honest, true, chaste, benevolent, virtuous, and in doing good to all men; indeed, we may say that we follow the admonition of Paul--We believe all things, we hope all things, we have endured many things, and hope to be able to endure all things. If there is anything virtuous, lovely, or of good report or praiseworthy, we seek after these things (Pearl of Great Price).

After passing the bishop's interview, the 12-year-olds will then leave Primary (as they do in the Mormon Church) and enter the Young Men and Young Women's organizations. No longer children, girls are expected to further develop the skills necessary for motherhood and polish their talents in the home. Boys are ordained "deacons" in the Aaronic 
Priesthood, beginning to climb up the steps of the male authority structure by setting up for the sacrament and helping all other priesthood members. ${ }^{15}$

A central focus for the Pinesdale community are the talents of their children. Any skill that can be perfected by a child is said to be a medal on the father's royal vest. Because of this, most Pinesdale residents have a high regard for musical talent. Piano instruction is the basis of the music education program both in the home and at school. Many students practice their lessons daily from Carol, the piano teacher, and perform what they learn at Family Home Evening and school. ${ }^{16}$ If a child can read from the scriptures, say a prayer, sing a solo, or make a statement about his belief, this is considered a special talent and is rewarded with hugs and verbal praise from both mother and father.

\section{Youth: Ages 12-18}

It is in the Young Women's and Priesthood or Boy Scouts organizations that the girls and boys begin to separate themselves fully from one another, and the male-female subcultures are further distinguished. Now the young men are taught responsibility and a separateness from women through a mindset that requires men to watch over women. (As was explained in the ideology, this is an "ideal" for men. In reality, women care for men.) The young women are taught to be strong in testimony, to learn skills that will help them in marriage, to be excellent mothers, and to distinguish and separate themselves from the authority structure of the community. (Boys at this same age are learning to identify themselves with this same structure.) They memorize the following scripture and recite it aloud while standing at attention at the beginning of every meeting:

15 The "Sacrament" is a ritual not unlike the Catholic mass, where bread and wine (in this case water) are eaten by the congregation in representation of the body and blood of Christ. In Pinesdale, as well as in the Mormon Church, this ritual is a renewal of the covenants one makes to Christ.

16 Though pianos and poverty don't usually go together, in Pinesdale, families either inherit them from relatives, borrow them from the storehouse, or buy them cheaply at rummage sales. Pianos are important in the instruction of a child and must be included in the home. 
Let thy bowels also be full of charity towards all men, and to the household of faith, and let virtue garnish thy thoughts unceasingly; then shall thy confidence wax strong in the presence of God; and the doctrine of the priesthood shall distil upon thy soul as the dews from heaven (D\&C 121:45).

Young women and men now have increased responsibility at home, yet more freedom from constant adult supervision and scrutiny. As children, their parents and leaders molded and conditioned them; as "youth," they are ready to begin to act on their own. During this transitional stage from childhood to adulthood, the community recognizes the physical and emotional changes of their youth and utilize these changes to "build testimonies" in the youth. ${ }^{17}$ "A testimony is the most important possession a person has," one young women told me. "It is faith in the Lord Jesus Christ and in his teachings." With a strong testimony, the youth are taught that they can move mountains. In spite of this great promise, adolescence is a time of emotional vacillation, when the loyalties of the individual have not completely crystallized. Disregard of community rules and mores is expected during this period.

Since the adolescent is considered physically capable of a higher level of work, he is quickly incorporated into the community and family work structure, often getting jobs outside to help boost the family income. Again, the money they earn is handed over to benefit the family and community. Parents rationalize that their youth do not have much time between school, church, work to be moody or skeptical. In reality, their children are cynical about the Pinesdale lifestyle at this age--boys being even more cynical, showing less enthusiasm for "the principle," than girls. It is not surprising, then, that more young men than young women eventually leave the lifestyle.

17 There is a whole separate language used to describe the activities surrounding a "testimony." Since this testimony is a statement of one's belief and devotion to the structure, it is highly encouraged and promoted within the community. As a child, one gradually "builds" one's testimony. As an adult, one "strengthens" one's testimony. During Sacrament Meeting, all "bear" their testimonies, which is to stand and speak of one's faith to all present in the room, as with the orthodox Mormon Church. 
Pinesdale youths have a great interest in sports, school office, and extra-curricular activities, such as theater, leadership camp, and debate. In these activities, there is no sex differentiation. But in community and familial tasks, a separation exists. Girls are taught the old skills of stitchery, embroidery, and sewing, and often make their own dresses. Boys are apprenticed to the men in construction, furniture making, farm work, and leadership skills. Gifts from parents given to youth at this age are sex typed, hoping that girls will build their trousseau with their gifts, and boys will use theirs for future work in the community.

At all times the young person is subject to the control and influence of the community, family and peers. The community permits very little dating among the young people; thus, it is more common to see groups of young people together, skating on the pond, working on a project, or talking outside church after a meeting than a young couple doing those same activities. It is not uncommon, however, for an older man, from age 20 to 80 , to date a teenage girl, with the permission of her father and the matchmaker. ${ }^{18} \mathrm{By}$ requesting a dance at the town social, or by inviting her out with his family for a picnic, he is showing interest in her as a possible mate. Ideally, before any courting of this sort occurs, the man will be advised by the matchmaker who will speak to the father about it. Yet, many times, the natural attraction between a man and a girl, leads to ignoring some of the lines of authority and may proceed without an advising third party. At times, the third party will be the wife of the suitor who may encourage him to court one girl over another. Courtship will be discussed in detail under "Marriage and Adulthood."

Besides courtship, proper dress and conduct are the main concerns of Pinesdale young women. Clothing, jewelry and make-up for vanity's sake are frowned upon in most families. This would include tight clothing, loud, flashy colors, or any fashion which

$18 \mathrm{Men}$, both married and single, of any age may marry. For this reason, I have indicated a male age range of "20 to 80." It is not uncommon for an elderly man to take a young wife, though this type of marriage is more common in the Colorado City, Arizona fundamentalist branch than in Pinesdale. 
emphasizes the human anatomy. Low necklines for women, sleevelessness and shorts are considered unseemly and immodest. Even cutting of the hair for some is not allowed, nor are coloring of the hair, or excessive jewelry. Many times the scripture in Isaiah (24) is read to young women at their meeting to remind them not to forget their appearances.

...because the daughters of Zion are haughty and walk with stretched-forth necks and wanton eyes, walking and mincing as they go, and making a tinkling with their feet..."

Though physical punishment is uncommon at this age, peer and group emotional punishment through peer ridicule is common. The Sunday school program and youth programs do not let an individual forget who they are and their spiritual status as children of God. The Pinesdale United Order suggests that if any youth or child does forget the rules of conduct, the parents will have to compensate for this disobedience in some way.

If any child shall get beyond the control of parental direction and shall violate the rights or destroy, injure, or otherwise abuse or misuse the property of others, the parents shall be held responsible and shall compensate the Order or the individuals concerned for said destruction (Article XI:2).

Adolescence is a time for testing boundaries. Ideally, most young persons are eventually likely to grow to the point where they will reject the world and choose the community way of life. Some, mainly males, will, however, leave not only the community but the principle as well, either joining the Mormon Church, or leaving the religion altogether. A partial cause for leaving may either be the ridicule Pinesdale youth receive from their high school peers and from outsiders, or their own distaste of the polygynous lifestyle. More often, rebellion is caused by a lack of attractive role models for the young men, and a lack of a desire to "follow in their fathers footsteps." Boys seem to be more susceptible to outside ridicule than girls because the girls have set up a support system of their own early on in life. Yet, in spite of this support system, both sexes suffer from the ridicule. "They call us 'polygs' and make fun of us," said one teen. Often a group of 
youngsters will go to "Hardees," a fast-food restaurant, and sit and talk to be "more like the world." This activity is discouraged by the community. Most youth own radios and listen to popular rock songs, which are frowned upon, and others watch night-time drama on the television. The girls may paint their nails and dress in popular fashions, and boys may try a cigarette or listen to "heavy metal" rock music. In doing so, it is much harder for youth to turn away from the world. But all of these activities are usually abandoned after marriage.

Around the age of 16 , an age of accountability for both sexes, young members of Pinesdale are taken to a General Priesthood Council member for a "patriarchal blessing." This blessing provides a map or blueprint for life, if they remain true to the faith. It also reveals their true heritage as sons and daughters of the Tribes of Israel, stating which tribes they stem from. The blessing is personalized by the patriarch who gives the ordinance, and the youths are told what to avoid and what to look for in life. ${ }^{19}$

In a rare opportunity to drive a handful of youth home from an activity, I was able to ask several girls about their life plans. One girl said she wanted to be a doctor, describing how her sisterwife, whoever she would be, would tend the children at home. Another girl, obviously not on good terms with the first, said "Being a mother in Zion is enough for me." Another said she wanted to be a teacher, like her mother. Still another said it didn't matter, as long as she had plenty of children, a nice home, and a man who honored his priesthood. I then asked the girls where they intended to live. One girl said "I'll stay here; it's better for raising children." Another agreed Pinesdale was the best place to live the gospel.

The girls then joked about courtship practices. They agreed that there is subtle flirting among girls and married men. One girl said that Brother Maynard asked her to

19 Patriarchal blessings are given to Mormon youths as well, although they are not required. Within the Mormon Church and within Pinesdale, blessings are given by a priesthood holder who has been set apart as patriarch, which is a life calling. 
dance at the last community social, while his wife sat looking on. The girl giggled and said she was embarrassed, but also said she liked this man, and let him show affection in this small way.

All of these answers reflected the behavioral patterns I had seen in the older generation. These girls seemed more culturally secure than girls their same age outside Pinesdale. They all said the best place for them was in Pinesdale, even though the idea of going to college did appeal to some. Later that night, when I returned to the Harvey home, I asked a member about the young men and why so many had left the community. ${ }^{20} \mathrm{He}$ said more young women stayed because they enjoyed it more. The young men struggled with finding jobs, or finding a place in the male hierarchy. Some left because of a lack of responsibility, or a dislike of their father's way of life. For young women, the chance to bear children, nurture a family, and retain their female friendships was more likely in Pinesdale, so they were eager to stay. This is an important factor in female satisfaction later on; female lives seem more easily fulfilled through the practice of the "principle" than do male lives.

\section{Marriage and Adulthood}

Marriage is a measure of the success of righteous living for Pinesdale residents. The ultimate goal is to bear children who will eventually embrace the "principle," plural marriage, and propagate a belief in the gospel through bearing even more children and kingdoms of their own. Thus, when a son or daughter is "sealed" to another in a priesthood ceremony, that means they are serious about their religion and will soon be

20 The marriage pool can best be explained through a brief summary of the dimensions of the population. Since there are, on average, 50 percent males and $50 \%$ females born into the community, polygyny poses problems of a surplus of male spouses and a lack of female plural wives. In Pinesdale, however, there is a male migration, that is, the bachelor pool is decreased because a significant portion of the single men leave the ranch to live elsewhere. Because of this migration, Pinesdale continues to thrive in polygynous marriages with no surplus of male spouses, and an adequate supply of plural wives for those males who remain in the community. 
building their kingdoms, showing proper respect for priesthood authority. If one measures the success of Pinesdale in terms of socioeconomic terms, such as economic security, the mental and physical health of its residents, and the survival of the social structure, then Pinesdale is a success. Though it is much harder to describe the economic security of Pinesdale members, it is much easier to point to individual sociological health and security within the structure.

Marriage promotes the value of righteous women. The greatest female virtues in the male ideology are purity and fecundity ("purity" in this context means to be of righteous character, rather than of a physical virginity). Romantic love is not necessarily the model for selection of spouses in fundamentalist groups, rather divine inspiration plays a substantial role in the process (Driggs 1990). The matchmaker, the father, and the individual are responsible for the successful union of a man and a woman. All three rely on God to inform them as to who will be the best selection.

Courtship in Pinesdale is usually short, lasting from a few weeks to six months. There is a great deal of variation in the degree of secretiveness maintained and in the opportunity couples have to visit each other. Some couples are known by everyone to be going together--these are usually young couples. This kind of union tends to be celebrated more openly. When a married man courts an unmarried women, however, more discretion is used. One woman described the courting process to me with a smile. "We have some charismatic older men here," she said. She told me that many married men are anxious for a younger bride for childbearing purposes, yet some want an older one with more maturity and experience. The range of marital prospects in Pinesdale is wider and richer for girls than for men, as most of the older women are already married, unless recently widowed or divorced, and every man above the age of 18 , whether married or not, is eligible for marriage. The divorce rate is less than $2 \%$ out of a marriage pool of $95 \%$, because these marriages must be sanctioned by God through the approval of Melvin Harris, the 
matchmaker. One woman, Rachel, told me her 29-year-old son, already married to two other women, was about to embark on a new prospect. "He visits the young girl's home quite often. She likes him too," she said. Often girls will show preference for older, more mature men over boys their own age. One young woman, a beautiful, intelligent, school athlete, keeps "putting men off" so she can attend college. Rachel said her son already "tried her" but she refused to comply with his wishes, as is her right.

Kay Barker explained to me about her courtship with Tom, the kindergarten teacher's husband. When she was just out of high school, Tom, a 35-year-old auto parts salesmen, showed an interest in her, having made his mind up that she was the one. Tom already had a strong, beautiful, and opinionated wife. Kay, then, somewhat quiet, extremely well liked and kind, would complement her. The two wives do get along well and spend hours and hours a day talking, working, and caring for their three children. I say "their" kids, because after the children's birth, the wives try not to allot the children to one or the other mother. The children, Kay's eleven-month old and Janet's two children, one girl and one boy, each call the two wives "mother" interchangeably. "That's the way it should be," said Kay.

Kay and Tom's courtship began with long visits with the her family. Tom would drop by occasionally for an informal conversation, or join the family for the Wednesday night "home evening" program. It was soon apparent that marriage was on his mind. Kay told Tom she wanted to wait a year, but Tom did not want to. Since women have the full right of refusal of marriage, Kay took this privilege and stated that she would go to trade school for a year and then marry Tom, or else she wouldn't bother marrying him. During that year she and Tom and Janet, Tom's other wife, would go on dates together. The prospective wife always dates the senior wife as well as the husband, as she will be marrying her as well. Kay now misses those "good" times when the three of them dated together. "We never get out much anymore," she said. 
The essential approval of a proposed match is in the hands of the priesthood council through the matchmaker. Yet often, a husband will seek the approval of his first wife in choosing the next wife. In this way, to some extent, the senior wife exercises a degree of control over the choice of subsequent wives. Senior wives are in an excellent position to see that their husbands' future mates are both amenable and cooperative. In order to preserve domestic tranquility, as well as to provide a kind of social security for the less fortunate members of their families, women sometimes have recommended their sisters and cousins as polygamous wives for their husbands. ${ }^{21}$ Men of wisdom, who desire peace and comfort at home, frequently acquiesce to some degree of control by their first wife.

The courting procedure is as follows. In the case where a polygynist married man wants to marry a single girl (a common practice in Pinesdale), he approaches the matchmaker of the town, General Priesthood Council member, Melvin Harris. Melvin also has been "set apart," or officially sanctioned, to assure that the principle is propagated. The procedure of a girl courting a married man is that she usually gets friendly with the senior, or second wife. Some women told me that at this point, if she thinks she can possibly grow to love the husband, she tells her father, who tells the matchmaker, who tells the husband.22 If a man wants to, he may go to the father of the girl and ask to court the daughter. Then the father asks the girl. Sometimes, as in the case of one man, whose wife did not approve of the prospective wife, he will consult his wives about his intentions and

21 Though rare, an interesting element of Pinesdale marriages can be found in the mother-daughter cowive relationship. When a widowed or divorced woman is converted to the sect, she may bring with her an older daughter, with whom she is very close. If a man is attracted to either the mother or the daughter, the other will naturally request that he marry both of them. This will enable them to remain together and be provided for.

22 Romantic love, overall, is not a big factor in marriage unions. The first priority in securing a mate is their willingness to obey the commandments of God; the second, being fertility and a desire for children. Romantic love, if it happens, is coincidental to the purpose of marriage in Pinesdale. 
get their opinion before courting the girl. It is better to keep the remaining wives happy than look for more trouble, said one man.

Polygyny allows a woman to choose a husband (regardless of his marital status) to provide for her in the style she desires. She may choose to decline any offer, and has ample opportunity to find the most righteous, upstanding man in town. ${ }^{23}$ Though this may not always be a girl's criteria, it is recognized as the prudent approach among most women for a happy marriage. They learn early in their marriage that sexual pleasure and physical attraction is not the main point of their union. Girls, watching their mothers, learn this early on. If a woman shows interest, the man can hardly decline, as it is protocol to allow a woman the right to choose. Marriage, in some instances, provides a kind of upward mobility for women, a chance to achieve a higher financial and political status (through their husbands) not available to orthodox Mormons who are bound to the monogamous system (Kern 1989). Similar reasoning would dictate the selection of a wealthy man as a second husband, after the first one died. A woman's second husband will be a temporal consort, not necessarily as diligent in faith, but a good provider. On the second marriage, the desire for comfort is stronger. For unmarried women, polygyny allows salvation through a postmortem nuptial ceremony, that is a type of "ghost marriage" after death for those that could not find their mate on earth. Some older women, often mothers or sisters, are married for soteriological reasons, that is, solely for the salvation they will receive. To reach the highest kingdom, one must be married, just as Christ is married. Often, then, marriages take place which are not consummated, but are done for a woman's soul's sake (Kern 1989). Marriage is not based on passion, but on principle. Every women is required to have a man to be her protector. Widows who have lost their own eternal mates,

23 Marriage is basically endogamous, that is, spouses are chosen from within the sect, and so, there is some amount of inbreeding going on among relatives. Recently, Owen Allred has put forth a decree that no first cousins shall marry, subscribing to the scriptural reference in Deuteronomy 23:2: "No child of an incestuous union may be admitted into the community of the Lord." 
are given "proxy" priesthood heads or husbands, who could be a neighbor, a relative, or a member of the priesthood council. These "proxy" unions are not solemnized in a celestial marriage ceremony or consummated in any physical way--they are merely ways of providing priesthood blessings for all women.

According to the rules of the community, any wife whose husband dies must be married to her husband's brother, if there are no other prospects. This rule comes from biblical tradition where God commanded men to marry their brother's abandoned wife out of charity. For Pinesdale, it is more than just charity; it is preserving the wife of a brother, who is "sealed," or officially bonded, to her first husband, until it is time for them to meet again in heaven. This is known as a proxy marriage, though some men may decide to consummate that marriage by conceiving additional children with this new wife. ${ }^{24}$

The marriage ceremony takes place in a sacred spot chosen by the priesthood. I was never told specifically where these weddings occur, as they are sacred. The location is not of importance, as long as someone in authority conducts the marriage union. One woman said she had been sealed to her husband in the company of one witness in a hidden room in a building "somewhere," in order to keep the marriage quiet. ${ }^{25}$ In the ceremony, the husband is presented with the new wife by the latest wife in the holy grip, a form of handshake, that is sacred to the group. The hand is placed in his hand as a symbol of the Law of Sarah. In the Bible, Sarah gave Abraham her handmaiden, Hagar, to marry, because she herself was unable to bear children. Though the senior wife, or latest wife, whichever the case may be, has no choice in who her husband ultimately chooses to marry,

24 One case where this type of marriage occurred was with Brother Melvin and his dead brother's wife Eileen. Melvin already had three wives: Shelly, Hannah, Martha, and Elma. Elma died the year before of cancer. When his brother was killed in an accident, it seemed most correct to add Eileen to his family, and all her eight children.

25 Though it is more usual to have more than one witness at the wedding, the obscurity of the "hidden room" is common in plural marriage ceremonies. Since bigamy is a third degree felony offense, and men may lose their jobs if it is found out that they are polygynists, marriages are kept extremely quiet with only a few family members, other wives, and the priesthood authority who conducts the ceremony present. 
at the ceremony at least, she gives him the wife--a symbolic gesture of commitment to the bride and to the principle. All the other wives then place their hands on top of the wedding couples clasp and they are all sealed together for eternity. In this way, not only is the husband married to the bride, but each wife is married to her as well.

During the ceremony, which is the most important ordinance in the sect, certain "oaths and covenants" are made. These oaths involve several promises to obey the laws of the gospel, to obey the Law of Consecration, or the United Order, to obey the Law of Chastity, and for the wives, to obey their husbands and their God. The "sealing" which is a term to define the eternal bond between married persons, is an ordinance that calls on the "Holy Spirit of Promise" to assure that the sealings will be made strong and true. ${ }^{26}$ The priesthood garment, which is a white full length undergarment that contains symbols of priesthood powers and covenants, as well as reminders to walk in the straight and narrow path of righteousness, is often worn by those who have made the marital covenants. As noted, it was not devulged to me whether only those individuals who have entered the orthodox Mormon temples, such as the one in Salt Lake City, Orem, or Provo, wear these special garments or whether all who enter into the "new and ever lasting covenant" of marriage automatically wear this garment. In general, new brides who have not been through the temple do not wear this garment in Pinesdale.

Adult Socialization. The education of the adult continues, though less rigorously than that of the child, throughout the rest of his/her life. The adult attends at least five different church and town meetings during the week: Sacrament Meeting, Sunday school, Relief Society for the women, Priesthood for the men, board meeting for the men, council meeting and, prayer meeting every morning for all members, and Saturday project meeting for both men and women, depending on the week. The Sunday services function in

26 In D\&C 76:53 this promise is somewhat explained: "and who overcome by faith, and are sealed by the Holy spirit of promise, which the Father sheds forth upon all those who are just and true." For Pinesdale residents, this promise is an official sanction from God that they will be blessed in their marriage. 
teaching and reinforcing the beliefs the adults have internalized. Adults must set a good example at all times.

The education and experience of the adult male is influenced by power and prestige. The life of the adult female is influenced by common experience. Biological brothers and cousins cooperate closely among themselves and with their father in most areas of life, but do not form powerful bonds in and among themselves as a group. Competition is detected among the men for better comforts for their families, and better positions in the authority structure. Leaders are respected by all and so, naturally, most men seek leadership positions in Pinesdale. The very fact that they joined the community shows that they are individualistic and nonconformist with the outside world and the Mormon Church. The proud nature of men in Pinesdale makes it hard to bring them together in agreement with other men in the structure. By contrast, most women easily conform to the system because they see that it gives them what they want and need; children for their heavenly kingdoms, a husband that holds the priesthood, but doesn't linger around the house day after day; and sisterwives who can help with childcare, housework, food preparation, shopping, and emotional and spiritual needs. Male competition and female cooperation are significant factors in promoting female groups as well as explaining the general structure of family and community life. Men struggle to cooperate because their lives are so separated from each other by jobs and concerns. Rather than admit these concerns to each other, and ask for help, they remain proud and distant, whereas women more easily ask their co-wives and other community women for help and cooperation at any time.

Social controls in Pinesdale are based primarily on the individual's fear of being turned away at the gates of the Celestial Kingdom by God, or receiving a lesser glory than others receive. But they are also based on fear of rejection and ostracism. The adult member of Pinesdale has identified with the group, perhaps all through his life, and for his self-esteem, he needs full acceptance by the group. 


\section{Old Age: Enduring to the End}

With the ancient is wisdom; and in length of days understanding.

JOB 12:12

Within Pinesdale the aged are also asked to contribute their time and energies to the community. They are asked to babysit or teach, tell stories, sew quilts, make cookies, or build toys for the young. Grandchildren take up most of their time, as mothers often will "drop them off at Grandma's" on their way to the store, or to the school. The aged are also busy preparing themselves for their entrance into another life. This involves doing Christian deeds, reading the scripture, tracing their genealogy, teaching classes, and repenting of all life's wrongdoings. Growing old is done without fear of death, but a longing, and a curiosity of what comes next.

As with every stage--baptism, marriage, childbearing, loss of husband, loss of sisterwife--older women have a common ground with those who have had their same experiences in life, who are about to go with them through the next stage.

The socialization of Pinesdale is a powerful system of commitment and obedience to the laws of the Order. All ages--from toddlers to grandparents--must obey these laws, and are taught to value the strict adherence to the principles of the gospel all their lives. This obedience is a reflection of years of doctrinal conditioning on the rewards one will receive in the next life, and the eternal grief if one does not succeed. For men, the years of socialization are precarious, as many of the male youth will end up leaving the sect. For women, who enjoy their part in the community and have built strong, spiritual bonds with their female age set, socialization is an unquestioning, necessary road to salvation, one that is rough with sorrows, but rich in blessings.

In summary, socialization patterns promote female solidarity through common experiences in childbirth, religious conviction, motherhood, and homemaking. From birth to death, females are taught to work with each other to "build the kingdom," and to share 
all that they have to their co-wives. As toddlers they learn to share toys and the attention of their mothers and fathers, and as grade-school students they share testimonials and experience the peer pressure of religious conviction. As teens they share in preparation for marriage and their future homes through the exchange of skills, stories, and spiritual support. And, at old age, they share in their preparation for death, where they will continue to relinquish part of their heavenly kingdom to their sisterwives. 


\section{CHAPTER V}

\section{NETWORKING: THE FEMALE REALITY}

Give her of the fruit of her hands; and let her own works praise her in the gates.

PROVERBS 31:31

...thou art my sister: that it may be well with me for thy sake; and my soul shall live because of thee.

\section{GENESIS 12:13}

This chapter, illustrates how daily living and female association yield stronger and more stable bonds between females, than it does between male-female, or male-male relationships. An analysis of female networking will be given in the chapter's summary. I hope to show in this chapter that though males hold formal authority over females in Pinesdale, the relations between the sexes are shaped by a culturally defined and separate division of labor, not on any biological inherited propensity. Women are seen to maximize the benefits of the ideology, polygyny, their kinship, economic networking, and the social structure in order to achieve the comforts and necessities of life for themselves and their children. Women more readily achieve these goals through the female network than through interaction with males. The following pages examine how this network functions for Pinesdale women.

\section{NETWORKING: HOW DOES IT WORK?}

For the purpose of this thesis, I have defined "networking" to be the reciprocal exchange of material goods, tasks, labor, ideas, and experiences between members of the same cultural category (women). In the case of Pinesdale, networking's purpose is to 
allow for social solidarity, for economic stability, for spiritual exchange, and for companionship. This definition was built upon Keesing's term "cultural category," a set of entities in the world that are classed as similar for some purpose, because they have in common one or more culturally relevant attributes (1935), and upon Marcel Mauss' term, "the gift," which is a principle of reciprocal exchange based on obligation, motive, generosity, and morality (Langness 1987). Networking of one type or another among women has been known to occur in cultures all over the world (Stack 1974, Draper 1975, Murphy et al. 1974, and Leis 1974), and is prevalent in the urban Black community, as well as in West Africa. It is also prevalent in Pinesdale, Montana.

\section{Communal versus Co-wife Networking}

Within the community of Pinesdale, there exist two types of female networking, which, for the purpose of continuity and ease of understanding, overlap in some places, and run together in others. The cooperation and close networking that occurs in the community, whether it be among the women in general or among sisterwives is of equal importance to my thesis question. But for the purpose of clarification, I will be separating the communal cooperation of Pinesdale women from the cooperation of co-wives to illustrate how both differ, without taking away from their collective importance in the study.

The confusing aspect about female cooperation is that it occurs without discrimination across co-wive and community women ties. Because there are so many strong links to female solidarity--kinship, residence, polygyny, ideology, economic need, emotional support, childcare, common experience, etc., there are numerous ways in which women meet and help each other. The most common of these ways, is found within cowife relations. There is no doubt that these relationships are the strongest bonds formed in the community. Co-wives meet daily to exchange tasks, such as childcare, food preparation, house cleaning, or shopping. Whether they live in the same household or not, 
these activities among co-wives occur with remarkable stability. The co-wives also share things that they cannot share with other women, such as their husband, his secret habits, his priesthood, his blessings, and the jealousies and personality conflicts that arise when two women run a household. It was my impression that even the later of these things strengthens the sisterwife bonds. ${ }^{1}$ There is also the compelling factor in the networking system of one co-wife being officially and ideologically "married" to another co-wife that wields strong bonds among sisterwives.

Yet, community women in general have significant bonds that are almost equal to the co-wife bonds. These bonds, though second to the sisterwife bonds, are still stronger than those made with the men of the community (including one's own husband). Women by relation, residence, church affiliation, childbirth, stewardship, or employment, form strong bonds with other women in the community, and work closely with these women on community projects and, at times, household projects. It is not only the sisterwives who work together on home canning or quilting. It is not only the sisterwives who exchange childcare duties. Because women in the community are also "sisters," that is "sisters in the gospel," they are considered nearly as close as a true sisterwife would be to another woman. Women in general, often will share in the economic networking of the community, as well as the healing and praying rituals of Sacrament Meeting, the delivery room, and their own testimony meetings.

The important aspect of both co-wives and community women in general in Pinesdale is that they share the practice of polygyny, which reinforces them as wives, mothers, and friends in the community. By polygyny's very nature, these women are

1 I heard countless stories of women who had trouble at first coping with the fact that they had to share their husband with another woman and work with that woman on a daily basis. In each case, the women described how they overcame their jealousies, "with the Lord's help," and became best friends with that woman. It seems, from informant response, that the very fact that women had problems at first, caused them to arrive at the resolution that they had much more in common with this other woman than they had with their own husband--which strengthened the relationship. 
forced to rub elbows with each other in everyday life, in motherhood, in homemaking, and in religious worship. They use their own language, and know just how to manipulate each other gregariously through communal sharing and service.

\section{A Woman's Day}

The basic operation of the female network, regardless of whether it occurs among co-wives, community women, or both, can best be seen during an average Pinesdale day. The following schedule of a woman's day differs somewhat from the general daily schedule of Pinesdale life, as mentioned in Chapter III, in its emphasis on the sharing and cooperation among sisterwives. It illustrates more clearly how women work together in a household to meet the needs of their families and themselves. One can see in this setting how the household activities revolve around four wives, their food procurement/preparation and childcare duties, and their two-hour mid-afternoon gossip sessions.

Meg rises at 6 a.m. to nurse her nine-month old baby girl. Sally, her sisterwife, who lives in a basement apartment of the same house, rises at 6:30 to wash the floor and begin breakfast. The rest of the family are awakened by the mothers at $6: 45$ to dress quickly and be at community prayer at 7 a.m. At 7:15, back at home, all kneel in a second prayer, facing the Salt Lake temple to the south, after which Sally serves breakfast to Meg's two kids, five of her own, and their husband, Joe. Meanwhile, Meg is dressing for work. She leaves at 7:30 a.m. Joe makes alternating visits with four wives: Meg, Sally, Kathy and Barbara. His routine requires him to stay with Meg on Monday; Sally on Tuesday, Kathy on Wednesday, Barbara on Thursday, and so on. On Mondays and Tuesdays, then, he eats breakfast with Meg and Sally, as they live in the same house. At 7:45, Meg gets Joey, her two-year-old, dressed, drops him off at Montessori, and leaves the ranch for Hamilton, where she is an accountant at the hospital. Sally cares for Meg's two kids and her own two-year old at home, while the rest of her kids are driven to school 
by Kathy. Sally then begins the housework and prepares her lesson for her fifth grade class which starts at 1 p.m. At 11:30, after all the housechores are completed, Sally feeds the young children in her care and gets them ready for nursery and afternoon kindergarten. At 3 p.m., when her classes are over, she picks up the kids and goes shopping at the Pine Mercantile for the evening supper. At 5 p.m., Meg returns from Hamilton, having picked up the extra household items for the following day and begins preparing supper, as it is her turn that night. She and Sally rotate supper and a few household chores every other night. In the evening, when Joe comes home, and dinner is over, there is the family evening sermon, conducted by Joe, and all sing songs and Meg tells a story to all. Sally helps her teenage daughter, Martha, with her algebra assignment, and then heads downstairs to bed. Tomorrow, a Thursday, Meg and Sally will go to Relief Society at 7:30 p.m., sewing costumes for the school play, and a short sermon on childcare will be given by Sally. The younger children will be watched by either Cindy or Barbara, the two oldest children in the house. Joe will relax and read scripture until they return. It will be Meg's turn to invite Joe to her bedroom. It will be four days until the next time they spend the night together.

During the summer Sally has a great deal more work. Cleaning is much heavier in the summer because the children and adults track in dirt and mud and there are a lot more food procurement activities as well as community, work to do. It is an unusual weekday in the summer when the women have no community or house work. Meg's working schedule changes, too, during the summer. She works only mornings, enabling her to help can fruit and vegetables and gather herbs with Sally and the other wives in the afternoon. The four wives work long hours in the summer months, often rotating childcare every other week to complete personal or familial projects. School is out and allows more time spent in the home environment. Since Meg's work hours are cut short in the summer, Joe works overtime to compensate for the small loss in income, and is rarely home in the evening before 7 p.m. 


\section{Female Work Patterns}

The daily schedule of the sisterwives described above gives rise to a number of questions. What type of work do women do in the community, home and marketplace, and do these jobs overlap? How do women have a job, raise a family, fix meals, and conduct community work at the same time? The answers to these questions are shown in the patterns of female work described below. Because women far outnumber men, they perform a larger variety of tasks in and outside the community. In all cases they are responsible for the care of their children, whether they share that care with another woman or not. Most women rotate in their callings and duties every several years or months or when ill. Certain women, though, have nonrotating positions of responsibility assigned to them. Among these are the storeclerk, the post office clerk, the herbalist, the midwife, the school secretary, the adult Sunday school teacher, and the librarian. The most influential position in the network is that of midwife. Not only does she deliver all the children of the community, but she has a special talent of rallying women in the network during emergencies such as accidents, illnesses, or other serious incidents.

I have indicated that at the school women cooperate in order to run it properly. The scheduling and rotation of female workers, as handled by the male/female board of education, is more rigid than anywhere else within the network, and succeeds in providing quality education for the community's progeny. Because the networking of the school works on a quarter basis, women who are expecting children, or have other familial or communal duties outside the school can stop working for a season. The network rotations of positions are based on an informal arrangement of need--when someone is in need, someone is provided to fulfill that need. If someone is needed to operate the library for one afternoon, a substitute librarian is quickly found. If the 6 th grade art teacher is sick for a week, another mother interested in the same subject is notified to fill the position. All special skills--artists, secretaries, bookkeepers, etc.--are found in several persons so that 
rotation and substitution are easily accomplished. Some women at the school work overtime teaching their sisterwife's class as well, when their sisterwives are ill or on vacation. Childbirth and teaching are the two most important female duties in the community, so scheduling is designed around these two activities.

Though female work patterns are basically traditional--cook, clean, care for children, etc.--they are modified by informal consensus of the women usually under the direction of the senior, or first, wife. They are also modified when finances are too low to sustain a family, and one or two must work outside the home, while the third or fourth wife cares for their children. It is here that one can see the true virtue of the female network--flexibility. When women are willing to adjust to do different sorts of tasks during emergencies (which seem to be frequent), shortages, additions to the family, deaths, or merely, when asked to do so, there is no break in the continuity of the flow of family resources and the achievement of necessary tasks. Anthropologist Mary Catherine Bateson describes this type of flexibility and the conflict that women in general have between work, home, and family.

...women have always been torn. We forget that when a woman who's been married for a period of time gives birth to a baby, she has to serve two masters. She has to respond to two different kinds of needs. Then she has a second baby. She's got one baby at the breast and one baby on her knee, and they're quite likely to be quarreling. So the traditional feminine roles as wife and mother of multiple children have involved caring for multiple issues, balancing them off, not neglecting that while you're caring about this, having one rhythm to respond to a husband and another one with an infant and another one with a growing child.

This is what it is to be a woman. And this is what it is to keep a household going, to have multiple skills, to deal with transitions to deal with the health of the whole. There is a sense in which women have retained the capacity to be generalists, to live in an ecology in which there is more than one life and you have to balance them off...(italics mine, Moyer 1989).

The network works in other ways to provide for the family and the community. Frequently the community will have special dinners in the church dining hall, where several women will prepare all the food for several hundred people. Several years ago, five to ten 
women would rotate each night to prepare food for the evening community meal in the school cafeteria. All would gather at dinnertime every night. The town stopped having this dinner, however, due to an increase in the population, making it impossible to feed 700 people in one sitting. In other ways, the network would be given assignments that require a large group of women to collectively sew several quilts, items of clothing, or cook several meals for someone in need, or a new member of the community. The president of the Relief Society, the women's organization, will call on and organize these services.

In addition to their community and marketplace work, each woman must keep her respective apartment, home, or rooms clean and maintained. At times, when one women is working all day nursing or teaching, her sisterwife will clean her rooms for her while caring for her children. This sisterwife will receive an equal split of the working wife's salary and so her services are not completely charitable. Each woman usually does her family's washing, and does the shopping, unless she rotates this service with her sisterwife.

The central maxim in working patterns--whether at home or in the marketplace--is that an increased number of wives provides for an increased leisure for the individual wife. Because polygynous women distribute tasks--those same tasks that one monogamous woman would be performing alone--there is simply less work done per person. ${ }^{2}$ This is in contrast to the long 10-hour days, and often when meetings are held, 13-14-hour days the male head puts in per day. In short, female networking provides Pinesdale women with more time per day to fulfill a variety of tasks. It provides them with more visiting hours, and more time to nurture children. It also provides them more time to develop their own talents and hobbies. Most importantly, the network brings them together in a tight-knit female group, where women associate and mix with other women in mutual aid and worship.

2 See the section on economic contribution in Chapter VI, or read Singh et al.'s study of the value of work-at-home and contribution of wives' household service in polygynous families (1987). 
The Victorian role of women still exists in theory inside the ranch. Women are supposed to be mothers and housekeepers, but in reality, they are forced to be independent because of the frequent absence of their husbands, and therefore have an opportunity to broaden their scope of tasks according to their interests, talents, and needs. A woman who seldom sees her husband can't expect him to settle every squabble or right every wrong. If something unexpected, like an accident or household problem occurs, she has to handle it alone. Many women learn to do small repair jobs; many have to make snap decisions on their own. They are businesswomen, figuring out each month's meager income and how far they can stretch it through small inputs and large outputs. They are teachers, mostly having large families and a rotation schedule sometime in their lives to work at the community school. They are employees in the market place (at least $75 \%$ of the women have or have had in the recent past some form of outside-the-home work), bringing in a significant part of the family's total income. And they are producers of children, giving birth collectively to at least $40-50$ children a year.

When one compares monogamous and polygamous wives in a contemporary setting, it is easy to see that more polygynous wives work outside the home, either in community work or marketplace work, than do monogamous wives (Murphy et al. 1974). And those who do not work for wages help support their families by frugally budgeting the goods their husbands provide them. Polygyny in Pinesdale, as elsewhere, develops independent women who bear much of the financial responsibility for their families (Goodson 1976). As a group they are seen as both good mothers and good providers, good teachers and companions, good cooks and good seamstresses. A common thread runs through all women in Pinesdale that is an integral part of each woman's psychological make-up. A Pinesdale woman is extremely thrifty and hard working. She has learned this through budgeting her scant resources. She is also more apt to have "a strong testimony" because she has gone through persecution from the law (by being a law breaker) and the 
outside world to be different. She learns to speak her mind in defense of herself and her own children.

The Pinesdale division of labor among sisterwives was mentioned in the school networking system. Yet it works just as well in the home. Women will divide household and shopping assignments occasionally, mostly working together on special projects while running their house separately. Since women's specialty talents are high in demand in the community, wives often are known for one thing and are asked to do that one thing in the family and in the community. For example, Katie is a specialist with medicinal herbs and so when someone has a problem with diaper rash or poison oak, they call for her special poultice, etc. And Mary is a specialist in first aid, so if there are any bad cuts or broken bones, she's the one to call. Karen is great at making deals; she is always coming home with the best buys in all of the Bitterroot Valley, so naturally, she buys the bulk food for the family. In this way, wives receive positive feedback for finding tasks to their liking and helping provide for the family with their talents. ${ }^{3}$ It gives them a sense of accomplishment and lets them know that they are contributing a vital part to the functioning of the whole.

\section{Visiting Patterns}

Most social interaction among men occurs in church and civil meetings; after job, chores, and church responsibilities are completed, there is little time for visiting. For

3 What Arrington said of pioneer Mormon women could also, to some degree, be said of Pinesdale women, "Mormon women were probably more independent than most Western women. For one thing, the men were often away on missions of one kind or another so that the women had to provide a livelihood for themselves and their children, as well as send occasional expense money to their husbands. For another thing, the practice of plural marriage insured that, in the case of many families, the husband could not manage his farms and other enterprises on a day-to-day basis; this had to be done by his various wives and their children. The women often had cooperative "bees" to build houses, canals, and fences and to make quilts. Finally, the inhospitable nature of the Great Basin and the isolated character of most of the settlements must have required women to be more self-reliant and self-sustaining than settlers in less harsh areas (Arrington 1971:23)." 
women, the social interaction is extended to household, community, and school working tasks, as well as gossiping at the store, talking long hours of the day on the telephone, chatting at church meetings, and taking outings and shopping trips at various times during the week. Women combine visiting with work and thus have more social contact with other women. Formally, women visit other women under the auspices of a religious duty in the Relief Society organization called "visiting teaching," where two women will teach another woman pre-assigned doctrinal lessons once or twice a month. Informally, woman meet with other women at least three different times a day in a number of different ways, 1) to pick up or drop off a child at school or childcare, 2) to plan, or budget, or organize some community or family event, such as dinners, parties, home improvement, food preservation, or some other house project, 3) to plan, or organize some religious function or activity, such as Primary, Sunday school, Young Women's, Relief Society, or testimonial, 4) to visit-teach, 5) to talk or gossip on the roadside, at the post office, or at the Pines Mercantile, or 6) to meet together by nature of living together under the same roof--in cooking, cleaning and childcare tasks. The paths of these visiting patterns vary, but on the whole, they follow the direction of other sisterwives' houses and quarters, the school/church complex, and the post office/store complex. The amount of visiting among co-wives is much more than among women in general, but because of the extended need for economic, social and religious services, there is a great amount of visiting among female community members whether they be related by marriage and/or blood, or not. 


\section{Religion and Married Life}

Look forward with one eye, having one faith and one baptism, having [your] hearts knit together in unity and in love one towards another.

\section{MOSIAH 18:21}

The emphasis on egalitarianism and cooperation in the Pinesdale ideology is an important factor in the organization of the female network. Women's religious experiences have been underestimated in much anthropological literature because it is believed that women are prisoners of a male religion (Christ 1980). I do not want to be guilty of this same offense. To reiterate my point, women are members of a religion that is theologically dominated by males. This does not mean they are misled in their belief, or cajoled by men to believe in a certain way. Women in Pinesdale are devoted members of the religious sect because they have a spiritual communion with other women who believe as they do. According to Karen Sinclair (1986), women's position in religious systems is often a reflection of women's status in society, yet religious experience frequently establishes a dimension that is absent in the more restricted secular lives of most women. Because the women are unable to be involved in the higher priesthood ordinances and authority structure of their religion, they must establish a level of religious activity in and among themselves. A more accurate statement about women and religion would be to say that the religious experience of Pinesdale women differs from that of men. Spiritual occurrences inevitably effect a separation between religious preoccupations and daily domestic concerns. Even in less restricted circumstances, religious participation often provides a means of achieving female solidarity. Ideology, then, as it is used and distorted by women for women, is a crucial factor in how women's networks get organized and helps explain in part why they have succeeded so well in the community. Not only do their groups not threaten the male structure, but these women are completely condoned for their actions by that structure. 
Through their belief and commitment to the gospel, to their children, and to their royal destinies, women are unified and strengthened in sisterhood. Pinesdale women have a tight circle of sisters who share in a desire to emulate their Savior, Jesus Christ. They are able to make covenants of righteousness, and participate in motherhood, the highest calling. According to their own ideology, women who give service selflessly will earn the highest reward--a reward that is found in the highest kingdom of the highest glory, where only love and harmony exist, in the presence of God. This tenet supports continuous service among women. Women in Pinesdale also rely heavily on their "faith"--faith in Jesus Christ. This faith states that good will conquer evil, that God is real and His kingdom of heaven is a beautiful place where friendships are renewed, children are protected, and blessings bestowed. This faith allows them to rally the strength needed to remain true to the community, their children, and their husbands. Seeing other women in the gospel stand up in church meetings to tell others about their convictions of "truth and righteousness" is a powerful peer tool in uplifting women--each woman becoming part of a continuing round of strengthening and being strengthened. These testimonials are a vital aspect of women's involvement in informal ritual, and will be discussed further in Chapter VI.

\section{THE SISTERHOOD}

\section{Informant Responses to Female Networking}

Sisterhood to Pinesdale women has a variety of meanings. To women in general, females of the sect are their "sisters in the gospel." To women who have married the same man, their co-wives are "sisters in marriage and covenant," "sisterwives," and, most often "natural sisters," as most women are consanguineally related to their co-wives even before marriage. This last section of the chapter is a sampling of informant responses to questions dealing with the female network system, more commonly known as "the sisterhood." The 
comments are arranged by subject, covering various aspects of female solidarity such as, work, children, spirituality, home management, and family life. In light of the large number of young and old women who remain in the community, the positive nature of women in Pinesdale is understandable. It is not the women who leave the community. Pinesdale women obtain psychological, economic, and spiritual nourishment from their sisterhood. They could rarely get this any other place, believing as they do.

Work and Economic Well-being. Jane stated that the community itself would not be sustained without sisterwife cooperation. She said the school would not stand without this cooperation. She said that women do community projects that are just as important, though not as visible, as those of the men. They help fix up the insides of new houses, repair, sew, bake, care for the sick, cook supper for a whole family for a week, can fruits and vegetables for several wives for the entire winter, and care for others' children. She personally cooperates with her sisterwife by sharing every item and household good in the house. The income provided by her sisterwife, who works as a store clerk and her husband who works in construction, is enough to sustain them financially. Jane's part is to care for the children, and maintain the home. When her sisterwife works the nightshift, the kids are under Jane's care, and when Jane teaches kindergarten at the school, once in a while, her sisterwife watches her kids.

Home Resource Management. One woman said that because the co-wives share in managing their resources, i.e., share gardens, supplies, childcare, housework, etc., the homefront is organized and sustained with adequate economic goods. A wife can contribute in many ways--working outside the home, management of resources, maintenance of home, procurement of food, and childcare--all of which count toward economic increase.

Another woman, Gretchen, told me she has five kids, and her sisterwife, Susan, has three kids, all living in the same house. She enjoys her sisterwife's companionship 
and cooperation. They rotate meals and house cleaning every other day. Sometimes, they rotate by week for variety, or when something comes up, such as post partum depression. On nights when Gretchen is free, she spends time with other friends, goes to a movie, or just reads at home. "On the night I must cook, I feel like cooking. I feel refreshed and ready to do a good job," she said. Weekly, Gretchen and Susan sit down and do the budgeting. Gretchen further explained:

We have $x$ number of $\$$ for cooking, $x$ for clothing, etc. We make a menu plan for the month and prepare a grocery list. Since Holly likes to stay at home and I am a goer, I do the shopping, while she watches the kids. We structure our lives and our children and our homes together. Its easier that way. For home maintenance, I was teaching first grade til noon in language and reading. We both had young infants and so she would tend and do light housekeeping during those hours. Then we would eat at noon together and she would teach my same first grade class social studies and math from 1-3:30 while I tended and did cooking for dinner. We both were able to give the time and care our young babes needed.

Ilness. Childbirth. and Loneliness. Another woman described her cooperation with her sisterwives as the following. She raises their children the way they would want her to, and they maintain the home and bring the supplementary income needed to sustain the household. In addition, one sisterwife cooperates by being the family pediatrician (her kids are always sick, so she keeps a stethoscope and ear probe in her home), another is the trauma or blood nurse, another is "wonderful" at soothing children (when one wife's girl got hypothermia and couldn't warm her up, the other could), and still another is the storyteller of the family. In all, she said, "our children get the best care any one mother could give, because we are four mothers doing the job."

Paula said that when she was in the hospital for two weeks, her sisterwife took over her household duties, and looked after her children. She said this type of care was expected since she had previously waited on her sisterwife during her confinement and after the birth of her seventh child. Anytime one of her children is sick, she takes him/her 
to the midwife for remedies. Her sisterwife is experienced in first aid so she has at least two women to turn to in the event of an emergency.

Friendship. Companionship and Empathy. One woman commented on her first encounter with the Work and her conversion to it because of her sisterwife.

My sisterwife, Erica, is just as much a part of me as my husband. I am married to her, too. We are "one flesh," and I wouldn't dream of hurting my own body. I met Erica before I met my husband. She introduced me to him on campus and suggested we marry. I had been dating for years, and was getting older. I was tired of looking. When I met him, upon the request of my future sisterwife, I knew he was the one for me. So in this way, sociologically, it gets rid of old maids. We had meetings together, lessons on the doctrine and fell in love. Now I'm talking about my sisterwife. Whereas Mark [her husband] didn't show me any romance-kissing, etc., Erica did a lot of hugging and kissing on the wives' part. She romanced us more than Mark did.

Sarah and Debbie, wives of the mayor, spend Sunday evenings gossiping-reinforcing their own position in the community and their own relationship. In spite of the fact that Sarah's husband of 35 years has taken this other women to be his own, she is extremely open and friendly with her. They spend long periods of time on the phone talking about the important things in life--children, food, and comforts. Dialogue between wives is the key to making female networking work. Men don't experience dialogue; said Debbie, they talk at each other, listening to their own voices. There are exceptions where some women try to keep to their own business, but this is usually sex business, they share in almost every other way. This dialogue is essential between wives and other women in order to function. As far as I can see intelligent dialogue between man and woman doesn't happen as much as between women-women.

Friendships do not always emerge among wives immediately. Patty recalled that when she first married Larry, Sandra's husband, she found that Sandra did not want this union to be made. For the first six months, Sandra refused to speak to Patty. Since Patty admittedly did not marry Larry for romantic love or emotional support, but for his testimony of the principle, she especially sought a friend in her first sisterwife--someone to 
talk to. Sandra finally came around and now is good friends with Patty. They work together closely at the school. After a year of marriage, the two women cooperated on canning and food preparation projects. Yet, they still had some differences to "iron out." Then, when Larry died the two were always seen together and became the best of friends. After Larry's death, Patty was left a widow with five kids, the oldest 12, the youngest 18 months. Brother Howard was chosen to propose to her, and she accepted.

Some wives modeled their relationships with each other as a mother-daughter dyad, where the older wife instructed and patronized the younger wife, still young and inexperienced, in need of counseling. When the older wife is then older and ill, the younger will care for her. Some wives, closer in age and personality, will become instant friends, often having promoted the marriage of their best childhood friends to their husband. These close wives will often form unions opposing their husband, or at least tease him and play practical jokes on him. One women said, "we love each other more than sisters. We know we will be together throughout Eternity. No quarrel is worth ruining that."

Spirituality and Religious Conviction. Almost every Sunday, during the meeting of the Sacrament, several women are called to stand up and bear witness to their beliefs. Sometimes women volunteer to stand. On the second Sunday I was in Pinesdale, two women were asked to speak. One woman, in her twenties, mother of three, spoke ten minutes about her sisterwives. She pleaded with the Lord to bless them and keep them from harm. In closing, she admonished all women to do the same.

Another woman got up and bore her testimony of the Spirit of Christ, which accompanied her throughout the day. She seemed to speak mostly to a row of women, her sisterwives, in front of the pulpit. She said that she had witnessed many miracles in her life, and would never deny the truthfulness of the gospel. Throughout the audience, women's eyes seemed to glisten with tears as she began to cry. She lost her voice, she 
was so excited. This type of belief ritual is common among women. It is common knowledge in Pinesdale that more women experience emotional outbursts in the meeting of the Sacrament than men.

Family Commitment and Childcare. One woman said that without voluntary networking among co-wives in the home, the children would not stay in the "principle," if the children happen to be born at all. ${ }^{4}$ Women, according to the biblical Sarah principle, must agree to share their husbands with other women, this is voluntary. Because of this, more children are born and raised with the desire to perpetuate this experience. In addition, because women cooperate, the community is able to sustain new generations of committed residents.

One woman said that in order to reach salvation, wives know they must cooperate. Most don't have to struggle to do this. One has to have common interests. One often may have no choice who your husband marries. He has to be attracted to the girl, unless one is very persuasive against it. The women said that when she joined she found that "the hardest thing is not that your husband is sleeping with another woman, but that he may be spending more time with her kids." Women will fight more over him for their children than for any other reason. That is why the sisterwives organize their husband's time so well, she said. It must be that way to keep all satisfied.

Another women said she would give anything to keep her children with her for eternity. She said that if anything happened to her, she would rely on her sisterwife to care for them until she would meet them in heaven. Her family, she said, was the most important thing in her life.

Political Asylum, Freedom, and Solidarity. Patty, a convert of the sect for 20 years, was described to me as a women's libber. She is the town's adult Sunday school

${ }^{4}$ Since it is more common for women than men to suggest having another child, women are more in control of the number of children they may or may not have. Women can arrange their sexual schedules to be more conducive to childbirth, or less conducive to childbirth. Men have no control over this area. 
teacher, a member of the town council, the board of education, and the Young Women's program, and tends to be the expert on the sect's doctrine, pronouncing her findings to both men and women. She told me she is determined not to let any man override her without the proper priesthood authority and through the proper channels. She is opposed to the seven-man board, and general all-male board, stating that there is no reason for an all male board. She thinks that women ought to be able to discuss youth and delinquency issues at the board meetings, but women aren't invited. Women know more about certain things and could easily solve the problems, she said.

One woman spoke of the freedoms and opportunities given to polygynous women. She said that when she was a girl, she wanted to be a mother and a teacher, and in the Work, she was able to do better. She said she wondered how she could be a proper mother and a teacher outside the principle.

To me an answer to my prayers was to be able to have a family, a job, a husband, and a sisterwife. I am a total woman. I could never have done what I do here in any other community. Here I am a homemaker, a teacher, and a mother, too. I love it. I have more freedom to spend doing things for my personal growth, because Sherry (her co-wive) allows me that privilege. When Bill (her husband) is home I am able to then concentrate on him and his needs and not be preoccupied with my loss of time. Sherry has him one night--my night for freedom from him. Then I have him the next and am ready for him, to care properly for him. The kids after a day away from him are then anxious to see him. Men have something in their characters that demands attention, good food, and the focus of their wives and children. Polygamy allows this to be quenched. Monogamy can't do that. We live now in a separate house. I love my sisterwife. We are friends and family too. We shared childbirth. She is a truer sister than my natural sister. We are bound in hearts.

Patty told me that polygyny makes the total woman--she can be anything she wants to be. In monogamy you are tied to a husband for sustenance, entertainment, conversation, comradeship, etc. But a polygynous wife is free and independent by necessity and makes her ties with other women. "When a (monogamous) wife doesn't have him (the husband) around, and with no other sisterwives around, she is helpless. Where does she get the friendship, the moral support? A polygynist wife has it all," she said. 


\section{SUMMARY OF FEMALE NETWORKING}

According to female informants, the most important function of female networking in Pinesdale is to provide for the sustenance of the dependent young and form the setting for the socialization of the community. ${ }^{5}$ Yet, my observation of the network suggests that the network provides a valuable economic exchange system for women to cope with the tasks of managing their households and feeding their families. It also functions to provide an alternative to the priesthood powers that the men wield. The networking of women promotes female solidarity, and emotional stability. After being submerged in the company of dozens of caring women for several weeks, I found suburban, monogamous, Portland to be somewhat lonely and boring. The neighborhood and the house seemed empty. In a study of the Mundurucu women of South America, anthropologist Yolanda Murphy experienced much the same female networking as I did with the Pinesdale women. She recalled that one Mundurucu women told her that the reason women go down to the river's edge to draw water in her village was not to get water per se, but to meet with other women. Yolanda told this woman that in America water comes through a hollow tube right into our houses. The women was shocked. "But if you don't go with the other women to get water and to bathe, aren't you lonely?" (Murphy et al. 1974:219).

Rather than feeling entraped and lonely, the Pinesdale woman feels busy, important, and an integral part of the community of women with whom she lives, works, worships, and shares an eternal kingdom. She is not cut off from the association of other women, such as many American women are, and is not caught in a nuclear family or single parent household in the constant company of small, demanding children. The female networking system in Pinesdale provides women with a release from their husbands and their children; women are not dependent emotionally, or for that matter, economically, on

5 The term "socialization" is here used as the standard education view of Pinesdale. It refers to the "raising up of a righteous seed" and the maintenance of belief in adults. 
their husbands. They have a group of women to encourage them, to help them, to satisfy their needs. Women need their husbands for the creation of their most valued possessions-their children, and they need them for access to the priesthood powers, but in nearly every other aspect, women fill the needs of women. ${ }^{6}$ (There also exists in Pinesdale the private sort of women--the contemplative female who doesn't crave networking or socializing, but one the whole, these loner types are rare.)

Whereas many American monogamous women have few bases for building relations with other women, the Pinesdale woman is strongly compelled to join in female cooperative activities out of economic need and for emotional support. One woman, in order to work in Hamilton at a job paying $\$ 22,000$ per year, must have the help of her sisterwife or another women who indirectly benefits from this money to tend her children while she is away. One woman, Shelly Harris, who is in the hospital for several weeks, relies on her sisterwife, Hannah, to feed and clothe her four children, and host their husband all those extra nights (which is always difficult when there are extra people to feed and care for). Whereas a monogamous American woman in her interaction with her husband has little support from others (especially in abuse cases), at the first hint of trouble or sorrow, a Pinesdale woman will talk about it with her sisterwives or female friends in the community. One woman told me that if the husband is to blame for some problem, the wives will collectively express displeasure at his actions, and if he is smart, he will change his ways. Whereas the average American woman may have a higher official status, the Pinesdale woman is far less directly dominated or individually coerced by a husband. The Pinesdale females are protected by their unity, while the American females, are separated from, or "pitted against" one another (Murphy et al. 1974:221).

6 According to Silverman (1987), infant research suggests that females choose their maternal mother over a control mother in tests of vocalization and olfactory discriminating devices. Females have greater responsiveness and earlier face discrimination toward other females and mothers than males do. Further, the author states that the interior life of the female is mentally configured toward female bonding. 
Pinesdale women find a cohesive core in work, polygyny, the opposing unity of men, kinship, and in some cases, residence. In short, the network is a vital, equal element in Pinesdale society. It supports the patriarchy, it builds stable and long-lasting female groups, it socializes the town's children, and it provides a supplementary source of economic support for the welfare of the entire community. The next chapter will discuss the factors promoting female groups in Pinesdale. 


\section{CHAPTER VI}

\section{CONCLUSION: IN SEARCH OF FEMALE GROUPS}

This exploratory study has focused on those aspects of the culture central to fundamentalist society in Pinesdale, Montana. It has shown the Pinesdale community as a unique system of partial communalism, plural marriage, and theocratic, male-authoritative leadership, supported by female networking. The purpose of this thesis has been to explore the social patterns of life within the community--analyzing both male and female roles in ideological, sociological and economic terms--and to discover the factors that contribute to the formation of female groups. Many of the patterns found overlap with other fundamentalist groups in and around the State of Utah. Many of these same elements of society overflow from mainstream Mormon doctrine. The unique features of Pinesdale Mormon fundamentalism, however, are found in their geographic isolation, the large ratio of women to men, and the tendency for women to build strong cooperative bonds with other women.

As an anthropologist, I am in search of cultural universals. As a student of cultures, however, I do not want to fall into the trap of conflating all women's experiences to the same reductionist point. I do not want to ignore the diversity of women's lives, their personalities, their economic conditions, their sexual orientation, their view of religion, and their psychological condition. Yet, within the scope of this study of polygynous women in Pinesdale, Montana, I feel justified in stating that, universally, Pinesdale females are inclined to join together because of 1) polygyny, 2) ideology 3) economic interdependence, 4) the separation from authority of men, and 5) co-wife kinship. Many of these same factors are found in other cultures that are polygynous, communal, rural, and patriarchal 
(Leis 1974, Schlegel 1972, White 1989, Clignet 1970, Murphy et al. 1974). Though it is dangerous to claim too much about female power in a beginning ethnography, I have included some mention of it in this text as it has some bearing on the formation of female groups. I have suggested that females in Pinesdale contribute significantly to the economic, social, and emotional stability of the community. The status of Pinesdale women is connected to the control over the most valued resource in the community-children. If, for some reason, women lose this control, due to social change and identity, they may fall even lower in status than they are at present. ${ }^{1}$

In the following paragraphs, I will be stating several points about the nature of polygyny and female groups in Pinesdale. In discussing the formation of female groups, I refer to a model of female groups developed by Nancy Leis (1974) in her study of the West African Ijaw, applying it to the female networking system found in the male dominated community of Pinesdale. I will also cite the Mundurucu of Brazil, studied by Yolanda and Robert Murphy, as a supportive case for the purpose of defining my premise about female groups. I will then discuss further factors that may contribute to, or weaken, the formation of female groups in Pinesdale, analyzing the social, economic, and religious change that will directly affect these groups.

\section{FACTORS ALLOWING FOR FEMALE GROUPS}

There are many different studies defining exactly how women's associations are formed (Lewis 1976, Tapper 1978, Hoffer 1975, and Lamphere 1974). Among the most well known is Nancy Leis' model (1974) which suggests that the combination of features relevant to the occurrence of female groups are 1) virilocality, 2) patrilineality, 3)

1 Peggy Sunday, in her pioneer work, Female Power and Male Dominance, suggests that female production is a necessary condition for the development of high female status. She states that women must not simply work, they must control some valued resource, good, or service (1981). Because Pinesdale male ideology places such high emphasis on the propagation of children for the kingdom of heaven, children are considered a "valued resource" in community. Women are without question in control of this resource. 
polygyny, and 4) economic independence. ${ }^{2}$ In spite of the male-supremacist perspectives of the Patani village, located in West Africa, Leis suggests that there are situations and times when women in the group have played a more prominent role in the economic, domestic, and sociological spheres of the community than men. This is due to their collective voice and informal organization in the networking system they have created to avoid poverty, loneliness, frustration with male leadership, sickness, and boredom. The Patani village, which exhibits these elements of female solidarity, is similar to Pinesdale in this respect.

The Patani village is one of two Ijaw villages of the Niger Delta. Korokorosei, the other village exhibits no female groups or solidarity, yet it is part of the same Delta group. Though both groups are dominated by a male prestige authority system and both share a similar political structure, Leis discovered that there are a number of factors that are present in the Patani culture that are absent in the Korokorosei culture. The Patani women are patrilineal with residential patrilineages, whereas the Korokorosei are ambilineal and live in exogamous residence groups founded by the sons of the village ancestor. Though both groups are polygynous, the Patani woman is not tied to her husband to care for him daily, whereas the Korokorosei women must cook and clean for their husbands on demand. Another important difference is that Patani women have working associations which help them cope with their husbands and their co-wife relations. The Korokorosei women have no such group. The Patani women utilize a market to sell their goods, and therefore, gain some income from their labors, whereas the Korokorosei have none.

Leis suggests that because the Patani women are oriented toward their husbands' kin groups, polygyny, and their own economic independence, they are able to form successful associations.

2 In spite of the kin-based nature of Leis' African study, limiting its applicability to Western society, she suggests that her model "would predict the presence or absence of women's groups elsewhere," and encourages a cross-cultural study to text her hypothesis. This ethnography is one such study. 
Another study that exhibits similar factors in the formation of female groups is the Murphy et al. study of the Brazilian Mundurucu women (1974). Like the Patani in Leis' study, the Mundurucu women are dominated by a male authoritarian system based on public prestige and patrilineality. Mundurucu women are also separated from their men in terms of labor and their lack of public power. Unlike the Patani, however, they live in matrilocal residences, apart from their men, and associate freely with their own kin groups. Mundurucu women collectively produce their family's staple food, farinha, while the men spend all day hunting, and do all of the household work with the help of their female coresidents and other women of the village. A distinctive sex role division exists in Mundurucu culture, where the male prestige factors and patrilineality shapes the symbolic expression of life in the community, but has little impact on day-to-day relations among women. Mundurucu women directly influence the lives of their children and control the decisions that are made in the household. Men do not violate this domain.

In light of these two supportive studies, my premise is that the formation of female networks in Pinesdale appears to have given women considerable status and power. Like the Mundurucu of Brazil, the lives of Pinesdale women are very much separated from those of the men--separated in terms of division of labor by sex, as well as in terms of residence and formal authority. Like the Patani of the Niger Delta, the women of Pinesdale have been empowered by their solidarity, their ability to share domestic and childcare tasks so that $75 \%$ of them can secure income, and their collective voice to provide a check against male authority. Both of these studies have provided vantage points for viewing Pinesdale society, and help support my theory that women in a polygynous, male-dominated culture can and do form strong female associations. Female networks in all three cultures--Patani, Mundurucu, and Pinesdale--assist women in coping with their difficulties in the husbandwife dyad and the wife-wife dyad. It also helps these women function while their husbands are out of town. When the men are in town, this network allows them some 
respite from their husbands. Given this breadth of evidence for female solidarity in the studies of Leis and Murphy et. al., what criteria can establish the occurrence of female groups specifically in Pinesdale, Montana? Can I extend the Patani and Mundurucu models to fit Mormon fundamentalist women? What factors contribute to Pinesdale female solidarity?

When the Mundurucu and Patani cultures are compared to Pinesdale, the resulting analysis is variable, but extremely enlightening. Mundurucu women share with Pinesdale women the complementary/contradictory relationship with men and the male public image that both cultures exhibit. The Mundurucu also shares the vital female collective voice, storytelling ("testimonials") sessions, and the residential core with the Pinesdale group. Yet, the Mundurucu rarely practice polygyny, and are more extreme in their separation and their ridicule of men than are Pinesdale women.

As for the Patani culture, as one may recall, Leis' model of female groups in the Patani village were: polygyny, economic independence, virilocality and patrilineality. My observation was that the first two terms in Leis' model, "polygyny" and "economic independence," were found in my study of Pinesdale polygynous women to foster the formation of female groups. The third and fourth terms, "patrilineality" and "virilocality," Leis' factors, however, were problematic when applied to Pinesdale society. It is not patrilineality or virilocality per se which endows the Patani women solidarity and the Korokorosei (the second Ijaw group in Leis' study) with none, but the lack of conflicting ties among women in the Patani group. What was found to be important is the vital separation of women from men that $\alpha c$ urs in patriarchal societies where male authority guarantees the formal rights of men over the lives of women and children. It is this distinction of women from men and the loyalties among women that sets the stage for the formation of women's groups. 
This alteration in Leis' model is justified by the following observations in crosscultural studies of polygynous women. For every study arguing in favor of a patrilineal descent system in the formation of female groups (Leis 1974), one can also find a study arguing in favor of a matrilineal descent system (Lebar 1975). Likewise, for every study favoring virilocality as a factor in female group building (Leis 1974), there is also a study favoring matrilocality (Murphy et al. 1974). This leads me to believe that neither of these factors are important. Leis found that virilocality effectively separated women from their natal residence groups and placed them "as strangers among people who have, by virtue of their birth, enduring ties with one another" (p. 232). Yet in their study of the Mundurucu, Murphy et al. write that matrilocality, where mothers and daughters reside together, as do sisters, is the key to the formation of female groups (1974, p. 215). Thus, residence is not a significant factor. Further analysis of cross-cultural studies reveals all descent systems to be associated with polygynous female groups at one time or another, including the bilaterality of the Upland Bagodo of the Philippines (Lebar 1975), not unlike Mormon fundamentalism's own system of bilateral kinship. This suggests that kinship is not as significant a factor as Leis suggested.

I repeat that I agree with Leis' model on three points: 1) polygyny, 2) economic independence, or "interdependence," as I have termed it for the purpose of this study, and 3) a separation from an opposing male authority. ${ }^{3}$ In order to illustrate how these factors are conducive to female solidarity, I will explain each factor in relation to the information collected from the Pinesdale community.

${ }^{3}$ Fox said in relation to polygyny, "it is not necessarily about sex but about dominance" (quoted in Tiger 1970:271). 


\section{Polvgyny}

Perhaps polygyny's greatest contribution to the formation of women's groups, as described in Chapter III, is in the large number of women in society who outnumber men three to one. In virtually every circumstance of polygynous marriage, there are more women in the home and community than men. Secondly, polygyny promotes common experience among co-wives. Co-wives have the common experience of sharing their husband's bed, cooking his meals, and rearing his children. This common bonding occurs out of a need to talk about one's experience with another woman, and to find that there is much to talk about in regards to a man one shares with another wife. In addition, women in polygynous societies have more leisure and seem more independent than monogamous wives do (Leis 1974). This is not so different from harem systems. Out of economic necessity, boredom, or emotional need, co-wives take turns and share tasks with each other. Even if the only task they share is to bed their husband and cook for him one day out of three or four, this is enough to be of help to other co-wives. But there is much more to it than this. There is childcare sharing, cooking, housework, and other tasks which take up a woman's time. With the space provided by another's help, a polygynous woman can stretch herself, physically and mentally, finding new distractions, new friendships, and time to get out of the house once in a while. She can participate in activities and groups on her own and over which her husband exercises no control. She will increase her visiting patterns to the point of taking a whole day just to talk and build friendships.

As was often illustrated in the analysis of Pinesdale culture, polygynous married men must constantly be involved with their wives; polygynous married women have some respite from their husbands (1974:233). ${ }^{4}$ Leis suggests that polygyny gives women a considerable measure of independence.

${ }^{4}$ Robert Netting, in his study of Kofyar men and women, states that nonpolygynous women are more likely to be independent. The results of his study show that $45 \%$ of Kofyar women leave their husbands, and are able to do so because they are not involved in polygynous relationships. Netting's study is a study of power, not female group formation, and so it is more interested in the status and social force women 


\section{Economic Interdependence}

Chapter III illustrated that female contribution to the welfare of the family and community is one of the many contradictions in male/female social and economic roles. Male dominance is regarded more as an ideological device for bringing order, than as an expression of economic power. In the Pinesdale workforce, women dominate in numbers (approximately 113 women and 50 men work). Women work in a variety of jobs and income levels to contribute to family income. I have categorized two types of employed women: 1) the community, low-paid employee, such as the school teacher, the store keeper, and the honey distributor, who make relatively little money, but provide a service that nets a community increase in goods and services, and 2) the full and part-time marketplace employee--accountants, nurses, and clerks who work in Hamilton and Missoula, making salaries anywhere from $\$ 18,000$ to $\$ 30,000$. From a sample of 30 working women, 20 were making more than $\$ 21,000$ a year--as much as most of the men (see Figure 5, Chapter III).

Since many of the female employees in Pinesdale are part-time workers, staying home with young children and taking care of household duties, it is important to bring up another aspect of the female contribution to the economy of the community: domestic labor. According to a study of the factors affecting the division of labor in Australian households (Antill and Cotton 1988), household tasks, including childcare, have remained sexually segregated. This suggests that the majority of household duties--cooking, cleaning, sewing, caring for children, ironing, maintaining the home and garden, and certain types of food procurement--are performed by the wife (p. 531). This is certainly the case for

Pinesdale women. Very few men contribute to household labor at the ranch. The question 
now becomes how much this work is worth to the family and community? Can it be counted in dollar value?

In Singh and Morey's study (1987) of the value of work-at-home in African polygynous families, they suggest that the number of wives in the family significantly determines the wife's productivity in the home. The household economy level rises, but each wife's individual workload is lessened (1987). ${ }^{5}$ For Pinesdale, this is especially true. More wives per household, and per family for that matter, contribute to the overall productivity of the family unit. This increase also contributes to the increased leisure and variability of female tasks for each co-wife. Additional support for including domestic labor as a significant contribution to the general economy of the home and community is White and Burton's study of 142 polygynous societies, taken from the Standard CrossCultural Sample, which showed that one reason for polygyny to arise in a group was for female contribution to subsistence and the household economy $(1988: 529){ }^{6}$

There is also the factor of the United Order, the community work stipend, and the rotation of used goods that families receive to help them get through the month. As mentioned in Chapter III, and throughout Chapter V, females are more successful at utilizing the United Order's prescriptions for sharing and cooperating than are males. The trickle-down effect of bulk buying, income sharing, and the rotation of household goods for one extended family alone is considered a valid economic contribution to income. Because of the United Order's provision of basic economic expenses, there is less need to

5 The authors attempt to estimate the economic contribution of wives to the home environment. Using a data set gathered from 100 household surveys in rural Burkina, West Africa, the authors developed a model of home production in order to compute the value of women's work. Home production is based on the value of women's work or the dollar value of the work-at-home if these women were being paid. The authors tested the variables of an econometric model of age, number of children, number of wives, etc., by mean, standard deviation and t-testing. The results showed that the number of wives in the household significantly determined the wife's productivity in the home. Also, the value of the mother's time in home production tended to rise as the number of children under the age of 4 in the household increased.

${ }^{6}$ The strength of this study is the systematic use of new codes to test the universality of polygyny. These codes are warfare, expansion of land, fraternal groups, environment, and household economy, and offer important guidelines for conducting cross-cultural research of polygynous societies. 
spend money outside the colony than in the average American home. ${ }^{7}$ If there is any emergency, such as an accident where an individual must be hospitalized, the community holds a pot luck dinner to help the family pay for expenses. Many times, the rest of the hospital bill will be paid for from the community kitty. In Pinesdale, as pointed out in Chapter III, there is no health insurance to pay, no central heating bills, virtually no housing costs (all land and most homes are owned by the community), and no debts of any kind. There is a $\$ 10$ per month water bill per family (that is for the entire family--all wives and children, but only one-third of the community are paying that. The others are getting their water free. There is a communal garden, the wheat mill, free lumber, free firewood (for some who live higher up on the mountain), and free use of goods and household appliances donated for rotation. Overall, the head of the family is not the sole bread winner for the family; his wives help make up the difference.

Another study measuring the female contribution to subsistence is Schlegel and Barry's study of 186 nonindustrial societies from Africa to Circum-Mediterranean countries, based on two sets of codes: adaptive and attitudinal. ${ }^{8}$ The authors found conditions under which women contributed to subsistence, ranging from gathering and incipient agriculture to hunting and fishing. The study suggested that female contribution to subsistence declines as society become more complex. They also stated that this contribution is a determining factor of adaptive and attitudinal features, that is, social arrangement and emotional stability (1986).

7 As mentioned, the community pays for land, some housing expenses, and some home goods and furnishings through the rotation system.

${ }^{8}$ Adaptive measures refer to environmental and societal adaptation, whereas, attitudinal measures refer to effective, emotional criteria. 


\section{The Separate Unity}

One of the maxims of patriarchal society is that men have power over women.

Pinesdale is no exception. Women are inferior in the ideology of Pinesdale men, as shown in Chapter II, and compensate for this inferiority or "difference," as they call it, by forming an opposing unity with other women who also are lacking in official authority. Because women are denied formal authority, they do not mix well with those who have that authority. Instead, they find others who are most like them, who share common experiences such as home management, childbirth, menstruation, motherhood, cleaning, cooking, nurturing, Relief Society, testimonies at the Meeting of the Sacrament, and husbands who are frequently absent from their homes. This common experience unites these women, in spite of their personality differences, or small jealousies and arguments. ${ }^{9}$ Another point of separation is in the exclusive part they play in propagating the "kingdoms of heaven" reproductively. Men may be able to influence their children in righteousness, but women bear and nurture these children, often in the absence of their husbands. They have control over whether they will ultimately join the group or not, as women have more religious influence over their children, through their testimonies, prayers, and constant display of affection for the gospel.

According to Barbara Aswad, visiting patterns are a significant factor in the exchange that occurs between females living in the same community (1974). ${ }^{10}$ Because

${ }^{9}$ As part of their uniting opposition to male authority, women will often use affliction as protest. Definitions of femininity and frailty in society can be turned to advantage by women who succumb readily to illness, prolonged post partum recovery, etc. Often, women will join in the affliction of their sisterwives and other women in close approximation to oppose the dominant ideology of male supremacy. Female solidarity is reinforced by this type of shared affliction. No attack to the social structure occurs directly, so the illness is harmless to the stability of the community. Examples of this type of joint affliction occur in menstruation discomfort, or other types of feminine illness, such as post partum depression and childbirth recovery.

10 The author analyzes one form of visiting (kabul), which is based on balanced reciprocity, among elite Turkish women. Balanced reciprocity refers to the exchange of one act for an act in kind. The author's analysis consists of two assumptions of the kabul: 1) communication cohesion occurs between politically divided families, and 2) powers of status are extended to the middle classes. Over a two-year project, the author used participant observation to record the relationship and frequency of visits among women, in 
Pinesdale men work full time usually outside the community, and sometimes outside the state, as well as are forced to spread out what little time they have at home among several wives and dozens of children, they have little time to form visiting patterns among themselves. But women, who have more time at their leisure, are able to meet with other women often, and, in light of the nature of their tasks, women of Pinesdale form visiting patterns in relation to the job they will be performing. For example, while visiting one woman's house to discuss the school system, the subject of honey distribution was brought up. The woman who hosted the discussion was in need of honey for her meal that evening, and so, another women who was on her way to get her own honey promised to deliver the honey to this other woman. Another example is of official visiting patterns through the Relief Society program "Visiting Teaching," which is supposed to be a religious instruction meeting where two women visit the house of another and teach her a pre-determined doctrinal lesson. What usually happens is that the women talk about whatever is of most interest to them, such as economic need, childcare, jokes about husbands, etc.

\section{Ideology, Sisterwife Kinship, and Matrifocality}

In the formation of female groups within Pinesdale, there are several other factors that are crucial to the success of these groups. These factors are: ideology, sisterwife kinship, and matrifocal residence.

Ideology. As discussed in Chapter V, women draw upon certain egalitarian concepts in fundamentalist ideology that fully supports their involvement in the female network. Because these women are taught all of their lives to work together, to share, and

terms of kin groups and social class, of six families. The author concluded that the frequency of visiting is directly related to social distance, that is, the distance between sisters versus the difference between sister-inlaw, with the most frequent visits being between close kin. Lower frequency of visits is observed between distant kin and non-kin groups. What this suggests about Pinesdale is that more visiting occurs among women that are in someway--consanguineally or affinally--related to each other, which is true for Pinesdale women. 
to love each other as "sisters," whether related or not, their very psychological make-up is geared toward female solidarity. Their salvation depends on how well they work together and how well they prove their love for each other. In fundamentalist society, nurturing relationships among co-wives is every bit, if not more, important that nurturing the husband-wife relationship. Once again, ideology is a crucial factor in the formation of female groups within Pinesdale.

Sisterwife Kinship. As illustrated in Chapter IV, it is common for women to be related by blood prior to their marriage to the same man. The most common form of this type of marriage is sororal polygyny and cousin polygyny, as indicated in Figure 7. Because women have a preadapted affiliation with each other prior to marriage, their bonds of love and friendship are already strong. In support of this "preadapted" bonding, a study by Mabuchi (1964) suggests that there is a spiritual predominance of the sister in Ryukyuar culture that strengthens women's status and position in relation to men in society. This could also be said of Pinesdale women. Women are bonded by nature of their birth and by nature of their large numbers, to the disadvantage of men who are neither have members of their kin in their immediate family or are large in numbers.

Matrifocality. Although a minor one, common female residence and the establishment of women as the residential core of the family is a positive factor in the formation of female groups in Pinesdale. I have shown throughout the thesis, women are permanent members of their household, whereas men are visitors, without permanent residence. Women are in control of the family residence the majority of the time and make most of the decisions that affect the family. For this reason, residence is termed "matrifocal," and deserves some mention in connection with the elements that give rise to female solidarity and unity. 


\section{SOCIAL, ECONOMIC, AND RELIGIOUS CHANGE}

I would further submit that the formation of female networks is strongest in times of economic necessity, within the context of informal religious rituals and meetings, and during periods of religious change. I suggest that a weakening of female solidarity may occur when too many women leave the community for outside work, relinquishing their childbearing responsibilities to fewer and fewer women. There is also the chance that women who work outside the community will lose that vital contact and commitment to family that exists when together on a day to day basis. The current recession in the Bitterroot Valley, Montana, forcing more and more women to supplement their family's income by working outside the home, or find other means for securing extra supplies through the networking system, has increased female economic inter-dependence. The following sections illustrate how female groups are strengthened by the shift in economic and social environment.

\section{Economic Necessity and Social Change}

More and more women are working at traditionally defined male jobs, such as accounting, business, medicine, and truck driving. Today they may even enter these jobs before they have children, something that would have been unthinkable 10 years ago. More often, though, they will take a job after their children are born, confident that their child will be cared for by a loving sisterwife. When males are away from Pinesdale at other jobs, women maintain the households and work at tasks ordinarily performed by their husbands such as wood cutting, machinery maintenance, etc. Because there is a minority of male workers within Pinesdale, women must fill other jobs and learn skills that are necessary to establish a community. Pinesdale is recognizing women's abilities and is relaxing the traditional definitions associated with sex roles. 
In a study of female friends and the reconstruction of intimacy among women, Acker, Barry and Esseveld (1981) questioned whether the changing life patterns and the emergence of women into the marketplace had influenced women's personal relations, leading to a transformation of those relations. In evaluating the nature of female-female bonds, the authors gathered data on the experiences of 28 American housewives and mothers through in-depth interviews over a period of three years. About one-third of the women were coded as working class; the other two-thirds as middle class. The data were analyzed through four criteria: 1) husband work relations, that is, friendships stemming from the husband's work, 2) housewives relations, 3) wife work relations, and 4) kinship relations. The results showed that female relationships with other women in the domestic sphere were central in structuring their lives, their sources of support, their affection and resistance, as well as their sources of commitment and obligation. Friendships outside this sphere, such as in the workplace, were shown to be not as cohesive (1981:108). In light of the large number of Pinesdale women moving from the domestic sphere to the marketplace, perhaps it would be accurate to predict a loosening of ties within the female network. This effect may be mitigated in polygyny because of the common experience women have as co-wives, bearers of children, and believers of the same religion. For this change to happen, though, the time spent in the marketplace would have to be much greater than the domestic time now spent in Pinesdale. It would be interesting to find out in five years' time, whether more women in the marketplace had any effect on the bonding patterns among Pinesdale women. Perhaps a longitudinal study would accomplish this.

\section{Religious Ritual}

Men are given more authority in formal religious ritual and ceremony. Ideally, they use their priesthood powers to dominate the connection between God and members of their family. Often women and children must go through their male head to be blessed and ordained in the sect. In reality, women are informally given the authority for much of these 
same rights and privileges. The informal rights for women usually come from expression of beliefs through testimonials, prayer, and the teachings of others:

1) Leadership--the right to conduct and control the Relief Society, Young Women's and Primary organizations and to select a small bureaucracy within each group to run efficiently.

2) Teacher--the right to teach Sunday school, Relief Society, Young Women's, and the Primary children, as well as, the general instruction of the vast majority of Pinesdale membership--the children.

3) Blessings--the right to administer to their children and sisterwives in the absence of their husbands.

Women of Pinesdale do not have the right to do ordinances of specific ceremonies such as weddings or baptisms or the Sacrament, nor do they have official right to enter the Council of the Order meetings. Yet, because of their concern for their children, and decisions made by men on their behalf, more and more women are requesting subtly to be allowed entrance to these general community meetings. Further, because of the large number of women, teaching, leadership positions, and healing administrations by women are becoming more prevalent. By sheer number, their teaching and interpretations of scripture and testimonials effect a gradual change in doctrinal directions. Because they are able to more frequently participate in these rituals, their solidarity is strengthened, as is their status in the community.

Pertaining to the powers of the priesthood, one significant right and privilege is the power to bless and administer to children. Because this power is performed by those having the priesthood ranking higher than "priest" in the Melchezedek Priesthood, only those who hold this power may administer these blessings. Now women are told that through their connection to their husbands who hold the office of priest or higher, they themselves can exercise this same power. This right and privilege allows women to rely more on themselves and other women in the network than on their husbands, who are so frequently absent. 
Females also play an expressive role in fasting and in testimony meetings at the first of each month. The testimonies are a form of personal rebirth and affirmation of lifestyle, telling of one's attempt to live the Gospel, telling about one's sins, or proselyting the truthfulness of one's belief. In either case, more women than men give testimony of the sect's belief and are more emotionally expressive in this ritual than men are. Often children will note more their mother's testimony than their father's for this reason, and will either believe or not believe depending on their mother's testimony. Love for a husband or sisterwife or child is usually expressed in full at these times. In this way, informally, one can gain spiritual strength without the laying on of hands by the priesthood; the act is purely female, her testimony, her voice. This, more than any other ritualistic factor, contributes to the formation of female groups by providing a collective voice and by providing a story-telling communion of common interests, desires, illnesses, beliefs, hardships, and sentiments.

Women also are playing a more active role in studying and teaching doctrinal aspects of their purpose on earth as sovereigns of their kingdoms. They are becoming educated on scriptural references to their Mother in Heaven and their part in the powers of the priesthood. They are learning the general history of the church and are leading classes that are ranked higher than Primary, Young Women and Relief Society, such as in adult Sunday school, because more of them are available to do so. More often women lead their own children in nightly readings and discussions of the scriptures.

According to Mernissi (1978), religious sanctuary, both physical and psychological, for women provides an opportunity for the expression of female solidarity in the face of a male dominant system. Women participating in rituals and religious activities are benefiting through the exchange derived from these activities. By sheer force of personality, such as in the case of the female adult Sunday school teacher, some women 
can fit quite comfortably into religious rituals and positions ordinarily held by men. But it is precisely these characteristics that separate them from other women. ${ }^{11}$

Socio-religious Change. Religious change comes from a search for a paragon of Pinesdale womanhood. Should she be smart? Should she bear 17 children? Should she teach? Should she work? Because there are a growing number of young women who seek to enter college and begin careers, there is more emphasis on female rights and female fulfillment. A recent revision of Mormon temple ritual, dropping wording that required women to pledge to obey their husbands, could effect Pinesdale ritual as well (Anderson 1990). Since the Mormon culture is called "mother" by the Pinesdale saints, any change in ceremony in the larger Mormon society directly affects fundamentalist society. Pinesdale women may begin to feel uncomfortable with the commandment of obedience to their husbands when they know that the Mormon Church no longer requires it.

More and more women are confronting situations in which they have to assume more responsibilities for such tasks as child rearing, religious indoctrination of children, household financing and managing, etc, as discussed previously. Though few women are professionals in the marketplace, more are becoming financially capable, and are sharing that wealth with their sisterwives to allow for all within the family to be provided for.

Though Pinesdale women have not generally questioned the male-controlled priesthood authority in the past, more are doing it now because of their extended scriptural and doctrinal study. Women are noted for the ease in which they feel "the Spirit." This too enables them to be authorities of a certain type over their husbands in "righteousness." What Jeffrey (1979) said of the twentieth century Mormon women is not true for the contemporary fundamentalist women:

...the leadership [of the Church] no longer had the same requests to make of Mormon women and no longer furnished the same support for expanded

11 Not all women are like Patty, the Sunday school teacher, and so do not share in her experience. Fortunately, Patty has enough other experiences in common with the majority of the women that she is completely welcomed by the network and contented within it. 
female roles....Mormon women lost respect and power, rather than acquired them. Even their organizations ceased to play the independent role they once had. By the mid-twentieth century, indeed, Mormon women had become the bulwarks of social and sexual conservatism (p. 178).

On the contrary, Pinesdale women are interdependent. They depend on other women and their own ability to work to get what their families require. I do not deny the contribution of the male economically and religiously, but to deny the importance of the female network would be to overlook an integral part of community structure.

\section{CONCLUSION}

In summary, Pinesdale women are motivated to form groups with other women due to several socio-economic, religious, and emotional factors. Among these factors, the most important are 1) polygyny, 2) ideology, 3) economic interdependence through the sharing of household and childcare tasks, and the increased income derived from outside marketplace employment, 4) the uniting separation from male authority, 5) matrifocality, or female domination of the residence, 6) common kin ties, and 7) common life experiences, i.e., a common husband, childbirth, ideological covenants, spirituality and motherhood. In addition to the above factors, economic need, religious and social change also may contribute to the formation of female groups. A weakening of these groups may occur when women's community and familial identity is changed through increasing contact with the workplace. Yet, as the community increases in number (as it has been doing steady for the last 30 years), there is a greater tendency for females to join the Order, and enough women may be staying in the home and the community to compensate for the increased number of women in the workplace. In addition, Pinesdale women, as long as they adhere to the belief in their own importance as "goddesses" of celestial kingdoms, will continue to be compelled to bear children--as many and as often as they possibly can. This fact alone leads me to believe that the female networking system of Pinesdale, Montana, will survive society's prompting to exchange family and religion for career and public acclaim. Further 
anthropological research in Mormon fundamentalism will be needed to justify these claims. At present, the field is just beginning to develop an understanding of women in contemporary American polygyny. The need for more physiological, psychological, and ideological research is vital to reach this understanding. A cultural comparison of women in the Mormon Church and women in fundamentalism would provide additional information on the character and experience of women in patriarchal-dominated societies, and give insight on the universal, and elusive, differences between monogamy and polygyny in the Mormon culture. 


\section{REFERENCES}

Acker, Joan, et al. 1981. "Feminism, Female Friends, and the Reconstruction of Intimacy," Research in the Interweave of Social Roles: Friendship 2:75-108.

Allred, Vance 1984. Mormon Polygamy and the Manifesto of 1890--A Study of Hegemony and Social Conflict, thesis for masters degree, Missoula: University of Montana, Department of History.

Altman, Irwin, et al. 1981. "A Cross-Cultural and Dialectic Analysis of Homes," Spatial Representation and Behavior Across the Life Span, New York: Academic Press.

Anapol, Deborah 1989. "The Future of the Family and the Fate of Our Children," The Truth Seeker. San Diego, California, 1(6):37-40.

Anderson, Vern 1990. "Mormons Delete Wifely Obedience from Church Ritual," Qregonian, 2 May, page 12A.

Antill, John K. and Sandra Cotton 1988. "Factors Affecting the Division of Labor in Households," Sex Roles, 18(9/10):531-553.

Arrington, Leonard J. 1955. "The Economic Role of Pioneer Mormon Women," Western Humanities Review, 9:145-64.

---- 1971. "Blessed Damozels: Women in Mormon History," Dialogue 6.

Aswald, Barbara 1974. "Visiting Patterns Among Women of the Elite in a Small Turkish Town," Anthropological Quarterly 47:9-27.

Baer, Hans 1976. The Levites of Utah: The Development of and Recruitment to a Small Millenarian Sect, Ph.D. disertation, Salt Lake City, Utah: University of Utah, Department of Anthropology.

Barry, H., et al. 1957. "A Cross-Cultural Survey of Some Sex Differences in Socialization," Journal of Abnormal and Social Psychology, 55:327-32.

Blakely, Pamela 1985. "Co-wives in Africa: A Discussion of Polygyny in Eastern Zaire." Lecture presented for the Women's Research Institute, Provo, Utah: Brigham Young University, 23 January.

Boserup, Ester 1970. Woman's Role in Economic Development, London: George Allen and Unwin Limited.

Bradley, Martha S. 1989. "Changed Faces: The Official LDS Position on Polygamy 18901980," Sunstone Symposium, Salt Lake City, Utah, August. 
1990. "The Women of Fundamentalism: Short Creek, 1953," Dialogue 23(2):1537.

Bronson, Lorraine 1982. Winnie (inhouse Pinesdale literature--not in print).

Burgess-Olson, Vicky 1975. Family Structure and Dynamics in Early Utah Mormon Families--1847-1885, Ph.D disertation, Northwestern University.

Burton, M.L. 1982. "The Plow, Female Contributions to Agriculture Subsistence and Polygyny--A Log Linear Analysis," Behavior Science Research, 16(3-4):275-305.

Christ, Carol P. 1980. Diving Deep and Surfacing: Women Writers on Spiritual Quest, Boston: Beacon Press.

Clignet, R. 1970. Many Wives. Many Powers: Authority and Power in Polygamous Families, Evanston: University of Illinois Press.

Draper, Patricia 1975. "!Kung Women: Contrasts in Sexual Egalitarianism in Foraging and Sedentary Contexts," Toward an Anthropology of Women, Rayna Reiter, ed., New York: Monthly Review Press.

Driggs, Ken 1990. "Twentieth Century Polygamy and Fundamentalist Mormons in Southern Utah," 3 January, Dixie College Performing Arts Symposium.

Duley, Margot, and Mary Edwards 1986. The Cross-Cultural Study of Women: A Comprehensive Guide, New York: The Feminist Press.

Dunfrey, Julie 1984. "Living the Principle of Plural Marriage: Mormon Women, Utopia, and Female Sexuality in the 19th-Century," Feminist Studies, 10:523-36.

Embry, Jessie 1987. Mormon Polygamous Families: Life in the Principle, Salt Lake City, Utah: University of Utah Press.

----- 1984. "Effects of Polygamy on Mormon Women," Frontier--A Journal of Women Studies, 7:56-61.

England, Eugene 1987. "On Fidelity, Polygamy, and Celestial Marriage," Dialogue 20 (Winter): 138-154.

Faux, Steven 1983. "Genetic Self-Interest and Mormon Polygyny: A Sociobiological Perspective of the Doctrinal Development of Polygyny," Sunstone 8:37-40.

Foster, Lawrence 1984. Religion and Sexuality: The Shakers, the Mormons, and the Oneida Community, University of Illinois Press Urbana and Chicago.

Goodson, Stephanie S. 1976. "Plural Wives," Mormon Sisters, Claudia Bushman, ed., Salt Lake City, Utah: Olympus Publishing.

Gronau, R. 1973. "The Value of a Housewife's Time," American Economic Review, 68:634-51. 
Hoebel, E. Adamson 1966. Anthropology: The Study of Man, 3rd edition, New York: McGraw-Hill.

Hoffer, Carol 1974. "Madam Yoko: Ruler of the Kpa Mende Confederacy," Women. Culture \& Society, M. Z. Rosaldo and L. Lamphere, eds., Stanford University Press.

Holland, Patricia T. 1989. "A Woman's Perspective on the Priesthood," LDS Relief Society Guide (See Mormon Literature, below Reference section).

Hughes, A. 1982. "Confidence of Paternity and Wife--Sharing in Polygynous and Polyandrous Systems," Ethnological Sociology, 3(3):125-129.

Hulett, James Edward 1939. The Sociological and Social Psychological Aspects of the Mormon Polygamous Family. Ph.D disertation, University of Wisconsin.

------ 1940. "Social Role and Personal Security in Polygamy," American Journal of Sociology, 5:538-49.

Hurston, Zora Neale 1937. Their Eyes Were Watching God (1968 reprint), Negro University Press.

Jeffrey, Julie Roy 1979. Frontier Women: The Trans-Mississippi West. 1840-1880, New York: Hill and Wang.

Johnson, LeRoy 1977. Sermon on Plural Marriage, delivered in Colorado City, Arizona.

Kanter, Rosabeth Moss 1968. "Commitment and Social Organization: A Study of Commitment Mechanisms in Utopian Communities," American Sociological Review, 33:499-517.

1973. Family Organization and Sex Roles in American Communes, in Communes: Creating and Managing the Collective Life, .M. Kanter, ed., New York: Harper and Row.

Kern, Louis J. 1989. In Ordered Love: Sex Roles and Sexuality in Victorian Utopias, Chapel Hill, North Carolina: Chapel Hill University Press.

Keesing, Roger, M. 1975. Kin Groups and Social Structure, (revised edition). New York: Holt, Rinehart and Winston, p. 9.

Kraut, Ogden 1983. Polygamy in the Bible, Salt Lake City, Utah: Pioneer Press.

1989. The Fundamentalist Mormon, speech presented at the Sunstone Symposium, August.

Lamphere, Louise 1974. "Strategies, Coopration, and Conflict Among Women in Domestic Groups," Women, Culture \& Society, M. Z. Rosaldo and L. Lamphere, eds., Stanford University Press.

Langness, L.L. 1987. The Study of Culture, (revised edition), Chandler \& Sharp Publishers, p. 143. 
Lebar, Frank M. 1975. Ethnic Groups of Insular Southeast Asia, Human Relations Area Files.

Leis, Nancy B. 1974. "Women in Groups: Ijaw Women's Associations," Women. Culture, and Society, Michelle Zimbalist Rosaldo and Louise Lamphere, eds., Stanford University Press.

LeVine, R.A. 1962. "Witchcraft and Co-Wife Proximity in Southwestern Kenya," Ethnology, 1:39-45.

Lewis, Barbara 1976. "The Limitations of Group Action Among Entrepreneurs: the Market Women of Abidjan, Ivory Coast," Women in Africa: Studies in Social and Economic Change N. Hafkin and E. Bay, eds., Stanford University Press.

Mead, Margaret 1935. Sex and Temperament in Three Primitive Societies, New York: Morrow.

Mernissi, Fatima 1978. "Women, Saints, and Sanctuaries," Signs, 3 (March) 101-112.

Merrill, Melissa 1975. Polygamist's Wife, New York: Simon \& Schuster.

Moyer, Bill 1989. A World of Ideas, New York: Doubleday, pp. 352-34.

Murphy, Yolanda, and Robert F. Murphy 1974. Women of the Forest New York: Columbia University Press.

Musser, Joseph W. 1944. "Celestial or Plural Marriage," Truth. Salt Lake City, Utah: Truth Publishing Company, p. 102.

1948. "The Inalienable Rights of Women," Truth Salt Lake City, Utah: Truth Publishing Company, p. 134.

Myerhoff, Barbara 1978. Number Our Days. New York: Simon \& Schuster.

Nelson, N. 1979. "Women Must Help Each Other" Women United, Women Divided: Comparative Studies of Ten Contemporary Cultures. P. Caplan and J.M. Bujra, eds., Bloomington: Indiana University Press, pp. 77-98.

Nelson, Russell M. 1987. "Lessons From Eve," Ensign, November.

Netting, Robert 1969. "Women's Weapons: The Politics of Domesticity Among the Kofyar," American Anthropologist. 71(6):1037-1045.

Penrose, C.W. 1918. Conference Reports of the Church of Jesus Christ of Latter-day Saints. Spring: 17.

Persky, M., et al. 1971. "Relation of Psychologic Measures of Aggression and Hostility to Testosterone Production in Man," Psychosomatic Medicine. 33(3):265-77.

Pratt, Orson 1853, 1854. The Seer, London.

Quinn, Michael D. 1985. "LDS Church Authority and New Plural Marriages, 1890-1904," Dialogue 18 (Spring): 9-105. 
Rogers, S.C. 1975. "Female Forms of Power and the Myth of Male Dominance: A Model of Female/Male Interaction in Peasant Society," American Ethnology, 2:741-54.

Rosaldo, M. Z. 1974. "Women, Culture, and Society: A Theoretical Overview," Women. Culture and Society M. Z. Rosaldo and L. Lamphere, eds., Stanford University Press

Sacks, Karen 1975. Engels Revisited: Women, the Organization of Production, and Private Property: Toward an Anthropology of Women, New York and London: Monthly Review Press.

Sanday, Peggy 1981. Female Power and Male Dominance: On the Origins of Sexual Inequality, Cambridge: Cambridge University Press.

Schlegel, Alice 1972. Male Dominance and Female Autonomy: Domestic Authority in Matrilineal Societies, New Haven: HRAF Press.

Scott, Ruth 1989. "Record of Pinesdale History" (informant recorded statement--not in print).

Silverman, Dorisk 1987. "Female Bonding: Some Supportive Findings for Kleinian Theory," Psychoanalytic Review 74(2):201-215.

Sinclair, Karen 1986. "Women and Religion," The Cross-Cultural Study of Women Margot Duley and Mary Edwards, eds., New York: The Feminist Press.

Singh, Ram D. and Mathew J. Morey 1987. "The Value of Work-at-Home and Contributions of Wives' Household Service Polygynous Families: Evidence from and African LDC," Journal of Economic Development and Cultural Change, 141160.

Smith, Raymond T. 1956. The Negro Family in Britsh Guiana, London.

Snow, Eliza R. Diary. LDS Archives. Salt Lake City, Utah.

Solomon, Dorothy A. 1984. In My Father's House, New York: Franklin Watts.

Spiro, M. 1970. Kibbutz: Venture in Utopia, New York: Schocken.

Stack, Carol 1974. "Sex Roles and Survival Strategies in an Urban Black Community," Women. Culture \& Society, M. Z. Rosaldo and L. Lamphere, eds., Stanford University Press.

Tanner, Nancy 1974. "Matrifocality," Women, Culture and Society, M. Z. Rosaldo and L. Lamphere, eds., Stanford University Press.

Tanner, Annie Clark 1976. A Mormon Mother, Salt Lake City: University of Utah Library, Tanner Trust Fund.

Tapper, Nancy 1978. "The Women's Subsociety Among the Shahsevan Nomads of Iran," Women in the Muslim World. Lois Beck and Nikki Keddie, eds., Cambridge, Massachusetts: Harvard University Press. 
Tiger, Lionel 1970. Men in Groups, New York.

Turnbull, Colin 1983. The Human Cycle, New York: Simon \& Schuster.

Van Wagoner, R.S. 1986. Mormon Polygamy: A History, Salt Lake City, Utah: Signature Books.

Verdoya, Ken 1990. "A Matter of Principle," KUED documentary aired May 15, 1990, Salt Lake City, Utah.

----- 1990. "A Matter of Principle," Utah Holiday May issue.

Wagner, Jon 1976. "Male Supremacy: Its Role in a Contemporary Commune and Its Structural Alternatives," International Review of Modern Sociology 6:173-80.

----- 1982. Sex Roles in Contemporary American Communes, Bloomington: Indiana University Press.

Werner, Carol, and Irwin Altman 1985. Home Environments, New York: Plenum Press.

White, Douglas R.

1989 "Causes of Polygyny: Ecology, Economy, Kinship, and Warfare," American Anthropologist, 90(4):871-887.

Widstoe, John 1939. Discourses of Brigham Young, Salt Lake City, Utah.

Young, Kimball 1947. "Sex Roles in Polygynous Mormon Families," Readings in Psychology, Theodore Newcomb and Eugene Hartley, eds., New York: Holt.

Zablocki, Benjamin 1971. The Joyful Community: An account of the Bruderhof--A Communal Movement Now in its Third Generation. Maryland: Penguin Books.

\section{MORMON LITERATURE}

The following is a list of Mormon scripture and literature that is not listed in the above reference section due to the religious nature of the material--exclusive to the belief of Mormon culture.

Journal of Discourses 26 vols. Liverpool: Latter-day Saints' Book Depot, 1854-86. A compilation of speeches by prominent nineteenth-century LDS leaders.

LDS Archives Library/Archives, Historical Dept., Church of Jesus Christ of Latter-day Saints, Salt Lake City, Utah.

Moses, from the Pearl of Great Price

Alma and Mosiah, from the Book of Mormon 
Isaiah, Proverbs, Psalms, Deuteronomy, Genesis, Timothy, Peter, Ephesians, Luke, John, and Corinthians, from the King James Version of the Bible, as translated by Joseph Smith.

$D \& C$ Doctrine \& Covenants, a volume of Mormon scripture containing letters, directives, and selections from the revelations given to Joseph Smith.

Relief Society Study Guide and Priesthood Guide 1988-1989, published by the LDS Church, Salt Lake City, a study guide for LDS men and women.

$H C$, History of the Church of Jesus Christ of Latter-day Saints. 6 vols. Introduction and notes by B.H. Roberts. Salt Lake City: Deseret Book, 1978. 


\section{APPENDIX A}

THE REVELATION OF PLURAL MARRIAGE, AS DICTATED TO JOSEPH SMITH, 1930-1934. 
(Doctrine \& Covenants: Section 132)

Revelation given through Joseph Smith the Prophet, at Nawvoo, Illinois, recorded July 12,1843, relating to the new and everlasting covenant, including the eternity of the marriage covenant, as also plurality of wives.---The Prophet's inquiry of the Lord--He is told to prepare himself to receive the new and everlasting covenant--Conditions of this law-The power of the Holy Priesthood instituted by the Lord must be operative in ordinances to be in effect beyond the grave--Though the form of marriage should make it appear to be for time and eternity, the ordinance is not valid beyond the grave unless solemnized by the authority of the Holy Priesthood as the Lord directs--Marriage duly authorized for time and eternity to be attended by surpassing blessings--Essentials for the attainment of the status of godhood--The meaning of eternal lives--Plurality of wives acceptable only when commanded by the Lord--The sin of adultery-Commandment to Emma Smith, wife of the Prophet.

1. Verily, thus saith the Lord unto you my servant Joseph, that inasmuch as you have inquired of my hand to know and understand wherein I, the Lord, justified my servants Abraham, Isaac, and Jacob, as also Moses, David and Solomon, my servants, as touching the principle and doctrine of their having many wives and concubines. matter.

2. Behold, and lo, I am the Lord thy God, and will answer thee as touching this

3. Therefore, prepare thy heart to receive and obey the instructions which I am about to give unto you; for all those who have this law revealed unto them must obey the same.

4. For behold, I reveal unto you a new and an everlasting covenant; and if ye abide not that covenant, then are ye damned; for no one can reject this covenant and be permitted to enter into my glory.

5. For all who will have a blessing at my hands shall abide the law which was appointed for that blessing, and the conditions thereof, as were instituted from before the foundation of the world.

6. And as pertaining to the new and everlasting covenant, it was instituted for the fulness of my glory; and he that receiveth a fulness thereof must and shall abide the law, or he shall be damned, saith the Lord God.

7. And verily I say unto you, that the conditions of this law are these: All covenants, contracts, bonds, obligations, oaths, vows, performances, connections, associations, or expectations, that are not made and entered into and sealed by the Holy Spirit of promise, of him who is anointed, both as well for time and for all eternity, and that too most holy, by revelation and commandment through the medium of mine anointed, whom I have appointed on the earth to hold this power (and I have appointed unto my servant Joseph to hold this power in the last days, and there is never but one on the earth at a time on whom this power and the keys of this priesthood are conferred), are of no efficacy, virtue, or force in and after the resurrection from the dead; for all contracts that are not made unto this end have an end when men are dead.

8. Behold, mine house is a house of order, saith the Lord God, and not a house of confusion.

9. Will I accept of an offering, saith the Lord, that is not made in my name?

10. Or will I receive at your hands that which I have not appointed? 
11. And will I appoint unto you, saith the Lord, except it be by law, even as I and my Father ordained unto you, before the world was?

12. I am the Lord thy God; and I give unto you this commandment--that no man shall come unto the Father but by me or by my word, which is my law, saith the Lord.

13. And everything that is in the world, whether it be ordained of men, by thrones, or principalities, or powers, or things of name, whatsoever they may be, that are not be me or by my word, saith the Lord, shall be thrown down, and shall not remain after men are dead, neither in nor after the resurrection, saith the Lord your God.

14. For whatsoever things remain are by me; and whatsoever things are not by me shall be shaken and destroyed.

15. Therefore, if a man marry him a wife in the world, and he marry her not by me nor by my word, and he covenant with her so long as he is in the world and she with him, their covenant and marriage are not of force when they are dead, and when they are out of the world; therefore, they are not bound by any law when they are out of the world.

16. Therefore, when they are out of the world they neither marry nor are given in marriage; but are appointed angels in heaven, which angels are ministering servants, to minister for those who are worthy of a far more, and an exceeding, and an eternal weight of glory.

17. For these angels did not abide my law; therefore, they cannot be enlarged, but remain separately and singly, without exaltation, in their saved condition, to all eternity; and from henceforth are not gods, but are angels of God forever and ever.

18. And again, verily I saw unto you, if a man marry a wife, and made a covenant with her for time and for all eternity, if that covenant is not by me or by my word, which is my law, and is not sealed by the Holy Spirit of promise, through him whom I have anointed and appointed unto this power, then it is not valid neither of force when they are out of the world, because they are not joined by me, saith the Lord, neither by my word; when they are out of the world it cannot be received there, because the angels and the gods are appointed there, by whom they cannot pass; they cannot, therefore, inherit my glory; for my house is a house of order, saith the Lord God.

19. And again, verily I say unto you, if a man marry a wife by my word, which is my law, and by the new and everlasting covenant, and it is sealed unto them by the Holy Spirit of promise, by him who is anointed, unto whom I have appointed this power and the keys of this priesthood; and it shall be said unto them--Ye shall come forth in the first resurrection; and if it be after the first resurrection, in the next resurrection; and shall inherit thrones, kingdoms, principalities, and powers, dominions, all heights and depths--then shall it be written in the Lamb's Book of Life, that he shall commit no murder whereby to shed innocent blood, and if ye abide in my covenant, and commit no murder whereby to shed innocent blood, it shall be done unto them in all things whatsoever my servant hath put upon them, in time, and through all eternity; and shall be of full force when they are out of the world; and they shall pass by the angels, and the gods, which are set there, to their exaltation and glory in all things, as hath been sealed upon their heads, which glory shall be a fulness and a continuation of the seeds forever and ever.

20. Then shall they be gods, because they have no end; therefore shall they be from everlasting to everlasting, because they continue; then shall they be above all, because all things are subject unto them. Then shall they be gods, because they have all power, and the angels are subject unto them.

21 . Verily, verily, I say unto you, except ye abide my law ye cannot attain to this glory.

22. For strait is the gate, and narrow the way that leadeth unto the exaltation and continuation of the lives, and few there be that find it, because ye receive me not in the world neither do ye know me.

23. But if ye receive me in the world, then shall ye know me, and shall receive your exaltation; that where I am ye shall be also. 
24. This is eternal lives--to know the only wise and true God, and Jesus Christ, whom he hath sent. I am he. Receive ye, therefore, my law.

25 . Broad is the gate, and wide the way that leadeth to the deaths; and many there are that go in thereat, because they receive me not, neither do they abide in my law.

26 . Verily, verily, I say unto you, if a man marry a wife according to my word, and they are sealed by the Holy Spirit of promise, according to mine appointment, and he or she shall commit any sin or transgression of the new and everlasting covenant whatever, and all manner of blasphemies, and if they commit no murder wherein they shed innocent blood, yet they shall come forth in the first resurrection, and enter into their exaltation; but they shall be destroyed in the flesh, and shall be delivered unto the buffetings of Satan unto the day of redemption, saith the Lord God.

27. The blasphemy against the Holy Ghost, which shall not be forgiven in the world nor out of the world, is in that ye commit murder wherein ye shed innocent blood, and assent unto my death, after ye have received my new and everlasting covenant, saith the Lord God; and he that abideth not this law can in nowise enter into my glory, but shall be damned, saith the Lord.

28. I am the Lord thy God, and will give unto thee the law of my Holy Priesthood, as was ordained by me and my Father before the world was.

29. Abraham received all things, whatsoever he received, by revelation and commandment, by my word, saith the Lord, and hath entered into his exaltation and sitteth upon his throne.

30. Abraham received promises concerning his seed, and of the fruit of his loins--from whose loins ye are, namely, my servant Joseph-which were to continue so long as they were in the world; and as touching Abraham and his seed, out of the world they should continue; both in the world and out of the world should they continue as innumerable as the stars; or, if ye were to count the sand upon the seashore ye could not number them.

31. This promise is yours also, because ye are of Abraham, and the promise was made unto Abraham; and by this law is the continuation of the works of my Father, wherein he glorifieth himself.

32. Go ye, therefore, and do the works of Abraham; enter ye into my law and ye shall be saved.

33. But if ye enter not into my law ye cannot receive the promise of my Father, which he made unto Abraham.

34. God commanded Abraham, and Sarah gave Hagar to Abraham to wife. And why did she do it? Because this was the law; and from Hagar sprang many people. This, therefore, was fulfilling, among other things, the promises.

35. Was Abraham, therefore, under condemnation? Verily I say unto you, Nay; for I, the Lord, commanded it.

36. Abraham was commanded to offer his son Isaac; nevertheless, it was written: Thou shalt not kill. Abraham, however, did not refuse, and it was accounted unto him for righteousness.

37. Abraham received concubines, and they bore him children; and it was accounted unto him for righteousness, because they were given unto him, and he abode in my law; as Isaac also and Jacob did none other things than that which they were commanded; and because they did none other things than that which they were commanded, they have entered into their exaltation, according to the promises, and sit upon thrones, and are not angels but are gods.

38. David also received many wives and concubines, and also Solomon and Moses my servants, as also many others of my servants, from the beginning of creation until this time; and in nothing did they sin save in those things which they received not of me.

39. David's wives and concubines were given unto him of me, by the hand of Nathan, my servant, and others of the prophets who had the keys of this power, and in none of 
these things did he sin against me save in the case of Uriah and his wife; and, therefore he hath fallen from his exaltation, and received his portion; and he shall not inherit them out of the world, for I gave them unto another, saith the Lord.

40. I am the Lord thy God, and I gave unto thee, my servant Joseph, an appointment, and restore all things. Ask what ye will, and it shall be given unto you according to my word.

41. And as ye have asked concerning adultery, verily, verily, I say unto you, if a man receiveth a wife in the new and everlasting covenant, and if she be with another man, and I have not appointed unto her by the holy anointing, she hath committed adultery and shall be destroyed.

42. If she be not in the new and everlasting covenant, and she be with another man, she has committed adultery.

43. And if her husband be with another woman, and he was under a vow, he hath broken his vow and hath committed adultery.

44. And if she hath not committed adultery, but is innocent and hath not broken her vow, and she knoweth it, and I reveal it unto you, my servant Joseph, then shall you have power, by the power of my Holy Priesthood, to take her and give her unto him that hath not committed adultery but hath been faithful; for he shall be made ruler over many.

45. For I have conferred upon you the keys and power of the priesthood, wherein I restore all things, and make known unto you all things in due time.

46. And verily, verily, I say unto you, that whatsoever you seal on earth shall be sealed in heaven; and whatsoever you bind on earth, in my name and by my word, saith the Lord, it shall be eternally bound in the heavens; and whosesoever sins you remit on earth shall be remitted eternally in the heavens; and whosesoever sins you retain on earth shall be retained in heaven.

47. And again, verily I say, whomsoever you bless I will bless, and whomsoever you curse I will curse, saith the Lord; for I, the Lord, am thy God.

48. And again, verily I say unto you, my servant Joseph, that whatsoever you give on earth, and to whomsoever you give any one on earth, by my word and according to my law, it shall be visited with blessings and not cursings, and with my power, saith the Lord, and shall be without condemnation on earth and in heaven.

49. For I am the Lord thy God, and will be with thee even unto the end of the world, and through all eternity; for verily I seal upon you your exaltation, and prepare a throne for you in the kingdom of my Father, with Abraham your father.

50. Behold, I have seen your sacrifices, and will forgive all your sins; I have seen your sacrifices in obedience to that which I have told you. Go, therefore, and I made a way for your escape, as I accepted the offering of Abraham of his son Issac.

51. Verily, I say unto you: A commandment I give unto mine handmaid, Emma Smith, your wife, whom I have given unto you, that she stay herself and partake not of that which I commanded you to offer unto her, for I did it, saith the Lord, to prove you all, as I did Abraham, and that I might require an offering at your hand, by covenant and sacrifice.

52. And let mine handmaid, Emma Smith, receive all those that have been given unto my servant Joseph, and who are virtuous and pure before me; and those who are not pure, and have said they were pure, shall be destroyed, saith the Lord God.

53. For I am the Lord thy God, and ye shall obey my voice; and I give unto my servant Joseph that he shall be made ruler over many things; for he hath been faithful over a few things, and from henceforth I will strengthen him.

54. And I command mine handmaid, Emma Smith, to abide and cleave unto my servant Joseph, and to none else. But if she will not abide this commandment she shall be destroyed, saith the Lord; for I am the Lord thy God, and will destroy her if she abide not in my law.

55. But if she will not abide this commandment, then shall my servant Joseph do all things for her, even as he hath said; and I will bless him and multiply him and give unto 
him an hundredfold in this world, of fathers and mothers, brothers and sisters, houses and lands, wives and children, and crowns of eternal lives in the eternal worlds.

56. And again, verily I say, let mine handmaid forgive my servant Joseph his trespasses; and then shall she be forgiven her trespasses, wherein she has trespassed against me; and I, the Lord thy God, will bless her, and multiply her, and make her heart to rejoice.

57. And again, I say, let not my servant Joseph put his property out of his hands, lest an enemy come and destroy him; for Satan seeketh to destroy; for I am the Lord thy God, and he is my servant; and behold, and lo, I am with him, as I was with Abraham, they father, even unto his exaltation and glory. thereunto.

58. Now, as touching the law of the priesthood, there are many things pertaining

59. Verily, if a man be called of my Father, as was Aaron, by mine own voice, and by the voice of him that sent me, and I have endowed him with the keys of the power of this priesthood, if he do anything in my name, and according to my law and by my word, he will not commit sin, and I will justify him.

60. Let no one, therefore, set on my servant Joseph; for I will justify him; for he shall do the sacrifice which I require at his hands for his transgressions, saith the Lord your God.

61. And again, as pertaining to the law of the priesthood--if any man espouse a virgin, and desire to espouse another, and the first give her consent, and if he espouse the second, and they are virgins, and have vowed to no other man, then is he justified; he cannot commit adultery for they are given unto him; for he cannot commit adultery with that belongeth unto him and to no one else.

62. And if he have ten virgins given unto him by this law, he cannot commit adultery, for they belong to him, and they are given unto him; therefore is he justified.

63. But if one or either of the ten virgins, after she is espoused, shall be with another man, she has committed adultery, and shall be destroyed; for they are given unto him to multiply and replenish the earth, according to my commandment, and to fulfil the promise which was given by my Father before the foundation of the world, and for their exaltation in the eternal worlds, that they may bear the souls of men; for herein is the world of my Father continued, that he may be glorified.

64. And again, verily, verily, I say unto you, if any man have a wife, who holds the keys of this power, and he teaches unto her the law of my priesthood, as pertaining to these things, then shall she believe and administer unto him, or she shall be destroyed, saith the Lord your God; for I will destroy her; for I will magnify my name upon all those who receive and abide in my law.

65. Therefore, it shall be lawful in me, if she receive not this law, for him to receive all things whatsoever I, the Lord his God, will give unto him, because she did not believe and administer unto him according to my word; and she then becomes the transgressor; and he is exempt from the law of Sarah, who administered unto Abraham according to the law when I commanded Abraham to take Hagar to wife.

66. And now, as pertaining to this law, verily, verily, I say unto you, I will reveal more unto you, hereafter, therefore, let this suffice for the present. Behold I am Alpha and Omega. Amen. 


\section{APPENDIX B}

THE DOCUMENT OF THE UNITED ORDER OF PINESDALE ESTABLISHED BY DR. RULAN C. ALLRED, 1961 


\section{Article I}

1. The success of this United Order is dependent primarily upon its members being subject to the General Council of the Priesthood and their appointed representative(s) to this Order.

\section{Article II}

1. The success of this Order is dependent also upon having a Council which shall supervise all functions of the Order, and which shall make all major decisions concerning the Order. 2. This Council shall consist of every Priesthood holder who is the head of a family within the Order with certain exceptions (see Article VII).

3. No decisions affecting the functions of the Order shall be made without the unanimous consent of the members of said Council.

4. Such decisions shall be subject to the review of and final action of the General Council of the Priesthood.

5. No reversal of any decision shall be allowed except under circumstances wherein the General Council of the Priesthood shall consider that the decision may hinder the works of the Lord and/or as provided for under Article XVI.

6. The Council of the Order is accountable to the General Council of the Priesthood.

\section{Article III}

1. It is necessary that a general fund be established by the consecrations and tithes and offerings of the members of the Order.

2. The disposition of this fund shall be under the direction of an acting Bishop.

3. In order to insure that this fund will be handled and utilized for the mutual good and benefit of the members of the Order, a common record shall be kept by a clerk appointed for that purpose by the Council of the Order in which all the dedications, tithes, offerings and consecrations shall be recorded, and in which all the businesses together with all the transactions pertaining thereto shall be recorded.

4. This record shall be accessible to said Council and to the General Council of the Priesthood. 


\section{Article IV}

1. The said clerk shall make and keep a detailed record of all income and expenditures pertaining to the Order.

2. All business related to the functioning of the Order shall be made a matter of record by the clerk.

3. He/she shall meet all corporation obligations from corporation funds.

4. All corporate funds shall be under the direction of an acting Bishop.

5. In all cases, the acting Bishop shall be accountable to the Council of the Order.

\section{Article V}

1. Any corporate body which is or shall be organized within the Order shall keep a record of all business transactions and expenditures so as to make proper record of every expenditure or other transaction that shall take place.

\section{Article VI}

1. Each family in the Order shall be given a stipulated allowance for their welfare and subsistence.

2. This allowance shall be determined according to the number of individuals in the family and the obligations of the various members thereof.

3. This determination shall be made by an Economic Committee of the Order.

4. Each adult and child shall be numbered and allowed an amount for subsistence commensurate with that which is reasonable as determined by the said Economic Committee in consultation with the head of the family.

\section{Article VII}

1. The law of tithing is part of the United Order and Law of Consecration.

2. When any funds or other means are given into the hands of the acting Bishop, one tenth shall be reserved as the Lord's to be used for the care of the poor and for the debts of the Priesthood. 
Article VIII

1. Each head of a family shall strive with all his heart to be in perfect harmony with the Economic Committee counselling with him concerning his financial affairs, realizing that if he is not one with his brethren he cannot be one with the Lord.

\section{Article IX}

1. All businesses shall be conducted in the interest of the Order with the understanding that the Order as a whole shall be the recipient of the increase derived therefrom, and that the success or failure of each business venture either advances or retards the Order as a whole.

\section{Article X}

1. Those principles which conform to the revealed word of God pertaining to reason, justice, judgment, mercy, love, and brotherly kindness shall be practiced and shall govern the conduct and the decisions of each man holding the Priesthood and every other member of the Order, remembering that the eyes of God are upon him or her, and that he or she is amenable to His righteous judgment.

2. Each man, as a holder of the Priesthood, shall regard himself as God's own agent and his brother's keeper.

\section{Article XI}

1. The children in the community shall be taught to respect the possessions of others and shall not be permitted to wantonly destroy or to injure or to otherwise abuse or misuse the property of others.

2. If any child shall get beyond the control of parental direction and shall violate the rights or destroy, injure, or otherwise abuse or misuse the property of others, the parents shall be held responsible and shall compensate the Order or the individuals concerned for said destruction, etc. 
Article XII

1. Each individual family shall have the responsibility of conducting itself as the children of God and shall be amendable to the Council of the Order in matters pertaining to good health practices and cleanliness of body, home, and surrounding premises.

2. Any family may be called to set themselves and their house(s) in order by the Council of the Order, and shall be accountable to the presiding Priesthood as they are to God for their manner of speech and conduct.

\section{Article XIII}

1. Property rights in all cases shall be held inviolate.

2. The property of the Order shall not be used except upon the advise or with the knowledge and consent of the acting Bishop.

3. No stewardship nor any part or portion thereof shall be used, trespasses upon, destroyed, or in any manner disposed of except upon the advise of or with the knowledge and consent of the steward thereof.

4. Any person who shall knowingly and/or willfully violate this provision shall be deemed in transgression and shall be held responsible for making proper redress as determined by the voice of the majority of the Council of the Order.

\section{Article XIV}

1. The general programs and projects of the Order as planned for or agreed upon by the Council of the Order shall receive the united cooperation and assistance of every member of that Council and by every member of the Order in carrying it to completion.

2. A refusal to cooperate or assist shall be deemed a violation of trust which shall be accounted for to the said Council.

3. Proper compensation for refusal to cooperation and assist in the general programs and projects of the Order, where such compensation may be determined and levied, shall be made payable to the Order through the acting Bishop. 


\section{$\underline{\text { Article XV }}$}

1. Each common effort or program or project of the Order shall receive the united cooperation of each and every member of the Order as though it were their own personal effort, program or project, whether it pertains to the building of a school, improvement of roads, buildings and grounds, or any other matter of general concern and welfare to the Order.

\section{$\underline{\text { Article XVI }}$}

1. It is understood that in times of necessity, exceptions to any one or more rules or decisions may be made.

2. Such exceptions shall be determined by the Council of the Order as directed by the word of the Lord.

\section{Article XVII}

1. Any head of a family, who may be a member of the Order, who shall elect not to abide by the rules herein specified, may retain his stewardship and act independently until such time as by his own choice he elects to sever relations with the Order and dispose of his interests and surrender his stewardship back to the Council of the Order, or until such time as he shall be deemed in sufficient transgression as to be expelled for cause from the Order by the united voice of the Council of the Order.

a. However, he shall not have a voice in the Council of the Order.

2. The remuneration for said stewardship shall be determined by the Council of the Order as governed by the laws of justice and judgment as specified by the word of the Lord.

3. Under no circumstances shall any steward in this Order dispose of any part or portion of his property or stewardship in any manner deemed detrimental to the Order.

4. Neither shall any part or portion of any stewardship be transferred by any means to any party not acceptable to the Council of the Order.

5. Neither shall any steward consummate any manner of business pertaining to the Order without the knowledge and unanimous consent of the Council of the Order.

6. In the event of the absence of any member or members of the Council of the Order from any regularly appointed meeting called to consider matters pertaining to the functioning of the Order or to its general welfare, a majority of said Council in attendance shall be deemed 
and considered sufficient to act in such matters, and their decisions shall be considered valid and final by the whole.

\section{Article XVIII}

1. Tithes and offerings or contributions of any kind, whether received from contracts or from any other source shall be submitted to the acting Bishop.

2. Tithes, offerings or contributions of any kinds shall be made a matter of record, and every person so contributing shall receive a receipt therefore.

3. Subsistence allowances issued to stewards or other members of the Order as provided for in Article VI shall be receipted and may be deemed as personal income subject to taxation.

\section{$\underline{\text { Article XIX }}$}

1. Any person, to become a member of the Order, must be recommended by the General Council of the Priesthood, and must receive a unanimous favorable vote by the Council of the Order. 


\section{APPENDIX C}

THE SERMON DELIVERED BY LEROY JOHNSON, JULY 10, 1977, SUNDAY, IN COLORADO CITY, ARIZONA 
I am certainly pleased, my brothers and sisters, to see this room filled this afternoon. I trust that the Spirit of God will be my companion while I speak to you, that I will only deliver to you that which $\mathrm{He}$ has for you.

We have been chastised pretty heavy this morning in both meetings. But I want the Latter-day saints to understand that this Gospel of the Kingdom is unto all people who will repent and do the works of our Father. All that we see moving about in the earth are creations of the God who created you and me. In going to the city you will find many types of people--people of many colors. In the animal kingdom you will find pintos, Arabians, but in or among the people of the earth the different colors that I speak about are the different types of people; but they are all the creations of our Father. He has said that this Gospel of the Kingdom was unto all men whether they be upon the isles of the sea or in foreign lands or wherever they are--they are subjects of salvation, and the Lord has provided salvation for all types of people. He says, "In My Kingdom there are many mansions." When the Savior was speaking to His disciples He told them this, and then $\mathrm{He}$ said, "I go now to prepare a place for you." So we are going to be saved, no matter what kind of people we are, except we commit murder or deny the Christ. But the degree of salvation that I would like to attain to is the highest degree of glory in the Celestial Kingdom. The Book [Pearl of Great Price] says that in the Celestial Kingdom there are three heavens or degrees. Man may attain to the lowest degree, but that is the end of his progress; he can't have an increase. So, if I want to increase, I am going to have to living according the requirements of the highest degree of glory in the Celestial Kingdom. And there are none of us who want to go through this life and go through what we have to go through and be turned away at the gate.

In 1953, we were all taken out of this place--women and children; very few of them were left on the Utah side of the line and there might have been a few on the Arizona side. But the majority of our people were taken away. Since that time, we have increased greatly in numbers, but what has been our progress in our preparation for the Celestial Kingdom? this is what concerns me and should concern you--everyone of you. We should have learned a lesson in 1953, that there is such a thing as being destroyed. I know a body of men were greatly disturbed in their feelings when they came home from the penitentiary after being held for a week in solitary confinement and found their homes desolate; and 
they didn't know at that time when or where they were going to see their loved ones. But the Lord was kind to us; He preserved us; He preserved the men. One of the reasons was because of the faith and prayers of the people who had been taught by the servants of God to keep all the commandments of God so that He would be justified in fighting their battles for them. I don't know what we could stand today.

When I listen to the news on the television and see what is going on in the world, I find the world is not better today than it was many generations ago. And I know this--that the Lord has got to have a prepared people, both men and women to work with. I doubt if there is a man that has a family but what realizes to some extent the value of those children, those wives and children. There are some among us who do not know the value of the young ladies when they are placed at the side of a young man, and there are many young men among us who are chafing at the bit because they haven't been added upon. I know one young man in particular that thought he had the right to go out and seek a companion regardless of the wishes and desires of the Priesthood over him. He tried it many times and started when he was seventeen years old to acquire a companion. It wasn't because he wasn't popular in the community where he lived, but the Lord was kind to him and he didn't know it at the time. The Lord let him go so far, and then He allowed him to be let down. He was let down several times. The Lord made him wait until he was twenty-seven years old--whipped him many times because he went over the heads of those whose right it was to direct him in his life.

I look back over my life and I see in my mind's eye what might have been if I had obtained what I thought belonged to me, but the Lord wouldn't give it to me. He finally led me to a lady that could bless me, and she blessed me with every blessing that was necessary for my eternal salvation, if I continued to do right and treat my family right. I saw many men added upon and I thought they were added upon into eternal life, but the Lord didn't allow me to be added upon until I met up with this order of the Priesthood. If I have done any good among this people it has been because the Lord has been kind to me and blessed me with wisdom and knowledge and understanding to the point where I have arrived at my present position. I have a blessing that was given me by a Patriarch when I was seventeen years old, and today it is history. There are a few things in the blessing that haven't been realized upon my head, but the majority of it has been fully bestowed upon me, including the position that I hold. That is the way the Lord preserved me because of the blessing that I obtained. He watched over me, brought me along and guided by footsteps around dangerous pitfalls. And every person that has been into the waters of baptism and 
had hands laid upon them for the Gift of the Holy Ghost has the same opportunity if they will seek the Lord in righteousness.

The Lord told the Prophet Joseph to go bear testimony to the world that Jesus was a man like other men and that God was a man glorified and sits upon His throne; and if we want to become life Him we must do what He has done. In the process of his learning he found out that God was once a man life the men you see around us today, and He prepared Himself through righteous living. He didn't attain to the position He holds by being disobedient for a certain period of time and then overcoming it. I find that in my life I have been retarded in some things because I didn't pay strict attention to the instructions I received.

There are many things going on in our community that have got to be righted. The Lord has got to do something to weed out the evils among us and take them out of our midst. We try to clean up the place we live in; and men who persist in disobeying the counsel we give them, we ask them to leave and leave us alone. They go away for a while and then they come back. They don't come to the Priesthood for counsel, but they come back and work in the nighttime. We have those among us who help them out. We have men within our society who abuse the privileges that God has given them and they have to be chastised for it. And the Priesthood is put to a test to see what they will do under these conditions.

It is necessary, my brothers and sisters, to continue to see to it that our preparation is going on from day to day, that at some time in the future the Lord might be able to gather up a sufficient number of our young men and middle-aged men to accomplish His work. He says, "I will take the young and middle-aged to redeem Zion." To me, this means both men and women, and every man that is given a wife should polish her and teach and train her and bring her along--she might be retarded in many ways, but it is your bound duty to polish the jewel the Lord has placed at the side of you and bring her along with you. There is no place in the Celestial Kingdom for a bachelor or a man that has destroyed those who the Lord has set by the side of him as a companion. It might be one, it might be many, but you have got to account for them all. When a girl is taken out of her father's home and set by a man, she can become the property of the man she has been sealed to by the Holy Spirit of Promise. And he is responsible for her even if she be a girl that has been untrained. It is his duty to take her and train her--study her character and see to it that she is not trodden down or cast out. We have many among us who have been cast out. Some girls who have been set by good men will not take their place. The Lord says there is nothing left for them but to be destroyed. And to be destroyed is something that cannot be explained by men. 
The Lord has said, "Leave judgment to Me, for judgment is Mine." But He has also said that if you find sin among you, cast it out. give them a chance to repent, and if they will not repent, you are to cast them out of your midst. But it is not an easy thing to do. We have tried it. We know what it is. But this place has got to be cleaned up. It is in a beautiful position for destruction.

When I read the scriptures, the history of God's people on the earth, when a people bear testimony that they are God's people and they are trying to do better to serve Him and keep His commandments, and then they fall away or begin to fall away from Him and these destructive elements come in, He does a very clean job. Both the righteous and the wicked suffer together. Just read the history of the Nephite Nation and what transpired. And read the testimony of Mormon and his son, Moroni, and you will get the picture of it. We have the whole history for four hundred years, from the time Christ visited the Nephite Nation and when it was destroyed, and we see the results of it by the roaming Indians of our nation today.

It grieves us very much--very much--when we have to do what we have to do, but we are under strict instructions to see to it that there is no sin among us, and when sin sticks up its head we have to do something about it--those who have gathered around the Priesthood. And great promises have been promised to the faithful elders of Israel.

My brothers and sisters, think deeply before you allow misgivings to be perpetrated in your homes, especially you who live in dedicated homes. We go into a home and dedicate it and the man of the house desecrates it himself--sets the example for his children to follow in his footsteps, and it becomes a cursing upon his head rather than a blessing. You women that will not support a righteous man, a man that is trying to follow the Priesthood, you had better think twice before you desecrate the home in which you live. Blessings offered and rejected often become cursings upon our heads.

But the Lord has offered to us the principle of repentance, and if we will repent of our sins, He says He will forgive us and remember them no more before His face. It is when we sin again that our former sins come back upon us; then the Spirit of God is grieved and it withdraws, and when it withdraws, amen, says He, to the Priesthood of that man. He says again, "My word is sharper than a two-edged sword and what I say to one I say to all." So, let us go to and tend to our knitting, Let us pray night and day for deliverance and the Lord might be able to accomplish His great and wonderful work in the earth--the bringing about of the thousand years of peace, for it is right at our door.

I pray God will bless us with wisdom, knowledge, and understanding, that He will shower His blessings upon us all, in the name of Jesus Christ, amen. 


\section{APPENDIX D}

THE RULES OF CONDUCT IN THE FAMILY ORDER BY ORSON PRATT, 1853 
1. Let that man who intends to become a husband, seek first the kingdom of God and its righteousness, and learn to govern himself, according to the law of God: for he that cannot govern himself cannot govern others; let him dedicate his property, his talents, his time, and even his life to the service of God, holding all things at His disposal, to do with the same, according as $\mathrm{He}$ shall direct through the counsel that He has ordained.

2. Let him next seek for wisdom to direct him in the choice of his wives. Let him seek for those whose qualifications will render him and themselves happy. Let him look not wholly at the beauty of the countenance, or the splendor of the apparel, or the great fortune, or the artful smiles, or the affected modesty of females; for all these, without the genuine virtues, are like the dew-drops which glitter for a moment in the sun, and dazzle the eye, but soon vanish away. But let him look for kind and amiable dispositions; for unaffected modesty; for industrious habits; for sterling virtue, for honesty, integrity, and truthfulness; for cleanliness in persons, in apparel, in cooking, and in every kind of domestic labor; for cheerfulness, patience, and stability of character; and above all, for genuine religion to control and govern their every thought and deed.

3. When a man has obtained his wives, let him not suppose that they are already perfect in all things; for this cannot be expected in those who are young and inexperienced in...married life. They, as weaker vessels, are given to him as the stronger, to nourish, cherish, and protect; to be their head, their patriarch, and their saviour, to teach, instruct, counsel, and perfect them in all things relating to family government, and the weifare and happiness of themselves and their children. Therefore, let him realize the weighty responsibility now placed upon him, as the head of the family; and also let him study diligently the disposition of his wives, that he may know how to instruct them...

4. Betray not the confidence of your wives. There are many ideas in an affectionate confiding wife which she would wish to communicate to her husband, and yet she would be very unwilling to have them communicated to others. Keep each of your wives' secrets from the others, and from any one else, unless in cases where good will result by doing otherwise.

5. Speak not of the faults of your wives to others; for in so doing, you speak against yourself. This is calculated to weaken their confidence in you, and sow division in 
the family. Tell each one of her faults in private in a spirit of kindness and love, and she will most probably respect you for it, and endeavor to do better for the future.

6. Avoid anger and a fretful peevish disposition in your family. A hasty spirit, accompanied with harsh words, will most generally beget its own likeness, or, at least, it will eventually, sour the feelings of your wives and children, and greatly weaken their affections for you. Do not find fault with every trifling error you may see; for this will discourage your family, and they will begin to think that it is impossible to please you; and, after a while, become indifferent as to whether they please you or not. How unhappy and extremely wretched is that family where nothing pleases--where scolding has become almost as natural as breathing!

7. Use impartiality in your family as far as circumstances will allow; and let your kindness and love abound towards them all. Use your own judgment, as head of the family, in regard to your duties in relation to them, and be not swayed from that which is right, by your own feelings, nor by the feelings of others.

8. Suffer not your judgment to be biased against any one of your wives, by the accusations of the others, unless you have good grounds to believe that those accusations are just. Decide not hastily upon partial evidence, but weigh well all things, that your mind may not be become unjustly prejudiced. When one of your wives complains of the imperfections of the others, and endeavors to set your mind against them, teach her that all have imperfections, and of the necessity of bearing one with another in patience, and of praying one for another.

9. Call your wives and children together frequently, and instruct them in their duties towards God, towards yourself, and towards one another. Pray with them and for them often; and teach them to pray much, that the Holy Spirit may dwell in their midst, without which it is impossible to maintain that union, love, and oneness which are so necessary to happiness and salvation.

10. Remember, that notwithstanding written rules will be of service in teaching you your duties, as the head of a family, yet without the Holy Ghost to teach and instruct you, it is impossible for you to govern a family in righteousness; therefore, seek after the Holy Ghost and He shall teach you all things, and sanctify you and your family, and make you one, that you may be perfected in Him and He in you, and eventually be exalted on high to dwell with God, where your joy will be full forever.

11. Let no woman unite herself in marriage with any man, unless she has fully resolved to submit herself wholly to his counsel, and to let him govern as the head. It is far better for her not to be united with him in the sacred bonds of eternal union, than to rebel 
against the divine order of family government, instituted for a higher salvation; for if she, altogether turn therefrom, she will receive a greater condemnation.

12. Never seek to prejudice the mind of your husband against any of his other wives, for the purpose of exalting yourself in his estimation, lest the evil which you unjustly try to bring upon them, fall with double weight upon your own head. Strive to rise in favor and influence with your husband by your own merits, and not by magnifying the faults of others.

13. Seek to be a peacemaker in the family with whom you are associated. IF you see the least appearance of division arising, use your utmost efforts to restore union and sooth the feelings of all. Soft and gentle words, spoken in season, will allay contention and strife; while a hasty spirit and harsh language add fuel to fire already kindled which will rage with increasing violence.

14. Speak not evil of your husband unto any of the rest of the family for the purpose of prejudicing their minds against him; for if he be informed thereof, it will injure you in his estimation. Neither speak evil of any members of the family; for this will destroy their confidence in you.

15. If you see any of your husband's wives sick or in trouble, use every effort to relieve them, and to administer kindness and consolations, remembering that you, yourself, under the same circumstances, would be thankful for their assistance. Endeavor to share each others' burdens, according to the health, ability, and strength which God has given you. Do not be afraid that you will do more than your share of the domestic labor, or that you will be more kind to them than they are to you.

16. Let each mother correct her own children, and see that they do not dispute and quarrel with each other, nor with any others; let her not correct the children of the others without liberty to do so, lest it give offence. The husband should see that each mother maintains a wise and proper discipline over her children, especially in their younger years: and it is his duty to see that all of his children are obedient to himself and to their respective mothers.

17. It is the duty of parents to instruct their children, according to their capacities in every principle of the gospel....Suffer no wickedness to have place among them, but teach them the right way, and see that they walk therein. And let the husband, and his wives, and all of his children that have come to the years of understanding, often bow before the Lord around the family alter, and pray vocally and unitedly for whatever blessings they stand in need of, remembering that where there are union and peace, there will also be faith, and 
hope, and the love of God, and every good work, and a multiplicity of blessings, imparting health and comfort to the body, and joy and life to the soul.

18. Let each mother commence with her children when young, not only to teach and instruct them, but to chasten and bring them into the most perfect subjection; for then is the time that they are the most easily conquered, and their tender mind are the most susceptible of influences and government.

19. Do not correct children in anger, an angry parent is not as well prepared to judge of the amount of punishment which should be inflicted upon a child, as one that is more cool and exercised with reflection, reason, and judgment. Let your children see that you punish them, not to gratify an angry disposition, but to reform them for their good, and it will have a salutary influence; they will not look upon you as a tyrant, swayed to and fro by turbulent and furious passions; but they will regard you as one that seeks their welfare, and that you only chasten them because you love them and wish them to do well.

20. Never deceive your children by threatenings or promises. Be careful not to threaten them with punishment which you have no intention of inflicting; for this will cause them to lose confidence in your word; besides, it will cause them to contract the habit of lying: when they perceive that their parents do not fulfill their threatenings or promises, they will consider that there is no harm in forfeiting their word.

21. Do not be so tern and rigid in your family government as to render yourself an object of fear and dread. Justice should be tempered with mercy, and love should be the great moving principle, interweaving itself in all your family administrations. When justice alone sits upon the throne, your children approach you with dread, or peradventure hide themselves from your presence and long for your absence.

22. Let each mother teach her children to honor and love their father, and to respect his teachings and counselings.

23. Suffer not children of different mothers to be haughty and abusive to each other; for they are own brothers and sisters the same as the children of the patriarch Jacob; and one has no claim above another only as his conduct merits it.

24. Be industrious in your habits; this is important as fulfilling the law of God; it is also important for those who are in low circumstances, that they may acquire food, and raiment, and the necessary comforts of life; it is also important for the rich as well as the poor, that they may be able more abundantly to supply the wants of the needy, and be in circumstances to help the unfortunate and administer to the sick and afflicted; for in this way, it is possible even for the rich to enter into the kingdom of heaven. 
25. When your children are from three to five years of age, send them to school, and keep them there year after year until they receive a thorough education in all the rudiments of useful science, and in their manners, and morals.

26. Use economy and avoid wastefulness. How discouraging it would be to a husband who has a large family, depending mostly upon his labor for a support, to see his wives and children carelessly, thoughtlessly, and unnecessarily, waste his hard earnings.

27. Let husbands, wives, sons, and daughters, continually realize that their relationships do not end with this short life, but will continue in eternity without end. Every qualification and disposition, therefore, which will render them happy here, should be nourished, cherished, enlarged, and perfected, that their union may be indissoluble, and their happiness secured both for this world and for that which is to come. 